Pentign DE92007533

FEB 101992

\title{
Preparedness for Hazardous Materials Emergencies in Railyards: Guidance for Railroads and Adjacent Communities
}

September 1991

Federal Emergency Management Agency

State and Local Programs and Support Directorate

500 C Street, SW

Washington, D.C. 20472 


\section{CONTENTS}

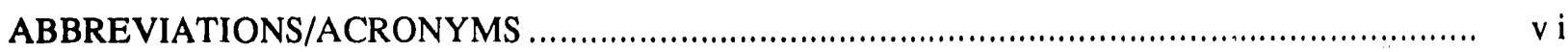

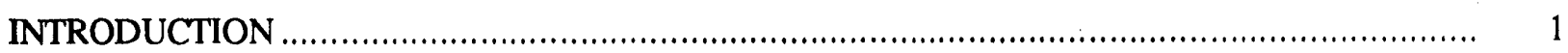

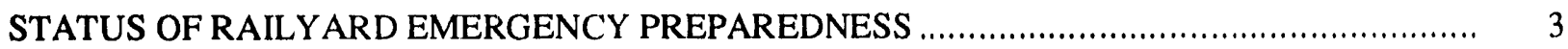

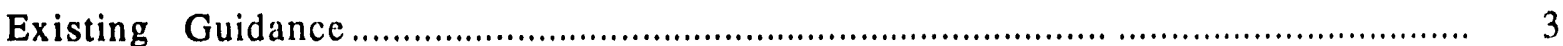

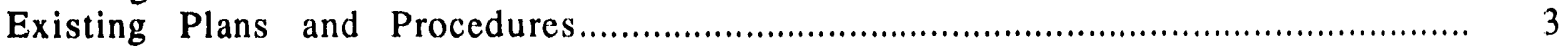

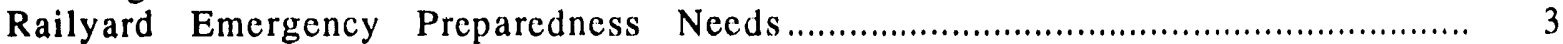

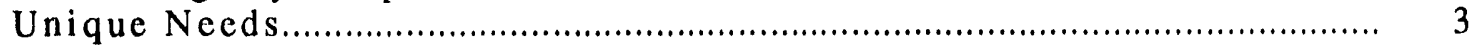

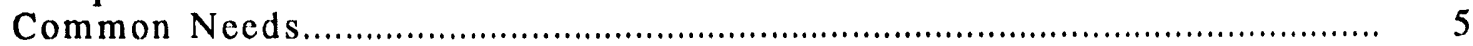

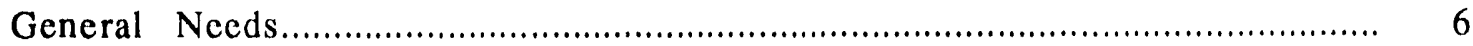

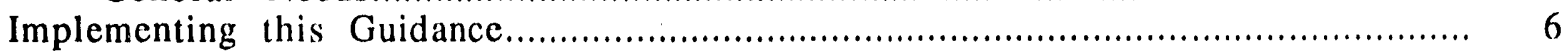

GUIDANCE FOR RAILROAD AND COMMUNITYY EMERGENCY PREPAREDNESS ............... 8

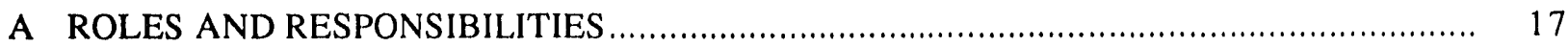

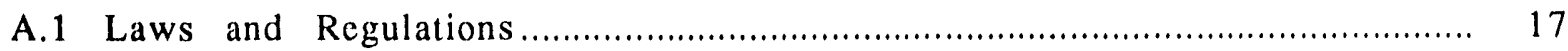

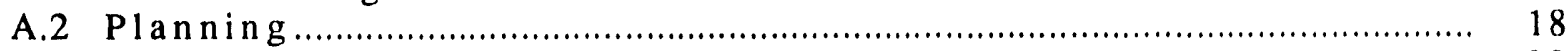

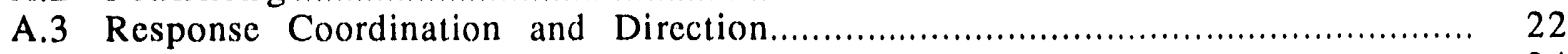

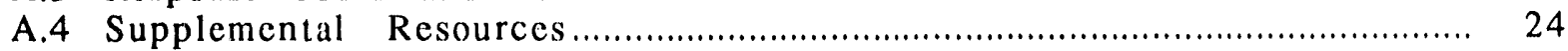

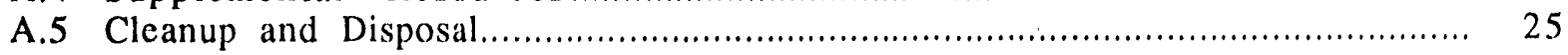

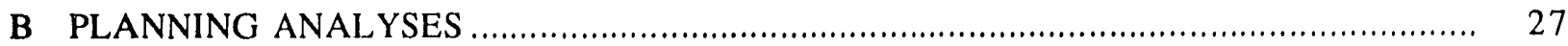

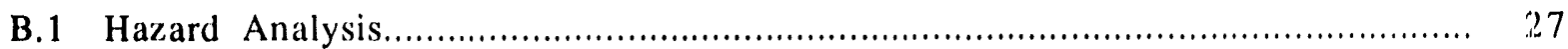

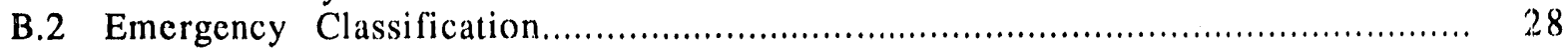

C ACQUISITION AND DEPLOYMENT OF EMERGENCY RESOURCES .............................. 32

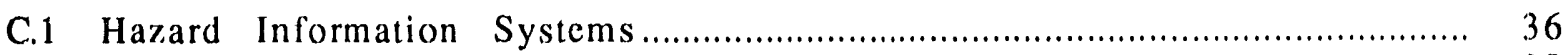

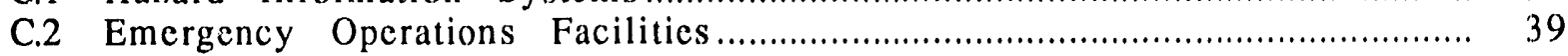

C.3 Emergency Communications................................................................... 41

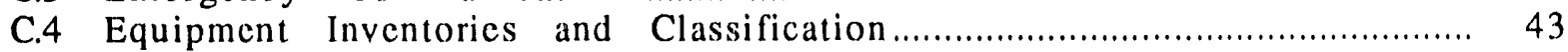

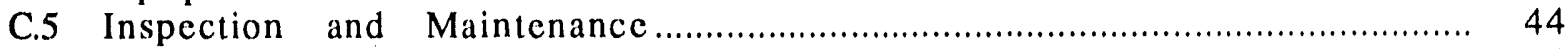

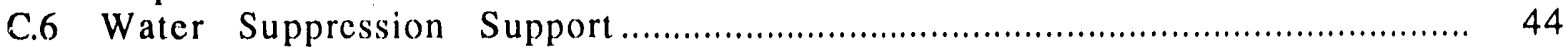

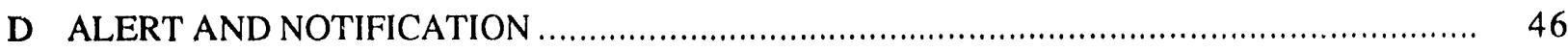

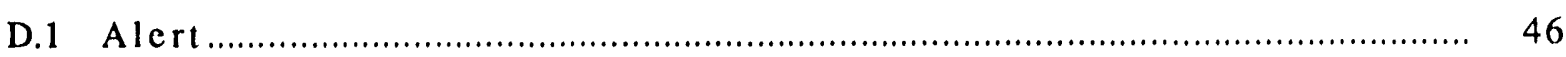

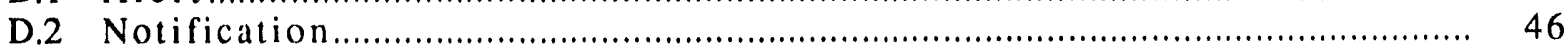

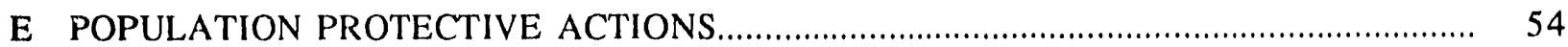

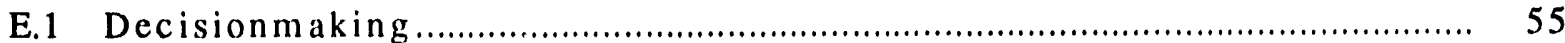

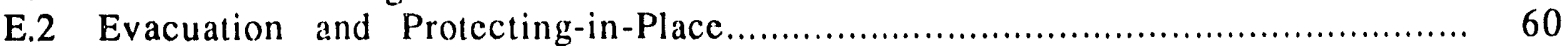

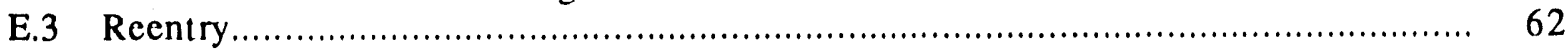


F RESPONDER SAFETY

F.1 Resources.

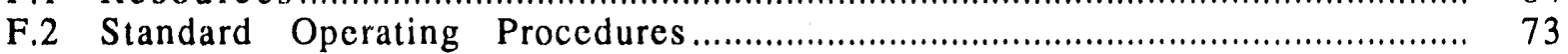

F.3 Operating Procedures Specifically for Railyards................................ 77

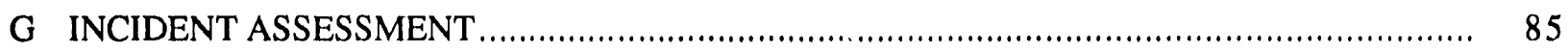

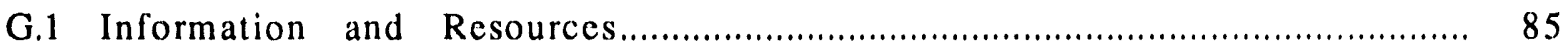

G.2 Impact Assessment and Mitigation................................................ 89

H EMERGENCY PREPAREDNESS AND RESPONSE TRAINING ................................... 93

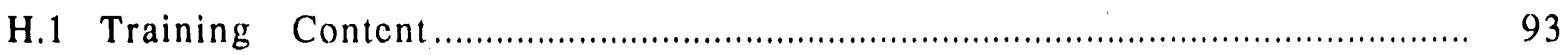

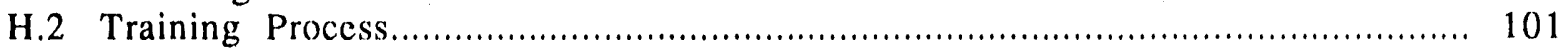

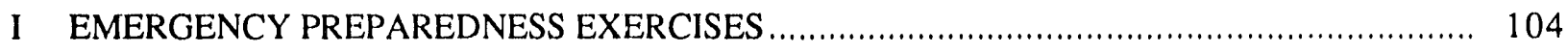

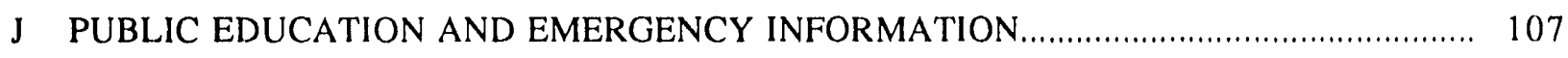

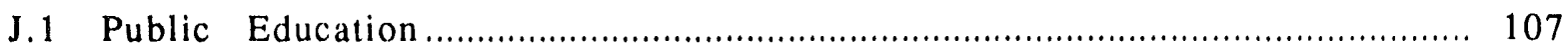

J.2 Communication of Emergency Information ....................................... 108

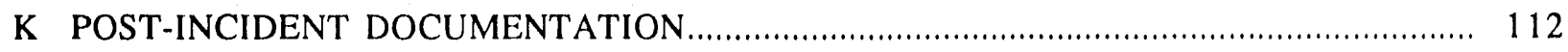

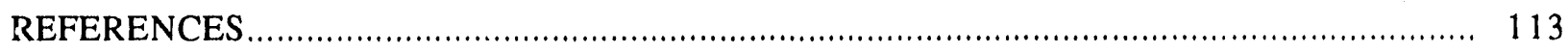

\section{FIGURES}

1 Locations of CHEMNET Emergency Response Teams ...................................... 48

2 Recommended Shelter-in-Place Instructions....................................... 58

3 Data Related to Safety of Personnel in Emergencies Involving

Anhydrous Ammonia, Emergency Action Guides....................................... 65

4 Data Related to Safety of Personnel in Emergencies Involving

Anhydrous Ammonia, Emergency Handling of Hazardous Materials

in Surface Transportation

5 Date Related to Safety of Personnel in Emergencies Involving

Anhydrous Ammonia, 1990 Emergency Response Guidebook......

6 Map of Sample Railyard Zone Showing Isolation Tracks, Internal Roadways, and Yard Access Point.

7 Procedures for Railyard Emergencies... 


\section{FIGURES (Cont'd)}

8 Foldout Card Entitled Employees in Yard Emergencies........................................ 81

9 Decision Flowchart for Emergencies Involving Explosives "A"........................... 87

\section{TABLES}

1 Fundamental Risk Differences between Railyards, Mainlines, and Fixed Facilities

2 Emergency Preparedness Functions and Activities to Improve Preparedness for Hazardous Matcrials Emergencies in Railyards...............................................

3 Alphabetical List of Equipment and Facilities Maintained by Major Railroads

4 Factors to Consider in Selecting Actions to Protect the Public 56

5 Training Useful for Implementing this Guidance. 94 


\begin{tabular}{|c|c|}
\hline $\begin{array}{l}\text { A A R } \\
\text { ALARA } \\
\text { A RCHIE }\end{array}$ & $\begin{array}{l}\text { Association of American Railroads } \\
\text { As Low as Reasonably Achicvable } \\
\text { Automated Resource for Chemical Hazard Incident Evaluation }\end{array}$ \\
\hline $\begin{array}{l}\text { CAER } \\
\text { CAMEO } \\
\text { CERIS } \\
\text { CFR } \\
\text { CHEMNET } \\
\text { CHEMTREC } \\
\text { CHLOREP } \\
\text { CMA }\end{array}$ & $\begin{array}{l}\text { Community Awareness and Emergency Response } \\
\text { Computer-Aided Management of Emergency Operations } \\
\text { Chemical Emergency Response Information System } \\
\text { Code of Federal Regulations } \\
\text { Chemical Network of the Chemical Manufacturers Association } \\
\text { Chemical Transportation Emergency Center } \\
\text { Chlorine Emergency Plan of the Chlorine Institute } \\
\text { Chemical Manufacturers Association }\end{array}$ \\
\hline DOT & U.S. Department of Transportation \\
\hline $\begin{array}{l}\text { EBS } \\
\text { EOPs } \\
\text { EPA } \\
\text { ERA } \\
\text { EYE }\end{array}$ & $\begin{array}{l}\text { Emergency Broadcast System } \\
\text { Emergency Operations Plans } \\
\text { U.S. Environmental Protection Agency } \\
\text { Emergency Response Agency } \\
\text { Employees in Yard Emergencics }\end{array}$ \\
\hline $\begin{array}{l}\text { FEMA } \\
\text { FRA }\end{array}$ & $\begin{array}{ll}\text { Federal Emergency Management Agency } \\
\text { Federal Railroad Administration }\end{array}$ \\
\hline $\begin{array}{l}\text { HMIX } \\
\text { HMRTs }\end{array}$ & $\begin{array}{l}\text { Hazardous Materials Information Exchange } \\
\text { Hazardous Materials Response Teams }\end{array}$ \\
\hline $\begin{array}{l}\text { ICAR IS } \\
\text { I D }\end{array}$ & $\begin{array}{l}\text { Industrial Chemical Response Information System } \\
\text { Identification Numbers }\end{array}$ \\
\hline LEPC & Local Emergency Planning Committec \\
\hline $\begin{array}{l}\text { NRC } \\
\text { NRT } \\
\text { NTSB }\end{array}$ & $\begin{array}{l}\text { National Response Center } \\
\text { National Response Team } \\
\text { National Transportation Safety Board }\end{array}$ \\
\hline OSHA & Occupational Safcly and Health Administration \\
\hline PSTN & $\begin{array}{l}\text { Pesticide Safely Team Network of the National Agricultural Chemical } \\
\text { Association }\end{array}$ \\
\hline $\begin{array}{l}\text { SARA } \\
\text { SOPs } \\
\text { STCC }\end{array}$ & $\begin{array}{l}\text { Superfund Amendments and Reauthorization Act of } 1986 \\
\text { Standard Operating Procedures } \\
\text { Standard Transportation Commodity Code }\end{array}$ \\
\hline TRANSCAER & Community Awareness and Emergency Response \\
\hline
\end{tabular}




\section{INTRODUCTION}

Continued growth in the quantity of hazardous materials produced, processed and stored in this country increases the need for emergency preparedness at all points in the production and distribution process. Railroads are a key part of the distribution system for hazardous materials and, thus, much hazardous material passes through railyards en route to intermediate or final consumers. While the vast majority of these materials are shipped without incident, both the number of shipments and the nature of the materials themselves dictate that railyards and surrounding communitics be prepared to respond quickly and effectively to emergencies. Such response requires planning for potential cmergencies, prepositioning equipment and other necessary resources, training personnel, and periodically testing plans and procedures to ensure their effectiveness.

Three issucs prompted the Federal Emergency Management Agency (FEMA) 10 develop guidance specifically geared to hazardous materials emergencies in railroad yards:

1. With adequate emergency preparedness, hazardous material relcases can be averted or their consequences can be reduced. In a railyard safety study conducted in response to one such accident, the National Transportation Safety Board (NTSB) concluded that increasing emergency preparedness is the most practical way to reduce harm from large-scale releases of hazardous materials in railyards. NTSB also recommended that FEMA develop emergency planning and response guidance for use by communitics and opcrators of railyards that handle bulk shipments of hazardous materials and that the guidance be incorporated into pertinent FEMA-sponsored training programs and manuals. (NTSB, 1985b)

2. Large numbers of people are at risk from hazardous matcrial emergencies in railyards. According to the Federal Railroad Administration (FRA), each year, approximatcly 1000 , or $40 \%$, of all railroad accidents occur in railyards. (FRA, 1986-89) Although comparatively few of these accidents involve release of hazardous materials (between 1984 and 1988, the annual number of such accidents ranged from 10 to 22 ), scrious property damage, injuries, and social and cconomic disruption can result. Further, although many railroads originally located their yards away from densely populated areas, urban and suburban development has encroached on them. Large numbers of people are now at risk from railyard accidents involving hazardous materials. Between 1984 and 1988 , FRA reports that lcaks of hazardous matcrials from railcars in railyards required a total of 19 evacuations which affected 8948 persons. (FRA, 1986-89)

3. Existing emergency preparedness guidance is not specifically directed to the needs and resources of railroad yards. Although guidance has becn developed to improve the emergency preparedness of railroad mainlines and fixed facilitics like chemical plants, no comparable guidance exists for railyards. Railyards are fixed-site facilitics that have many conditions amenable to precmergency planning, but they are also 
transportation facilitics through which a wide variety of hazardous material shipments pass.

4. Recent changes in the railroad industry have altered emergency preparedness capabilitics. Passage of the 1980 Staggers Act climinated most regulation of railroad service pricing and contracting arrangements, and removed most barriers to mergers and consolidations. The numercus mergers that followed improved operating efficiencies by permitting more freight to be processed through fewer classification railyards. Along with the climination of many union requirements, deregulation permitted major railroads to abandon rail lines and new "regional" railroads to be formed. While these regional carriers have inherited some of the facilities of their "parent" railroads, many have inherited very little of their know-how about handling hazardous materials. 


\section{STATUS OF RAILYARD EMERGENCY PREPAREDNESS}

\section{EXISTING GUIDANCE}

Existing guidance tends to be oriented toward either of two audiences: (1) communitics that are developing emergency preparedness plans or (2) companies that produce, process, ship, or stere hazardous materials. While the Hazardous Materials Emergency Response Plan Guidance Document for Railroads developed by the Association of Amcrican Railroads (AAR) does address such important issues as the division of responsibility and control between railroad and civil responders, its focus is on mainline cmergencies. (AAR, 1989a) As stated above (and claborated on below), there are important differences between the emergency preparedness needs of railroad yards and railroad mainlines. Further, communities adjacent to railyards are ant to have different emergency planning resources and responsc capabilitics than communities along mainlines.

Because railyards have some characteristics in common with other fixed-site facilitics, some "all hazard" guidance is applicable to railyards. The U.S. Environmental Protection Agency (EPA), in conjunction with FEMA and the U.S. Department of Transportation (DO'T) (1987, 1989), has developed such guidance as has the National Response Team (NRT) (1987, 1988, 1990), and the Chemical Manufacturers Association (CMA) (1985). However, such guidance does not address the unique cmergency preparedness necds of railroad yards and adjacent communitics.

\section{EXISTING PLANS AND PROCEDURES}

According to the last official survey conducted by the FRA, only 110 of 408 operating railroads have published plans for dealing with emergencies involving hazardous matcrials. (Brooks, 1986) Most of the railroads with emergency plans are probably Class I carriers, however, FRA's data base does not specify carrier size. As might be expected, the plans of larger railroads tend to be more comprehensive than those of smaller railroads. The plans and procedures for most adjacent communitics are part of overall disaster plans and tend to be for hazardous materials emergencies in gencral.

\section{RAILYARD EMERGENCY PREPAREDNESS NEEDS}

\section{Unique Needs}

The hazards posed by shipments of explosive, toxic, corrosive or flammable matcrials present railyards with a set of emergency preparedness needs that differ from those faced by either mainlines or other fixed-site facilities. As shown in Table 1, railyards are similar 10 mainlines in terms of the variety of hazardous matcrials handled, but different from both mainlines and other fixed facilities in terms of exposure duration. These (and other) similaritics and differences in conditions creatc unique or specialized preparedness needs. 
TABLE 1 Fundamental Risk Differences between Railyards, Mainlines and Fixed Facilities

Duration of Exposure to Risk

Range of Materials

Railroad Yards

Variable

(several hours to days)

Wide variety

Railroad Mainlines

Transicnt

(minutes/line-mile)

Wide variety

Fixed Facilitics

Long term

More limited

Normal railyard opcrations often involve a wider range of cars and hazardous substances than typically found at fixed-site facilities. Railcars can be of different sizes, types, ages, designs, and conditions. Like railyards, mainlines transport a variety of hazardous materials in an equally diverse variety of cars. However, once blocks of cars have been assembled, their locations within the train consist are fixed and therefore the forces on them are more predictable than in railyards.

Not only do in-yard movements increase the possibility of tank car damage, they also shift hazardous materials to different locations within the railyard. Yard personnel are responsible for detecting changes in car condition and location. Such monitoring is crucial becausc carly detection can avert many cmergencies. Additionally, accurate location information is critical for responders likely to be faced with logistical problems greater than those found either at fixed-site facilities or along mainlines. Typical logistical problems include (1) crossing several sets of tracks to reach the immediate hazard scene, (2) positioning apparatus, particularly if little or no night time lighting is available, (3) running long stretches of hose, (4) promptly and correctly identifying the specific hazard, (5) isolating clectrical service in and around the incident, and (6) combatting the release of toxic, explosive, corrosive, or flammable matcrials in a location not specifically designed for containing such matcrials.

Special equipment and supplics, as well as emergency procedures, have been developed by railroads and communities to meet the specialized needs of railyards in hazardous materials cmergencies. Summarized below and discussed further in this guidance manual, these range from relatively simple, low-cost measures like designating an isolation area for damaged railcars to more elaboratc (and costly) measures like implementing release containment systems. For the most part, these measures are alrcady in usc by many railroads with heavy or diverse hazardous materials traffic and, thus, more advanced cmergency preparedness programs. Special measures include:

- Designating a yard tower or other clevated location as an cmergency command center and equipping it with a telescope or high-powered binoculars, metcorological instruments, and such other equipment and/or supplies to make the facility a safe haven (c.g., tape for sealing doors and windows). 
- Designating an isolation area wherc damaged railcars can be safely moved. These tracks should be away from air intakes for buildings, tunnels, or other facilities.

- Positioning support locomotives at each end of the yard so workers relocating railcars can stay upwind of any potentially toxic plume.

- Constructing containment ditches or pits along isolation tracks, and installing oil retention booms and skimmers to prevent escaping materials from migrating farther into the environment.

- Installing fixed overhead trays or small culverts so fire hoses, cables, and other equipment can be routed over or under tracks.

- Spot-checking intermodal shipments of hazardous materials for proper blocking and bracing of cargo.

- Installing automated or manual controls to prevent consists from leaving the yard if any railcars containing hazardous matcrials violate DOT placement rules.

- Providing local response organizations with maps showing the locations of yard access points, rendezvous points inside or at the edge of the yard, and fire hydrants inside or adjacent to the yard.

\section{Common Needs}

Table 1 illustrates two of the parameters along which the emergency preparedness needs of railyards differ from those of mainlines and other fixed-site facilities. Like mainlines, railroad yards are exposed to a wide range of hazardous material traffic and present unique logistics challenges. Thus, emergency preparedness measures applicable to railyards and mainlines include training responders in procedures for safely crossing tracks and approaching placarded railcars: using "high railer" dual mode vehicles that can operate either on roads, over the ground, or on rails to move emergency response equipment into hazard zones; training yard workers to stack intermodal containers so that placards are visible from all sides; routinely checking the consistency and accuracy of placards, waybills, and shipping papers; and automating the monitoring of yard locations of placarded railcars (for example, via computerized inquiries of waybills flagged as hazardous materials ("HZ" or "HM" code). Again, many of these measures are already in use by railroads with more advanced emergency preparedness programs. With the exception of computcrized location monitoring, all are relatively low-cost measures.

As at other fixed-site manufacturing and storage facilities, hazardous matcrials can remain in railyards for extended periods of time. Measures appropriate for both railyards and fixed facilities include designating a company responder for each site; equipping on-sitc command posts with extra telephore jacks, communications equipment capable of transmitting hard copies of messages, and meteorological instruments; installing on-site sirens or horns, emergency eycwash fountains and showers, and systems to automatically detect and monitor leaks; and indicating storage sites for hazardous materials (for example, fucl or solvents) and emergency equipment on facility rnaps. With the exception of revising facility maps, these 
measures tend to be somewhat more capital intensive and, therefore, more feasible for larger railroads or those with high volumes of hazardous materials traffic.

\section{General Needs}

Some aspects of emergency preparedness apply to a wide range of settings, including mainlines, other fixed-site facilities, and railyards. The following five steps summarize and generalize key recommendations from this and other guidance, and highlight those aspects of emergency preparedness that need not be restricted to particular audiences.

\section{STEPS FOR INCREASING EMERGENCY PREPAREDNESS}

1. Heightened Awareness. Increase the awareness of hazard sources and recognize the importance of being prepared for cach type.

2. Planning. Develop plans for potential emergencics and the responses for each type.

3. Training. Educatc planning and responsc personnel about dealing with the specific risks of specific substances in specific situations.

4. Exercise. Test plans, evaluate the effectiveness of training, and improve emergency response through drills and excreises.

5. Assessment. Review and inspect emergency preparedness resources and capabilitics to verify equipment and personnel readiness, identify opportunities for improvement, and update key response information.

\section{Implementing this Guidance}

The value of this guidance to railroads and communities will depend on how well prepared they already are for hazardous materials cmergencies in railyards. The guidance should be especially useful for railroads and communities whose plans and procedures, facilities, equipment, training, excreises, or cvaluation capabilities limit their preparedness for such emergencies. The guidance recommendations provide clear blucprints to the kinds of activitics, procedures, and techniques that can dramatically improve emergency preparedness. Coupled with determined effort, they show that there is much that railroads and communitics with limited preparedness capabilitics can do to improve.

This document contains a wide range of information on cach of 11 emergency preparedness functions. There are 150 guidance recommendations presented herein. Some of them are being used by more than a few railroads and communitics and will come as no surprise to many readers. Others are being used at only one or a few railroads and communitics, or are based on lessons learned from recent hazardous materials emergencies, practices developed for other types of emergencies, or recent 
research findings (most notably, on the merits of sheltering versus cvacuation). These may be less familiar to most readers, who are encouraged to keep an open mind as they compare these recommended practices with their own. Clearly, each railroad and community must review its individual situation as it evaluates the merits of each practice recommended in this document. ${ }^{*}$ In deciding whether to accept, reject, or modify each such practice, railroads and communities should be guided by the five steps for increasing cmergency preparedncss (awareness, planning, training, exercises and assessment) presented above.

In considering individual guidance recommendations, railroads and communities should also be aware of four basic messages that run through and tic together most of the guidance in this document. These messages illustrate why specific combinations of the guidance recommendations should be considered together and how adopting such combinations can be especially effective. The inessages are as follows:

1. Increase inter-organizational cooperation and coordination in all aspects of cmergency preparedness planning and response.

2. Improve the availability of life-saving and injury-reducing resources and provide the training needed to access them.

3. Increase the frequency and scope, and improve the quality of emergency preparedness exercises as a tool for testing the effectiveness of planning and training programs.

4. Develop emergency preparedness plans and procedures specifically for railyards, and update and increase the comprehensiveness of existing railyard plans and procedures.

As they launch new emergency preparedness efforts or cxpand existing efforts, railroads and communities would do well to be guided by these messages. As they look for specific opportunitics for improvement, railroads and communities are encouraged to consider the guidance recommendations that follow.

\footnotetext{
*The table that summarizes the training aspects of this guidebook (Table 5) provides a handy checklist for making such comparisons, as does Sec. H (Emergency Preparedness and Response Training).
} 


\section{GUIDANCE FOR RAILROAD AND COMMUNITY EMERGENCY PREPAREDNESS}

The efforts of railroads and communities to prepare for and respond to hazardous material emergencies in railroad yards can be grouped into 11 functional areas ranging from roles and responsibilities in emergency planning and response to post-incident documentation and follow-up. Table 2 lists these functions, along with a number of specific actions or activities essential to accomplishing them. In some cases, the activities could apply equally well to many kinds of hazardous material emergencies; in others, they are specific to the circumstances likely to be encountered in railyards. While every effort has been made to target the discussion to the kinds of situations and events unique to railroad yards, certain genera! actions or activities are also discussed because they are particularly critical to effective planning and response for a wide range of emergencies.

Although both railroads and communities have some measure of accountability for each of the activities listed in Table 2, some are primarily railroad (or community) responsibilitics while others (e.g., planning) are joint responsibilitics. Clcarly, railroads and communities play different and distinct roles -- roles which reflect their diverse organizational missions. This guide combines the discussion of those roles and activities to promote broader understanding and appreciation, and to help identify opportunities for organizational coordination, cooperation, and assistance.

The following discussion is organized by functional area and activity. For each of the activities listed in Table 2, the discussion has two parts: (1) an overview of current practices identified in a limited number of site visits and plan reviews, and (2) brief descriptions of recommended improvements to enhance emergency preparedness capabilitics. Note that the overview is a general discussion of railroad and community roles and activities, while the recommended improvements are more specific.

The discussion is geared to railroads and communities of all sizes, even though smaller railroads (or communities) may be constrained by limited resources. Small railroads and communities are key audiences for this guidance. Thus, guidance that is particularly relevant to these groups is highlighted by putting the phrases small railroads and small communities in italics. Generally speaking, the highlights focus on how small railroads (or communities) can overcome resource limitations. 
TABLE 2 Emergency Preparedness Functions and Activities to Improve Preparedness for Hazardous Materials Emergencies in Railyards

Majer Responsibility

Function and Activity

Railroad Community

\section{A. ROLES AND RESPONSIBILITIES FOR PLANNING 'AND RESPONSE}

1. Identify laws and regulations that require and authorize the plans that could be activated in an emergency and the local, state, and federal governmental agencies and officials empowered to act.

$x$

$x$

2. Identify planning responsibilities of local, state, and federal governments, railroads, manufacturers, shippers and receivers; develop coordinated plans and procedures specific to railyards; and regularly review and update them.

3. Identify government and industry response organizations, and meet regularly with official liaisons to coordinate planning and response.

4. Assign responsibilities to public and private responders, and designate (by title) the individuals responsible for coordinating and directing responses to railyard emergencies. Prepare organization charts illustrating relationships among response units (including the railroad and the Incident. Commander from the designated civil protection organization) and the chain of command.

5. Make advance arrangements (preferably written agreements with clear activating conditions) to secure supplemental resources.

6. Identify qualified contractors for the safe and timely cleanup and disposal of debris and contaminated media, and arrange for their services. Inform them that they will be under the direction of the Incident Commander (who will coordinate with responsible railroad officials) until the emergency is completely over.

\section{B. PLANNING ANALYSES}

1. Conduct hazards analyses, identifying the hazardous materials most frequently stored or handled at the railyard, likely emergency sequences and consequences, and overall risk. $\mathrm{x}$

$\mathbf{x}$

$\mathrm{x}$

$\mathbf{x}$

$\mathrm{x}$

$\mathrm{x}$

$x$

$\mathrm{x}$

$\mathrm{x}$

$\mathrm{x}$ 
TABLE 2 (Cont'd)

Major Responsibility

Function and Activity

Railroad Community

2. Establish standard emergency classification levels with corresponding response actions. Coordinate with railroad and community cmergency response officials to ensure compatibility.

$\mathrm{x}$

X

2. Designate off-site support facilities to direct railroad response activities, to coordinate public and private response efforts, and to provide public information. Establish criteria for activating these facilities.

3. Establish an on-scene command post, equip it with additional communications links, and assign responsibility for $24-\mathrm{hr}$ maintenance, security, and the staffing of communications links.

4. Designate primary and backup emergency communications links to contact other railroads (if tracks are shared), shippers, and chemical experts. Designate at least one dedicated radio band for emergency communications and response coordination. Provide responders with mobile communications equipment tunable to local frequencies.

5. Inventory and classify by EPA hazard category (A-C) all emergency equipment and supplies that are on hand at the railyard or jurisdiction or available through supplemental support agencies, jurisdictions, or private organizations. Regularly update inventories, verifying equipment location and readiziess. Coordinate with railroad or community staff to avoid duplication.

6. Periodically inspect and perform regular maintenance on stored equipment and facilities. Maintain inspection records. 
TABLE 2 (Cont'd)

Major Responsibility

Function and Activity

Railroad Community

7. Establish procedures for the deployment of personal protective equipment, containment equipment, emergency monitoring devices and instruments, detoxification agents, and cleanup and disposal equipment.

8. Evaluate water supplies and the hookup needs of fire and rescue equipment. Add or upgrade on-site hydrants and provide safe connections to off-site hydrants.

9. Install properly lined ditching systems and/or containment pits to avoid contaminating underground watcr.

\section{ALERT AND NOTIFICATION}

1. Maintain and update lists containing the telephone numbers of contacts at manufacturers of the hazardous materials most frequently handled at the railyard.

2. Establish procedures and methods for 24-hr notification of local civil authorities (primary responders) of hazardous materials cmergencies and for verifying such notifications with the railyard. Use standardized (e.g., "fill-in-the-blank") messages and include chemical-specific information in initial notifications.

3. Establish procedures, methods and priorities for 24-hr alcrting, notification, and mobilization of additional primary and secondary responders (including those from neighboring jurisdictions and facilities, and railroad, shipper, and industry response teams), second-shift personnel, and cognizant federal and state agencics.

4. Establish procedures and means (c.g., sirens, Emergency Broadcast System [EBS]) for alerting the public that an emergency has occurred and for issuing emergency instructions.

5. Where incidents can have dire consequences, (e.g., those involving Class A poisons, Class A and B explosives, or flammable liquid or gas), require that yard personnel promptly notify adjacent communities and request backup support.

$\mathrm{X}$ $x$

6. Maintain and update lists of adjacent buildings and occupancies, including managers and custodial names. 
TABLE 2 (Cont'd)

Major Responsibility

Function and Activity

Railroad Community

\section{E. POPUlation PROTECTIVE ACTIONS}

1. Establish guidelines and critcria for deciding at the scene whether on-site actions (e.g., access control, immobilization in the railyard or adjacent mainline operations) or off-site actions (c.g., sheltering, or cvacuation) are necessary, depending on the specific circumstances of the emergency.

$x$ evacuation recommendations. Develop prescripted messages.

3. Designate one or more buildings in the railyard as shelters, indicate their locations on site maps and in emergency plans, and stock them with appropriate supplies, including instructions for their use as emergency shelters.

4. Establish procedures for the reentry of an evacuated area adjacent to a railyard and for the railyard itself. Establish criteria for determining when it is safe to reenter, and designate by tille the official responsible for recommending recntry.

5. Establish procedures for handling long-term physical and psychological effects on victims.

\section{F. RESPONDER SAFETY}

1. Kecp copies of the AAR and DOT hazardous materials guidebooks at the railyard to assist responders in selecting appropriate protective gear and to minimize exposures below hazard limits. Send relevant information to adjacent communitics and to the hospital with all contaminated or injured individuals.

2. Designate response sectors or zones within railyard. Use Standard Operating Procedures (SOPs) for response activities in those sectors.

3. Develop SOPs specific to railyards yet parallel to generally applicable procedures for hazardous materials emergencies (e.g., procedures for evaluating progress, putting on and taking off protective clothing, recording the presence of personnel in the hazard zone, monitoring release concentrations, relocating containers exposed to heat and flame, etc.). $\mathbf{x}$ 
TABLE 2 (Cont'd)

Major Responsibility

Function and Activity

Railroad Community

4. Conduct regular training sessions on personal safety.

$x$

5. Establish a warning system for emergency evacuation of teams operating in the hazard zone.

6. Structure response and repair operations for maximum personnel safety (e.g., obtain assessment data upwind and from a safe distance; keep a combustible gas meter on hand if combustible and/or flammable materials are handled; equip vehicles used for public notification with respirators with the proper cartridges).

7. Inform responders of the hazardous materials involved, exposure symptoms, and hazard limits. Monitor exposures and relieve personnel at intervals appropriate to limits. Locate monitoring (and decontamination) near the checkout point.

\section{G. INCIDENT ASSESSMENT AND ANALYSIS}

1. Improve incident detection by installing commercially available stationary devices to monitor toxic, corrosive, and flammable vapors and gases.

2. Provide the Incident Commander with clear and concise information, including rosters of available railroad personnel that are trained and qualified to assist with mitigation and recovery, inventories of available equipment and supplies, data already obtained (from placards, shipping papers, standard references, the Chemical Transportation Emergency Center [CHEMTREC], etc.), and response actions already taken.

3. Increase the usefulness of incident assessment data by automating and expanding hazard information systems to include important firefighting information (e.g., site maps, floor plans, and the locations of stored supplics), maintaining comprehensive records of train consists, computerizing hazardous materials inquiries, and developing the capability to obtain hard copies from CHEMTREC or other hazard information data bases.

4. Obtain accurate, site-specific meteorological data to track airborne releases and support plume dispersion models. 
TABLE 2 (Cont'd)

Major Responsibility

Function and Activity

Railroad Community

5. Establish procedures for containing releases (c.g., with dikes and absorbent pads) or otherwise restricting the spread and intensity of emergency consequences, and for collecting environmental samples to monitor the success of those procedures.

$x$

$x$

6. Establish procedures for undertaking environmental assessment, biological monitoring, and contamination surveys, and for deploying field teams to monitor the size, concentration, and movement of hazardous materials releases.

7. Identify and begin appropriate actions to restore the railyard and, if necessary, the surrounding environment. Monitor the success of those actions, and assign long-term responsibility for site control.

\section{H. EMERGENCY PREPAREDNESS AND RESPONSE TRAINING}

1. Familiarize fire and rescue personnel with railyard characteristics (including layoul, access points, and possible points of unauhorized entry), the railroad's SOPs for handling involved ratcars, and railroad information and response resources and capabilities.

2. Instruct yard personmel and civil responders in the proper use of basic references (c.g., waybills, shipping papers, decision flowcharts, emergency classification levels, AAR and DOT guides, and CHEMTREC) for identifying involved materials, determining their physical propertics and potential hazard, and indicaling appropriate responsc measures. Maintain training records.

3. Take advanlage of available courses and other training resources. Assemble a library of videotapes applicable to hazardous materials emergencies at railyards or borrow lapes through lending libraries.

4. Where gaps exist, develop programs and materials to supplement and cnhance available resources. Emphasize the importance of efficienlly locating information on specific chemicals, assessing container damage, and minimizing responder exposure, and the danger of railcars with "empty" or "residue" placards. Designate (by title) the individual responsible for emergency worker training. $\mathrm{x}$

$\mathrm{x}$ 
TABLE 2 (Cont'd)

Major Responsibility

Function and Activily

Railroad Community

5. Create opportunities for railyard personnel to train with firefighters and other local responders.

$\mathrm{X}$

$\mathrm{X}$ over.

\section{I . EMERGENCY PREPAREDNESS EXERCISES}

1. In conjunction with training activitics, conduct an initial tabletop exercise to verify workers' understanding of their roles and responsibilities, and test their ability to perform assigned tasks.

2. Develop a regular program of internal, teamwork-oriented exercises (tabletop, functional and full-scale) to systematically evaluate portions of the plan, response skills and coordination.

3. Develop a system to evaluate how well exercises meet specified objectives.

4. Establish guidelines for participating in safe excreises, and work with involved agencies to periodically conduct joint functional or full-scale excreises.

$x$

$x$

5. Use exercise results to identify shortcomings and suggest revisions to emergency preparedness plans, procedures, and training programs.

\section{J. PUBLIC EDUCATION AND EMERGENCY INFORMATION}

1. Participate in public mectings to develop plans for protective actions.

$x$

$\mathrm{x}$

2. Improve public education. Provide public speakers and information that explain potential hazards and the planning and response measures that are in place for hazardous materials emergencies. Tell local media what to expect, how to get additional information, and which locations are off-limits during actual emergencies. 
TABLE 2 (Cont'd)

Major Responsibility

Function and Activity

Railroad Community

3. Plan for and standardize as much public information as possible. Develop prescripted messages in several languages, if appropriate, to convey standard information and assistance. Enter into formal EBS agrecments that include regular broadcast of test messages.

4. Develop plans and procedures for alcrting and communicating with such "special needs" populations as the vision- and hearing-impaired, the handicapped, and forcign-language speakers.

5. Develop a joint rumor-control program and train participating personnel. Designate (by title) an official spokesperson.

\section{K. POST-INCIDENT DOCUMENTATION}

1. Maintain detailed, chronological logs of events, conversations and activitics undertaken during the emergency, including during recntry and restoration phases.

$\mathrm{X}$

2. Evaluate response effectiveness. Identify necessary changes to
plans and procedures, and additional needs for training and public information.

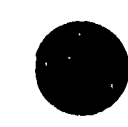




\section{A , ROLES AND RESPONSIBILITIES}

Both railroads and adjacent communities are responsible for emergency planning, coordinating their planning and response activitics, and acquiring the resources necded to carry out their respective roles. Generally speaking, the roles and responsibilities of railroads and adjacent communities in responding quickly and effectively to hazardous matcrials emergencics and in mitigating adverse impacts are spelled out in emergency plans themselves and/or in cnabling laws and regulations.

\section{A.1 Laws and Regulations}

Most large communitics are well aware of (1) the legal authoritics that affect their planning and response efforts; (2) local response organizations and their capabilities; (3) existing plans that could be activated and which must be coordinated during an emergency; (4) other federal, state, and local planning responsibilitics and response capabilitics; and (5) privale-sector response organizations and resources. Generally speaking, small communities have limited awareness of private-sector response organizations and resources, particularly those outside the local community (sec Sec. A.4). Small communities also tend to have limited awareness of existing private-sector plans that could be activated.

At this time, most communities should have rewritten, or are now rewriting their plans to conform to the "right-to-know" requirements of the Superfund Amendments and Reauthorization Act of 1986 (SARA), Title III. Many are following NRT (1987) guidance on plan content a.d organization. For most large communities, either an emergency preparedness, civil defense or emergency management department within city government or an arm of the city's fire and rescue service is responsible for planning. Often this planning organizalion's efforts are supported by the Local Emergency Planning Commillec (LEPC), which is required under SARA Title III to develop a local hazardous malerials emergency response plan. All communitics, cities, or planning districts such as LEPCs should and must coordinatc their efforts with statc, county and other local emergency preparedness organizations in order to comply will SARA, Tille III. Typically, these plans become annexes to existing Emergency Operations Plans (EOPs).

SARA Title III contains stringent reporting requirements for companies (including railroads) storing hazardous matcrials in fixed facilitics. Although the requirements of the Act could be interpreted 10 apply to transient shipments passing through railyards, this has not yet oceurred (sec Sec, B.1). Nonetheless, the nature of area-wide emergency planning for haxardous materials is changing as a result of Title III.

Statc laws can also have strong impacts upon railroads and railyards. For cxample, California is considering adopling safely standards for the rail transportation of hazardous materials. The proposed standards include provisions that each railroad transporting hazardous matcrials in California shall (Califomia Public Utilitics Commission, 1991): 
- immediately notily by telephone the appropriate Emergency Response Agency (ERA) of any incident involving the release or threatened release of a hazardous material which is believed to pose a signilicant present or potential harm to persons, property or the environmenl;

- provide cach of its dispatchers with procedures for the immediate notification of the appropriatc ERA of any incident, including the name and 24-hour emergency number of each ERA along each rail line;

- provide cach ERA along each rail line with the railmad's current 24-hour emergency telephone number(s);

- upon request by an ERA, provide information for the most recent 12-month period on each lype of hazardous malcrial transported through or wilhin the line segment that includes such ERA;

- upon request by an ERA, provide information regarding leases for storage of hazardous materials, including the name of the commodity and the location of cars;

- have an emergency preparedness plan which includes incident notification, mitigation, and training procedures for railroad personncl;

- ensure that all trains are equipped with at least iwo radio transceivers in good working order; and

- provide its customers with appropriate standards for static protection of all track which is used for the transfer of flammable liquids and gases and which is outside the general raitroad system of transportation.

\section{Guidance}

Nonc.

\section{A.2 Planning}

Railroad yard plans, which tend to be brief, emphasize such items as alcrt and notification procedures and yard entry locations where company and community responders are to meet. Those developed by larger railroads cover a more complete range of response activities, and often limit the role of adjacent communities 10 major emergencics. (Sec Sec A.3) Because of limited resources, small railroads usually rely on SOPs to guide their personncl in responding to hazardous material cmergencies, and lypically do not have cmergency proparedness plans and procedures specilically geared to yard situations.

Railroads and communities almost always have separatc, rather than joint, plans for responding to railyard emergencies involving hazardous materials. While integrated planning is the exception, some large railroads have designated liaisons to work dircctly with their community counterparts to improve coordination in 
emergency planning and response to railyard emergencies. Often, the designated liaison is also the railyard representative to the LEPC, and to the Community Awarencss and Emergency Response (CAER) and Transportation Community Awareness and Emergency Response (TRANSCAER) programs.* This individual, along with others involved in the production, shipment, and storage of hazardous materials in a given area, may allend regular meetings to exchange knowledge and experience.

Historically, most railroads have not favored joint cmergency preparedness planning because of the fear that assigned roles might constrain their flexibility in handling cmergencies originating on their property. This reluctance is understandable because full-blown civil responses, whether necessary or not, disrupt service and may damage the plant and equipment. Thus, railroads generally strive to do everything feasible to prevent minor emergencics from becoming major ones that require civil intervention. Nevertheless, few railroads, large or small, report difficulties in working with authorized civil response organizations under scparate plans.

Community emergency preparedness plans tend 10 be more comprehensive. Most large communilies have or are developing plans for responding to a wide range of natural and man-made emergencies. Although tailored 10 particular sets of circumstances, including existing resourses and capabilitics, communty plans cond to share the following features:

1. Although self-sufficiency is emphasized for most response and recovery operations, the plans provide for maintaining mulual-aid and assistance agrecments with neighboring jurisdictions and eontracts with privale-sector resources for supplemental manpower and eyuipment.

2. The plans build upon and supplement the SOPs of the alfected agencies and cily departments.

3. The plans incorporale incident command concepts, including standard protocols for command and control of units responding 10 mulual-aid requests.

4. The plans provide for establishing a forward command post near lie secne of the emergency and, if warranted, an emergency operations center at a centrally located public building away from the secne. In many cases, the city hall serves this latler purpose.

5. The plans provide for regular training programs and excreises (including reviews and critiques) 10 lest procedures and idenlify arcas necding improvement.

\footnotetext{
* Initiated by the CMA, CAER is a cooperative effort of industries involved in the production of hazardous matcrials to increase public awareness about those materials and cncourage integrated emergency preparedness planning. Its sister program, TRANSCAER, has a similar focus. TRANSCAER is supported by industries involved with the shipping, manufacturing, distribution, and transportalion of hazardous materials.
} 


\section{Roles and Responsibilities}

Most community plans do not specifically address railyard emergencies involving hazardous matcrials. However, some incorporate SOPs for fire and rescue units responding to rallyard emergencies. (See Sec. F.3) These procedures emphasize pinpointing the exact location of the emergency and using railroad maps and personnel to assist civil responders. More specifically, railroad personnel are asked to provide yard sector letters (for yards so divided), track and railcar numbers, and escorts at the appropriate yard access point to accompany responding units. Railyards are likely to undergo dynamic and significant changes in the years ahead as a result of the major restructuring now underway in rallroad organization and operation. These changes should be continually monitored and recvaluated to determine their effect on response needs.

Most large communities retain a file copy of the railroad emergency preparedness plan and maintain contact with the railyard representative to the LEPC. LEPCs are appointed by state emergency response commissions; therefore, their jurisdictions usually do not cross state lines. In some metropolitan areas, two or more committecs may develop plans with little or no interstate coordination. Separately developed and uncoordinated plans can create significant problems during hazardous matcrials emergencies. Mutual-aid agreements should be used to promote coordinated planning and emergency response.

Communities that have emergency preparedness plans for hazardous materials cmergencies should update them at least annually. Plans are sometimes revised if a problem or awkward situation developed during an actual (or simulated) emergency (for example, if the emergency revealed a flaw in the plan or a hazard that was inadequatcly covered in the plan). More frequently, however, updates focus on those sections of the plan that contain specific information that is likely to change. This information is often formatted into easily replaceable modules. For cxample, resource inventorics and call lists containing the names and telephone numbers of specific individuals with designated responsibilitics may be updated quarterly, while command and control structures and response roles might remain fixed for several years. The replacement pages often become the basis for notification and communications drills.

\section{Guidance}

1. Develop comprehensive emergency preparedness plans and procedures specifically for railyard hazardous materials emergencies. This document -- along with information available from the NRT, other railroads and communities, and the AAR -- can assist railroads and communities in revising, updating, and expanding such plans.

2. Wherever possible, large communities and railroad officials should undertake joint planning for hazardous materials emergencies in railyards. Small communities should always develop railyard emergency procedures and/or comprehensive railyard emergency plans with the railroad and take advantage of opportunities to combinc resources. Likewise, small railroads should combine resources with adjacent communities. However, railyard emergency 
procedures of limited scope can be developed by small railroads without community help.

3. Participate in mutual-aid compacts covering communities served by rallyards. Railroads actively participating in mutual-aid compacts are assured that expertise and equipment needed for a hazardous materials cmergency, but unavailable in the railyard, can be obtained immediatcly. Railroads also gain an opportunity for regular interaction with manufacturers and users of hakardous materials and with civil responders.

4. Improve interstate coordination. Although bi- or tri-statc metropolitan areas are not legally bound to coordinate their emergency planning, such interstate coordination could greatly enhance emergency preparedness. For example, LEPCs for areas crossing statc boundarics could jointly designate cvacuation routes and mass care facilities across state lines. Local emergency planners recognize the need for such coordination; however, it frequently cannot occur until interstate agreements are in place.

5. Regularly update existing railyard-specific SOPS or any generic SOPS as they apply to railyards. Indecd, anmual updates may be needed to reflect changes taking place either in the railyard or adjacent neighborhoods. All railroads and communities should update, al least annually, the telephone numbers of the responders and organizations to be contacted in the event of an emergency. All such updates should be carricd out, if possible, with the cooperation of and in coordination with railroad and community officials.

6. Designate official liaisons to work directly with railroad and community counterparts to improve coordination, overcome barriers to effective communication and understanding, and emergencies. Yardmasters, trainmasters, yard superintendents, and general foremen are typically appointed as railroad liaisons.

7. Hold regular meetings for all parties involved in the production, shipment, and storage of hazardous materials in a given area to exchange knowledge and experience. Regularly scheduled joint mectings can build the kind of close working relationship that promotes better understanding of mutual response necds and capabilitics.

8. Adopt a loose-leaf, "annex" format for emergency preparedness plans. Plans can be updated more casily and cheaply if parts of the plan can be revised independently of the others. Revision pages should always carry the date of the revision. Many states and large cities already use this format. 


\section{A.3 Resporse Coordination and Direction}

Many railroads make a clear distinction in the role of civil authorities in responding to minor versus major emergencies on railroad property. Major emergencies are those the railroads believe may extend beyond railroad property and therefore require outside assistance. Minor emergencics are those the railroads believe they can handle on their own. For major emergencies, railroads recognize the authority of civil responders empowered by state, county, or local plans. Whether minor or major, coordination is critical because flawed responses may aggravate not only the initial hazard, but also related or unrecognized hazards. Since few small railroads can afford to maintain their own response resources, small railroads tend not to distinguish between minor and major emergencies.

Some railroads regularly inform civil authorities about changes at the railyard that could affect the local response. For example, railyard access points may change; classification humps may be relocated or removed; the total car throughput may increase; or the composition of the traffic may change significantly. Relations with off-site responders are best when railroads provide them with the information they need to perform their job quickly, efficiently, and safely.

Another responsibility of railroads is controlling access 10 their railyards and the scenes of railyard emergencies. Most major railroads have railroad police to handle this function, at least until local police units arrive. Some yard personnel may be assigned this responsibility for fast-breaking emergencies. Authority 10 control access passes to the local police upon their arrival. Many railroad plans also provide for security or other railroad personnel to assist in public notification (for example, door-to-door visits) during evacuation.

As with all emergency situations, clear, erfective command and control are vital to executing a successful response. A final rule of the Occupational Safety and Health Administration (OSHA) (29 CFR* 1910.120[a][3]) requires establishment of Incident Command Systems. Incident Command Posts established under such systems should be within view of potential emergency locations. The Incident Commander -usually the ranking officer of either the local hazardous materials response team or the responding fire and rescue squad -- directs and controls response activities. Thus, under federal law, the Incident Commander supersedes the management authority of the railroad. In most plans, such authority docs not end until the emergency is completely over. Railroads may choose to establish their own forward command post at or near the railyard to coordinate decision making regarding ongoing railyard operations.

To assist in identifying or mitigating hazards, Incident Commanders examine shipping documents provided by railroads and consult various references. They also contact CHEMTREC, a service of the CMA, or the shippers of the affected hazardous materials. Shippers are often the best source of supplementary information on the nature of hazards. If a potential hazard exists, the AAR's Burcau of Explosives will provide inspectors, on request by full and affiliate members, to assist in emergency response.

${ }^{*}$ Code of Federal Regulations. 
Fire departments may provide necessary mitigation equipment, as well as protective gear. Railroad personnel can advise and assist as needed and may provide equipment or conduct support operations. An example of such assistance is moving other railcars containing hazardous materials away from the scene of the emergency. All of this, however, requires advance coordination and cooperation.

\section{Guidance}

1. Increase organizational cooperation and assistance. Communitics know that railroads can provide additional manpower and specialized technical expertise. Civil responders should understand, however, that railroad personnel remain under railroad control and that organizational cooperation is necessary for assistance in emergency operations. A common arrangement is for the ranking railroad official to become, in effect, a special advisor to the Incident Commander.

2. Keep all parties informed. To effectively combat railyard emergencics, civil responders need to know relevant aspects of railyard configuration, practice, and throughput, particularly as such factors affect access to and movement within the railyard. Railroads should provide this information either by means of a designated liaison (see Sec. A.2) or as a separate activity. Railroads should also provide detailed site maps, particularly for major yards.

If possible, the concerns of civil responders about railyard operations and layout should be resolved jointly. If differences remain on matters beyond the community's legal authority, then the railroad and community should seck to jointly enhance preparedness by safely accommodating the railroad's policy position. Contact should be maintained on a regular, mutually agreed upon basis, even if there are no changes in policy or procedures. The regular flow of information kecps community relations positive.

3. Clearly define lines of authority and organizational roles and responsibilities. The definitions in railyard and community emergency preparedness plans should be clear, unambiguous, and consistent with SOPs and whichever other plans might be activated during emergencies. Response personnel should be familiar with these roles and the associated chain of command.

4. Conduct joint emergency exercises. Virtually all railroads that have participated in exercises with communities report that well-designed joint emergency excreises provide the best test of coordinated emergency response plans and procedures. 


\section{A.4 Supplemental Resources}

Resource acquisition can take the form of physically prepositioning the necessary manpower, equipment and supplies, or maintaining agrcements to quickly mobilize and deploy those resources from outside suppliers. Most large communities and many large railroads (particularly those operating in sparsely settled arcas) maintain dedicated response teams with specialized equipment and supplies. Smaller communities and railroads are rarely able to afford such specialized resources.

Representatives of shippers and manufacturers sometimes become directly involved in railyard emergencies, but always under the direction of the Incident Commander. To cnable prompt response, mutual-aid compacts are sometimes negotiated. For example, chemical companies and construction contractors in nearby communitics may agree to provide materials, equipment, and expertisc on an immediate basis. Chemical companies may provide specialized expertisc relating to their chemicals and enginecring advice and assistance needed to mitigate the problem, as well as sophisticated equipment for detection and analysis. Such expertise and equipment may not be immediately available to railroads or firc departments. Construction contractors may provide diking capabilitics (for example, sandbags and backhoes) and clcanup equipment at no or low rental cost. The Houston Channel Industries Mutual Aid Organization, with over 80 member organizations, is a good example of the size and scope of mutual aid assistande available to some railroads and communitics.

Although many large railroads maintain emergency response teams, team members may be far from the emergency and therefore unable to function as first responders. The role of such teams is covered in the plans. Once civil responders have taken command, team members provide information and support to the responsible fire department. They also help in mitigating hazards. Plugging leaks is a good example of such intervention.

Small communities tend to depend on outside resources when faced with emergencies involving hazardous materials. -Very few of them maintain emergency response teams. Even when they have plans, most small railroads also look outward for support. However, small railroads with years of experience handling hazardous matcrials are less likely to look for outside assistance than those with less experience.

Some small communities are aware of the services available from hazardous matcrials responsc teams (HMRTs) and have developed valuable working relationships with them. However, many small communities have limited awareness of private-sector response organizations, resources, and plans.

\section{Guidance}

1. Investigate the availability and capabilities of HMRTs and, if possible, establish working relationships with them. Depending on location, CHEMNET (CHEMical NETwork of the Chemical Manufacturers Association), CHLOREP (CHLORine Emergency Plan of the Chlorine Institute), and PSTN (Pesticide Safety Team Network of the National Agricultural Chemical 
Association) may be available for responding 10 railyard emergencics. All three may he contacted through CHEMTREC. (Sec Sec. D.2) Such teams van be especially valuable to small railroads and communities.

2. Enter into mutual aid compacts with nearby communities and private organizations that have emergency response capabilities. (Sec also Sec. A.5)

\section{A.5 Cleanup and Disposal}

In the plans of most major railroads and some small railroads, responsibility for stopping, containing, or controlling the runoff of contaminated liquids is assigned to specific personnel. Provisions are also made for specialized contractors to conduct damage analyses, clear wreckage, and clean up and dispose of hazardous materials and contaminated media. In some locations, regional compacts make a wide range of heavy equipment available to railroads and communities in the carly stages of a hazardous materials emergency.

Most railroads maintain standing arrangements with waste management and disposal contractors for field and laboratory analytical services and safe and thorough waste removal and disposal. In addition to the scriousness of the task itsclf, liability concerns dictate that railroads select support contractors very carefully, monitor their performance records, and periodically confirm support arrangements. Contractors presumably on call for handling releases of certain chemicals have sometimes been found to no longer be in that business when called upon. Arrangements should also stipulate that all activitics conducted by these contractors be closely coordinated with local authorities.

In an emergency investigated by the NTSB (1984), for cxample, a wreckage contractor and railroad caused substantial releases of a hazardous matcrial during tapping operations on a tank car whose leak had been stopped. The Board noted that neither the railroad nor the contractor had coordinated their activitics with the commodity manufacturer or local emergency response personnel in planning and implementing the tapping operation.

Small railroads using small specialty contractors may experience problems -perhaps more so than large railroads using large contractors. For example, onc small railroad encountered problems after hazardous matcrial was offloaded from a railroad tank car into a disposal contractor's tank trucks. Somc trucks leaked; others went to the wrong disposal site.

\section{Guidance}

1. Establish procedures for selecting and confirming the availability of specialty contractors. Contractors for clearing wreckage and cleaning and disposing of contaminated materials shouid be carefully sclected. Their performance should be periodically evaluated, and their availability should be regularly checked to 
ensure that they are still dealing successfully with the substances most likely to present hazards at the railyard. Because of their infrequent contact, small railroads are particularly vulnerable to problems in working with specialty contractors. Yet, because of their limited resources, they are particularly dependent upon them. Thus, they must be particularly diligent in selecting, evaluating and confirming contractor availability.

2. Notify any salvage, cleanup, or disposal contractors that they will be under the direction and control of the Incident Commander until the area is safe for reentry and appropriate restoration actions have been initiated. Such notification may already be a feature of the agrecment. This command structure cnsures close coordination between the Incident Commander and any railroad using contractors.

3. Require evidence that contractors are properly licensed and insured, that their personnel are adequately trained, that contaminated material is being disposed of properly, and that cleanup and disposal equipment is in good repair. The railroad may be beneficial owner of the hazardous material involved in the emergency. If so, it is respensible for the actual cleanup or for securing qualified cleanup and disposal contractors. However, civil authoritics may not relinquish control of the railyard until the area is safe for recntry and appropriate restoration actions have been initiated. Civil authorities are also responsible for ensuring that appropriate measures are taken to return the environment to its earlicr state.

4. Enter into local or regional mutual-aid compacts to secure cleanup and disposal capabilities. Mutual-aid compacts ensure timely access to a wide range of heavy equipment, especially during the carly stages of emergencies. For the first 24 hours, the equipment is often provided frec or at a significant discount. Compacts are therefore an extremely cost effective alternative until the legal responsibility of the hazardous matcrial owner for cleanup and disposal is established. 


\section{B PLANNING ANALYSES}

All functional arcas involved in emergency preparedness require advance planning to assure that responses are promptly and efficiently executed during a hazardous matcrial emergency. In addition to this functional planning, however, two other planning activitics, hazard analysis and cmergency classification, arc critical to a sucecssful responsc.

\section{B.1 Hazard Analysis}

The Handbook of Chemical Hazard Analysis Procedures (FEMA, DOT and EPA, 1989) provides a useful overview of the hazard analysis process. Applied to railyards, that process has the following steps:

1. Identily the hazardous materials most frequently stored or handled at the railyard.

2. Based on the volume and type of hazardous matcrials in storage or transit, determine likely emergency sequences and assess their probability of occurrence.

3. Estimate the consequences (for example, property damage, injury, environmental impact) of the most probable emergency sequences.

4. Evaluate the overall risk of the hazard as a function of the probability and severity of emergency sequences.

5. Incorporate analysis results in cmergency planning.

To comply with SARA, Tille III, communitics are identifying hazards (sec itcm 1 above), including lhose at railyards. Developing the initial inventory or updating an outdated one is relatively straighlforward in some communities but a major undertaking in others. The size of the task depends on the number of facilities where hazardous materials arc produced, processed, or stored. Generally speaking, personnel from local emergency planning agencies or HMRTs are developing inventorics by conducting on-site surveys.

For many communitics, however, hazard analysis is limited to identifying the nature and location of hazards at fixed facilitics. Although inventorics and maps of hazardous matcrials stored at railyards (for example, because of railcar maintenance requirements) are being developed under SARA, Title III, comparable information about hazardous matcrials moving through railyards is not required. (Sec Sec A.1) Nevertheless, many large and small railroads do provide annual or semiannual lists of hazardous materials handled most frequently to communitics adjacent to their railyards.

Large communities tend not to undertakc railyard vulncrability or risk analyses (sec itcms 3 and 4 above) because of the size of the lask. Also, some communities secm to believe that railyard hazards are somewhat less serious than 
fixed hazards. In addition, they feel compelled to give top priority to developing the initial inventory.

If sufficient resources are available, some small communities arc using personal computers 10 automate their hazards inventories, code site maps, create facility floor plans, and record important access and firefighting features of siles. Such data can be important inputs to hazard information systems. (Sec Sec. C.1)

\section{Guidance}

1. Communities should request and railroads should provide lists of hazardous materials most frequently handled at the railyard. At a minimum, these lists, should be updated annually. The lists can be in descending order by carload counts, and can be based on roulinely prepared internal summaries of hazardous materials traffic.

In addition to their use in hazard analysis, such lists are valuable tools for planning and training. For cxample, firclighters and other responders can undergo specialized training that focuses on the most frequently handled substances, and communitics can acquire specialized resources geared to those substances. Training based on such lists has a high payoff for the lime and resources spent. The Emergency Action Guides (AAR, 1984) for the chemicals on the lists, or even the complete guidebook, can be transmilted with the lists. Because the lists are provided on a regular basis, they do not constitute prenotification of shipments actually passing through the yards.

2. Automate hazard information systems. Communitics can use existing cmergency management systems to automate their harards inventory by coding site maps (including those of railyards), facility floor plans, and important access and fircfighting features of the site (for example, the locations of fire doors, sprinkler systems, and stored fircfighting supplies). While automation would be a major underlaking for communities with numerous facilitics where hazardous materials are produced, processed, or stored, the accuracy and speed of incident assessment could be greatly cnhanced. Al a minimum, small communities should automate their hazards inventory if sufficient resources can be made available.

\section{B.2 Emergency Classification}

Virtually all railroads classify hazardous matcrials emergencies into two types: minor and major. For minor cmergencies, the railroad is usually the responder, either undertaking or contracting for all necessary activities. For major emergencics, the railroad secks the participation and assistance of civil responders. Major emergencies therefore reguire a modified command and control structure. 
Emergencies automatically become "major" as soon as railroads decide that a civil response is necessary. However, there is no objectively defined and uniform basis for deciding when to notify local responsc organizations. The AAR (1989a) recommends that railroads classily incidents into the following levels, based on the expected hazard to people, property and the transport environment.

1. Minor Incident. This level is for situations involving no significant exposure of nearby personnel to hazardous materials, although lowrisk hazardous materials may have becn released. Significant offsite exposures are impossible, and recovery does not require special protective measures.

2. Moderate Incident. This level is for situations involving a large release of a low-risk hazardous material or a likely or actual small release of a highly dangerous material. Exposure of emergency response personnel to toxic vapors may occur and be significant, but will probably not be deadly. Off-site exposure or contamination is possible, but may not be scrious. Evacuation of nearby areas may be necessary, and some immediate and positive steps must be laken 10 control the spread of contamination.

3. Severe Incident. This level is for situations involving release of large amounts of highly dangerous matcrals. Exposure to toxic fumes at the emergency secne must be strictly controlled, and evacuation of nearby areas will probably be necessary.

Threc action levels are associated with this classification system. Action levels focus on the hazard or threat posed by the substances involved in the emergency (AAR, 1989a).

1. Notification. This level is triggered any time a train carrying hazardous material is involved in an accident or a low-volume leak or spill is discovered. Civil responders are notified of the event, even if it is not yet known whether the incident will be classified as "minor."

2. On-scene cmergency. This level is triggered by rupture of or significant leakage from containers of hazardous matcrials. It is also triggered when such rupture or leakage is judged imminent, likely, or possible. Major railroads can usually base their decision on obscrvation or informed conclusion; small railroads must rely on obscrvation or a conclusion stressing caution. At this action level, the incident is classified as "moderate" (or "severe"), depending on the substances involved (sec Sec. D).

3. Arca cmergency. This level is triggered by major releases of highly dangerous material (for example, Class A explosives or poisons). It is also triggered when such releases are judged imminent or likely, and when off-site consequences are likely to be serious. In all cases, this action level corresponds to a "severe" incident. 
The above action levels are initiated by the responsible rallyard official. The magnitude of the civil response will depend on the severity of the emergency. The senior officer of the local fire and rescue service generally assumes control at the "moderate" incident level. Thus, by the time measures to protect the off-site population are found necessary, civil authoritics will be in control of the response and able to take responsibility for those decisions. Specific trigger mechanisms for notifying local response organizations and for event classification and action level determination are therefore clearly advantageous. Such mechanisms should be based on standardized types of emergency events and should be mutually agreed upon by railroads and communitics in advance.

Few railroads have established formal systems for classifying emergencies. However, some are considering implementing systems like the above. Generally speaking, railroads are more likely to adopt formal systems if such systems are part of a community-wide response plan.

The most common practice among small railroads is to contact civil responders if there is any doubt about the railroad's ability to handle the emergency on its own. Because of their limited response capabilitics, small railroads, in particular, should establish definite critcria for notifying local response organizations. However, it is not clear whether an emergency classification scheme like the above should be adopted by all small railroads. For some small railroads, railyard personnel may not have the expertise needed to distinguish belween classification levels.

The standard opcrating procedure of most large communities is to classify all fire and rescue emergencics as involving or not involving hazardous matcrials and as a still or general alarm. Hazardous materials emergencies typically are further classified by severily.

Upon notification, and if the initial report indicates hazardous materials may be involved, the call may also be classificd as a possible hazardous materials call or incident. The ranking officer of the first responding unit is responsible for assessing the situation and determining whether the community's hazardous materials response team or any other support is needed. The officer may call in more manpower and equipment, or additional, specialized equipment.

In most large communities, cvents involving hazardous matcrials are automatically classified as gencral alarms. They may be further classified as major emergencies if ultimate resolution requires outside assistance. Other communities use threc-level classification schemes requiring judgments as 10 severity. The catcgorics may be numcric (that is, 1, 2, or 3) or descriptive (for cxample, extremely severe, dangerous, or innocuous). Generally speaking, classification of emergencies is largely relative and judgmental.

In small communities, the ranking officer of the first responding unit may decide to bring in specialized cquipment and manpower from neighboring communitics through a mutual-aid agrecment. 


\section{Guidance}

1. Use clear criteria for classifying emergencies involving hazardous materials. In most cases, the ranking officer of the civil authority arriving first at the emergency scene uses his or her judgment in classifying the emergency. Possible confusion could be avoided and valuable response lime saved if elassification were based on severity categories (for example, minor, moderate, and severe), Most emergency preparedness plans and SOPs provide litlle guidance or formal criteria for classifying comergencies.

2. Train key responders to promptly and properly identify and implement emergency classification levels and action level guidelines. Key responders should include those rallyard and community personnel who direct initial emergency response activities.

3. Crosis-reference railyard and community emergency cilassification categories. Most fire and rescue departments use the community emergency classification system described above. It has the weight of tradition behind il, having served communities well under a varicty of circumstances. However, because this system is different from that used in railyards, a means of cross-reforencing the classification calcgories should be devised.

4. Use carefully crafted decision charts that illustrate the main factors to be considered in classifying and responding to hazardous materials emergenciess. Factors should include whelher the hazardous matcrial is on fire, exposed to fire, or not exposed to fire. Such charts should be presented to decision makers as cools intended to supplement, not replace, their expert judgment, and should be part of responder training. Many railroads already use decision charts like the one shown in Fig. 8 in their training programs.

5. Clearly specify action guidelines associated with each severity level. Guidelines for such actions as activating lac community's cmergency operations center, implementing protective action recommendations, and notifying additional responders should be clearly specified in emergency preparedness plans and standard operating procedures. If the guidelines are well crafted and properly flexible, they can assist decision making, prevent possible confusion, and speed implementation of appropriate ations.

6. Prohibit railyard personnel from classifying any emergency as "minor" that involves Class A poisons. Class A and B explosivess, or flammable liquid or gas. Railroads with limited havardous malcrials experience should probably add emergencies involving severely toxic but nonlethal chemicals to this list. The above materials are very dangerous, and the conseguences of faully railroad responses can be very severe. In addition, dangerous problems related to the initial cmergency sometimes go undetected. Therefore, emergency response support from civil authoritics should be sough, at least in the form of backup equipment, supplies and personnel. 


\section{ACQUISITION AND DEPLOYMENT OF EMERGENCY RESOURCES}

A wide range of resources and facillties are needed to handle emergencies involving hazardous materials. Large communities often maintain inventories of emergency equipment and have specially trained response teams, or they have entered into agrecments to obtaln these resources on short notice. While small communities also maintain some emergency resources, they tend to rely more on mutual ald agrecments. The types of emergency equipment and manpower resources that are called upon to combat a hazardous matcrials emergency include the following:

1. Supplics, Examples include extinguishing agents (sand, foams, and other dry chemicals), neutralizing agents (soda ash and hydrated lime), and dispersants.

2. Proteclive equipment. Examples include full protective clothing (helmet, hood, bunker coat, pants, boots, gloves, and positivepressure self-contained breathing apparatuses) and various types of chemical and thermal protective clothing. The size of the community and the amount of hazardous matcrials produced, processed, and stored nearby detcrmine the number and types of chemical protective clothing that will be kept on hand. Appropriate chemical protectlve clothing, listed by EPA category, might include (NFPA, ${ }^{*}$ 1989):

a. Level $A$.

Pressure-demand, full facepicce, sclf-contained breathing apparalus (NIOSH't approved)

Totally encapsulating chemical protective suit

Gloves, outcr, chemical-resistani

Gloves, inner, chemical-resistant

Boots, chemical-resistant, stecl toe and shank

Two-waly radios

b. Level B.

Pressure-demand, full faccpiece, self-contained breathing apparatus (NIOSH approved)

Hooded chemical-resistant clothing

Gloves, outer, chemical-resistant

Gloves, inner, chemical-resistant

Bools, chemical-resistant, steel toe and shank

Bool-covers, outer, chemical resistant

Hard hal

Two-way radios

\footnotetext{
*National Firc Protection Association.

\#National Institute for Occupational Salfely and Health.
} 
c. Level C.

Full-face of half-mask, air purilying respirators (NIOSH approved)

Hooded chemical-resistant clothing

Gloves, outer, chemical-resistant

Gloves, inner, chemical-resistant

Boots, chemical-resistant, stecl loc and shank

Hard hat

Two-way radios

Once the chemical has been identified, responders typically consult charts that indicate the appropriate chemical protective clothing for that substance.

3. Analytic and sensing devices. Examples include various types of oxygen sensors or explosimeters, equipment for monltoring vapor concentration and radiation, and thermal sensors.

4. Monitoring devices and instruments. Various means are used for tracking airbornc and waterborne relcases, monitoring their dispersion, and assessing the progress of containment and cleanup activities. The devices and instruments arc typically provided through the community's environmental monitoring and control department, or local or regional water and sewer agencies. Clcanup activities are typically undertaken by contractors to the responsible partics (for example, rallroads, shippers, or contractors). Nonctholess, community, state, and county cnvironmental monitoring agencies should oversec cleanup activities to ensure that contractors are properly licensed and insured, and that clcanup, disposal, and decontamination activities do not violate applicable local, state, and federal laws.

5. Hazardous materials icsponse team. The hazardous materials response leams maintained by many large communitics receive specialized training in incident assessment, stabilization, containment, and recovery, Team members arc familiar with team operating procedures, with specialized monitoring and protective equipment, and with the firefighting and stabilization aspects of particular matcrials (for example, chlorinc, ammonia, pesticides, and liquefied petrolcum gas). They know how to use standard hazardous matcrials reference documents and how to obtain technical assistance. Team members are selected from fire and rescue applicants, but work only on cmergencies involving hazardous materials. Additional trained personnel are usually available from such community departments and agencies as cnviroumental monitoring and control, santation, emergency services, and public works.

6. Heavy equipment. Large communities gencrally have access to an extensive inventory of heavy equipment through their public works 
departments, In the carly stages of a railyard emergency, heavy equipment may be requested from municlpal departments or partics to reglonal mutual-aid compacts. Once the situation is under control, the owner of the hazardous material is legally responsible for decontamination, cleanup, and disposal of any material relcased into the environment. The owner is therefore responsible for obtaining whatever resources are needed for those tasks. The owner is either the rallroad or consignee, depending on whether title was transferred at the loading dock. In the later stages of an emergency, communily-supplied equipment is usually withdrawn or placed on standby.

Very fow simall communities maintain a comprehensive inventory of chemical protective clothing. Such clothing is usually provided by rallroad, shipper, or industry response teams or from the state's emergency services stores. Likewise, personnel trained to evaluate emergencics involving hazardous materials and proced with stabilization, containment, and recovery are often obtained from railroad, shipper, or industry responsc tcams. Similarly, few small railroads maintain comprehensive inventories of protective equipment, analytical devices, and protective clothing. In the carly stages of a hazardous materials emergency, small railroads gencrally oblain these capabilities from local civil authoritics and cosignatorics of mutual-aid compacts. Later in the emergency, contractors or shippers often provide the necessary capabilities and personnel.

Table 3 lists the types of equipment and facilities typically maintained in railroad inventorics for responding to cmergencics involving hazardous matcrials. No one railroad has all of them. Even if a railyard handles a large volume of hazardous matcials, maintaining an extensive inventory of expensive items is still too costly. However, selectively stocking particular items for example, additional fire hose for connecting to off-site hydrants) may be advisable, particularly if adjacent communities have limited linancial resources.

Valuable information on the personal protective equipment listed in Table 3 is given in Recommended Terms for Personal Protective Equipment (CMA and AAR, 1985). The document contains sections on respiratory protection and protective clothing. A glossary is included as an appendix. Other appendixes discuss decontamination, inspection and maintenance, and the EPA's fact shect cntitled Levels of Protection. The fact sheet should be of particular interest to those organizations in the market for protective equipment.

During ralyard emergencies, standard equipment is often used in special ways. For example, engines stationed to each end of the railyard may be called on to uncouple railcars and isolate them, but only from upwind. Likewise, logistics and water pressure and supply dictate which hydrants should be used, including off-site hydrants from which hoses can be run with litle risk of being severed by passing trains.*

\footnotetext{
*Unless the railyard emergency is very serious, it may not be necessary to suspend all train and classification operations in the yard or through-train operations that bypass the yard. However, hose should not be laid over active track.
} 


\section{TABLE 3 Alphabetical List of Equipment and Facilities Maintained by Major Railroads}

- Acid neutralizing agentsa

- Class B hazard disposable suits

- Dry powder fire extingulshersa

- Explosimetersa

- Eyewash fountains or portable cycwash units (for example, commercially avallable units or containers of distilled water) for rapidly mittigating exposure to some corrosivesa

- Fire hydrants (if possible, jointly planned and installed with fire department)a

- Fixed emergency showers on site or stand-up portable showersb connected to fire hoses (plastic piping used is perforated with about 1.5 -in.-diameter holes) ${ }^{b}$

- High-intensity or explosion-proof llashlightsa

- Hi-raller-mounted water tank trucks, response vans, carthmoving equipment (like backhoes for diking), and crapesc

- Isolation tracks

- Leak-detection equipment for tank car domes (varying levels of sophistication)a

- EPA Level A or B acid suits (butyl rubber or similar material) and solvent-protective gloves

- Metal or plastic vessels for capturing leaking substances

- Oil and grease separation systems (skimmers) used with drainage impoundment and isolation ditches

- Oxygen concentration monitorsa

- Patches and plugging kits for minor leaksa

- Plastic containment liners and large disposal bags or drums for contaminated clothing and other used response materialsa

- Plume (toxic cloud) dispersion simulators

- Portable ambient concentration monitors

- Portable chemical detectors

- Radiological survey meters

- Rubber apronsa

- Sandbags, absorbent pads, and containment and diking booms

- Self-contained, positive-pressure breathing apparalus (one per designated responder), either of a disposable or cartridge type

- Splash goggles (worn at all times in hazard \%ones) a

- Telescope or high-powered binoculars (in yard tower)a

- Thermometers for measuring tank car temperatureal

- Video cameras for monitoring emergency site, as well as for security surveillance

- Water-fogging equipment

- Warning devices (for example, fusees, horns, flashers, and public-address systems)a

- Water pumps for removing contaminated standing water or, as necessary, drawing fïrefighting water from an adjacent river or lake

- Weather data services

- Wind socksa

aBasic precautionary equipment.

b This type of portable shower is used by U.S. Coast Guard emergency response tcams.

'Equipment of this type is also mounted on standard road vehicies, but the hi-railers offer grealer flexibility in reaching the site of the emergency.

dAs a preparedness measure, one major railroad is upgrading its concrete containment pits and connecting them to water treatment facilities. 
Many major railroads have drainage impoundments and isolation ditches. Some of these railroads use oil and grease separation systems (skimmers) in conjunction with these ditches. Concrete separators are also used to collect water contaminated with oil and grease from normal operations. By skimming contaminated water before it is released to storm sewers, such systems help protect storm srwers during releases of hazardous materials. To further protect undergre and waters, ditches should be properly lined.

Small railroads can also provide some form of environmental protection. Depending on traffic and resources, drainage ditches and oil and water separators may be advisable 10 protect storm sewers during releases of hazardous materials. In general, small railroads and their adjacent communities should be able to combine efforts in their mutual sc!f-interest.

\section{Guidance}

1. Avoid duplication of emergency equipment and supplies, except when trained and qualified railroad personnel can be quickly deployed to the site of the emergency. Railyards should consult with the local fire department and regional mutual-aid organization about available protective gear and detection equiprnent before acquiring on-site emergency stores. For example, civil responders may know which rubber gloves and suits protect best against certain chemicals.

2. Establish procedures for the deployment of personal protective equipment, containment equipment, emergency monitoring devices and instruments, detoxification agents, and cleanup and disposal equipment.

3. Install properly lined ditching systems andlor containment pits to avoid contaminating underground water supplies. Properly lined ditching systems for diversion and impoundment should be provided along the tracks on which railcars containing hazardous matcrials are classified or on which they would be isolated in an emergency.

In addition 10 acquiring and deploying equipment and manpower, emergencies involving hazardous materials require establishing and maintaining a number of other specialized resources. The ic include a hazard information system, emergency communications capabilities, on- and off-site support facilitims, rosters of key contact persons and supplics, equipment inventorics, ctc. The following discussions focus on these resources.

\section{C.1 Hazard Information Systems}

In response to SARA Title III, most communities are conducting hazard inventories and some are developing hazard information systems. (Sec Sec. B.1) A number of communitics have begun 10 use a system called Computer-Aided 
Management of Emergency Opcrations (CAMEO). ${ }^{*}$ CAMEO was developed by the Hazardous Materials Response Branch of the National Oceanic and Atmospheric Administration in cooperation with the fire department of Scattle, Washington. This comprehensive computer-based modeling package aids in the identification and treatment of hazardous chemicals that are particularly complex and difficult to combat. The system is location-specific and can be installed on a personal computer mounted in a command van.

Using CAMEO requires assembling an extensive data base before any emergency takes place. For example, detailed maps of the city and its railyards, floor plans of fixed facilitics, typical chemical inventories at specific locations, and other SARA, Title III, information can be entered. Railyard maps should indicate key features such as the control tower, isolation tracks, and locations of stored hazardous matcrials, as well as equipment and supplies for responding to emergencies involving hazardous matcrials. High-risk arcas, such as air intakes for major buildings or tunnels, and the locations of storm sewers and pipelines, should also be indicated. All of these items should also appear in the emergency preparedness plan for the railyard.

Also included in CAMEO is prestored decoding information for chemical synonyms, United Nations and Emergency Response Guidebook (DOT) identification (ID) numbers, Standard Transportation Commodity Code (STCC) listings, general characteristics of included chemicals, and detailed information on more than 2600) chemicals. The number of chemicals in the CAMEO data base continues 10 grow.

CAMEO also contains an air-dispersion model that estimates downwind spread of chemical vapors from metcorological data entered by the user or collected by a radio-controlled atmospheric monitoring station that accompanics the personal computer. The results of the analysis, along with hard-copy schematic diagrams, are available within minutes. Outputs include plume footprints overprinted on city or railyard maps, layouts of hazard sectors, and detailed readouts from the chemical response data base.

For railroads, hazard information systems revolve around waybills or similar shipping documents. These are usually maintained in readily accessible computer files and on board trains, and are used for initial verification that certain types of hazardous matcrials are in the railyard. In compliance with DOT regulations, railroads also generate manifests with appropriate hazardous matcrials codes for different hazards. Many of these manifests include basic information on the characteristics of the hazardous materials in the shipment and relevant mitigation measures for each affected railcar or block of railcars. This information is generally obtained from the following da:a sources: Emergency Action Guides (AAR); Emergency Handling of Hazardous Materials in Surface Transportation (AAR); and Emergency Response Guidebook (DOT). The guidebook Emergency Action Guides and downwind modeling capabilitics are also available via modem through the Industrial Chemical Response Information System (ICARIS). Similarly, the AAR's Emergency Handling of Hazardous Materials in Surface Transportation is available in personal

\footnotetext{
*In the following discussion, "CAMEO" refers to both CAMEO-II for Macintosh computers and CAMEO-DOS for IBM-compatible computers.
} 
computer form through the Chemical Emergency Response Information System (CERIS). Both of these services are available at low cost from the AAR.

Most large railroads are able to monitor the locations of railcars containing hazardous materials in a railyard at a particular time by entering STCC code (generally code 48 or 49) and hazard class (explosive, poisonous, or corrosive) into automated systems. The STCC code is a unique numericai identifier for each commodity transported. An HM or $\mathrm{HZ}$ (or some similar code word) inquiry results in a printout of hazardous materials cars by track position in the yard. This type of information is valuable if special protection is needed for hazardous materials shipments on nearby tracks. Such printouts also permit the yard superintendent to quickly determine which locations are safe and, as necessary, to rearrange cars both among and along trains.

Federal train placement rules (49 CFR 174.83-174.93) significantly constrain the possible makeup of trains carrying explosives, toxics, flammables, or radioactive matcrials. Some major railroads have developed advanced computer software for considering hazardous material characteristics in making up train consists. The train profilc (that is, commodity placement, railcar block descriptors; weight distribution, and railcar origins and destinations) is quickly cntered into a formatted computer file and can be accessed anywhere in the railroad's computer network. One railroad has developed software 10 identify consists that violate placement rules and alert personnel to prevent the consist from leaving the yard.

Some small railroads (for example, those serving as bridge lines for major railroads) also have access 10 sophisticated, efficient, and relatively incxpensive computer systems for making up train consists and tracking railcars containing hazardous matcrials. These systems take hazard characteristics into account and are consistent with federal train placement rules. A very small railyard that handles relatively few railcars containing hazardous materials could reasonably rely on a magnetic board or file-card system for representing consists in the yard at any given time.

In addition 10 waybills and shipping documents, commercially available stationary systems can be used to monitor the presence of toxic, corrosive, and flammable gases in railyards. Such monitoring sysicms, which are usually designed for use at chemical manufacturing facilitics, link remote samplers to a central collection and data analysis point. Continuous sampling provides readouts of gas concentration by sampler location. Some advanced systems use infrared- or laserbased detection and data transmission, which avoids the need to lay cable. Depending on railyard size and equipment sophistication, commercially available systems can cost $\$ 50,000$ (basic system with multiple remote samplers usually connected by cable) or $\$ 250,0(0)-300,0(0)$, or more (laser-fixed beam and scanner around the entire railyard perimeter). However, if hazardous materials are handled at only one railyard location, a single monitor able to detect the substances usually handled may be adequate. The manufacturer must know in advance the substances 10 be monitored. A simple system of this type might cost about $\$ 25,000$. Obtaining all-weather and vandal-resistant containment for the monitor increases this cost. Additional expense should also be expected if the instruments have to be calibrated for gas concentrations other than the action levels specified by OSHA for its workplace exposure standards. 


\section{Guidance}

1. Visit railyard(s) regularly to familiarize fire and rescue personnel with railyard characteristics and railroad hazard information systems. Civil responders need to know the layout of the railyard, including the locations of yard access points, fire hydrants, isolation tracks, and release containment systems. They also need to be generally familiar with the railroad's SOPs for handling involved railcars and its general resources and response capabilities.

2. Consider gaining access to or acquiring automated hazardous information systems like CAMEO and ICAR'S, and use them for training as well as response activities. Sinall railroads and communities may want to develop joint systems in conjunction with county or regional response units.

3. Maintain comprehensive records of train consists. Major railroads enter this information onto a central computer from which it is accessible to responsible railroad personnel at all points along the route, including classification railyards. All railroads should consider developing or acquiring systems to prevent assembly of train consists that violate DOT placement rules.

4. Develop the ability to perform computerized hazardous materials inquiries. As a train enters the railyard and is routed onto a particular track, the train's identification number should be entered. Such input should result in the complete consist description being stored in the filc. The locations of all railcars containing hazardous materials, including those moved to other trains, can then be determined later for the entire yard. When a train leaves the yard, entering its identification number should result in all of its railcar records being deleted from the yard file.

Small railroads that cannot afford this expense, should consider magnetic board, file-card or other manual systems.

5. Consider installing stationary systems to monitor the concentrations of gases at key locations in the yard and around its perimeter. Depending on local conditions and traffic volume and composition, such systems can aid in the carly discovery of developing hazards by railcar inspectors or other railyard personnel, particularly in large railyards that sort large numbers of railcars containing hazardous materials and smaller yards that specialize in certain hazardous matcrials and have limited nighttime staffing.

\section{C.2 Emergency Operations Facilities}

Because the locations of emergencies vary, few railroads see the need to designate a single-purpose building or structure as an on-site command center. Some intend to use the railyard tower or another elevated structure, as long as the 
emergency is reasonably distant and downwind (the hazardous material itself will greatly affect whether distance, wind direction, or both are important for safety). Some railroads have already equipped their towers to serve as command centers.

Similarly, communities rarely maintain a single-purpose facility from which all emergency operations can be coordinated and controlled. More typically, a room or area in the municipal building is designated as the emergency operations center. Its communications capabilitics are sufficient for coordinating activitics and maintaining contact with external organizations. The center can be quickly staffed with officials from the organizations responsible for various aspects of the response. Some communitics designate a primary and an alternate emergency operations center.

Many large communitics have "command vans" that serve as on-scene command posts. Being mobile, such vans arc usually positioned within vicw of, but at a safe distance from, the emergency scene. The Incident Commander decides where to locate the command post and which organizations to call on to staff it. Command vans are equipped to (1) maintain contact with and, if necessary, request assistance from outside agencies and jurisdictions, (2) maintain contact with municipal offices, and (3) coordinate ficld communications. In some communitics, a command van is routinely dispatched for all responses involving hazardous materials; in others, it is dispatched for the more serious emergencies only.

Most small communities establish a command post in or near the railyard, usually in a fixed structure (for example, the yard office). If the command post is located out of doors, its communications capabilities may be limited to the equipment in the Incident Commander's car. A command van operated by state or county emergency services sometimes arrives somewhat later to supplement local resources.

Civil authoritics are responsible for choosing the location of any joint operations center which typically is located off railroad property.

\section{Guidance}

1. Designate an off-site railroad support facility to direct company activities and to coordinate with public officials and other railroads (particularly if tracks are shared). Establish criteria for its activation.

2. Designate an off-site emergency operations center to coordinate public and private response efforts and to provide public: information. Establish criteria for its activation.

3. Establish an on-scene command post, equip it with additional communications links, and train personnel on its activation and use. In most cases, the command post will be the railyard tower or another clevated structure located on site. Small railroads without railyard towers should consider arranging in advance to use space in tall buildings adjacent to or near the yard as operations centers during cmergencics involving hazardous matcrials. 


\section{Assign responsibility for maintenance and security, and for 24-hr} staffing of communications links at the command post.

\section{C.3 Emergency Communications}

Railroads also maintain important communications capabilitics that can be called upon in a hazardous materials emergency. Internal communications are rarely a problem. Railroads have redundant systems, including microwave transmitters and numerous radio channels on both bands. In an emergency, a railroad may be asked to allow civil responders to use its communications systems to deploy personnel or to summon additional workers and experts to the Incident Command Post.

In general, communities are responsible for mainlaining or identifying a 24-hour warning point for all cmergency calls. As appropriate, special arrangements are made for very large facilitics like railyards. Notification procedures and protocols are discussed in Sec. D.2. For the most part, protocols for hazardous materials emergencies are the same as the SOPs used daily by fire and rescue personnel, law enforcement officers, and other special-skills personnel. For example, responders generally switch from general to ficld communications channels as soon as they arrive at the emergency secne. Similarly, the fire alarm office or the dispatcher requests exclusive use of the local emergency radio frequency to coordinate all aspects of emergency communications, including calls for mutual aid and communications with neighboring jurisdictions.

On-scene command posts (fixed facility or mobile) and ofl'-secne emergency operations centers maintain extensive communications capabilitics. Siall members need them to coordinate response activities and to notify and maintain contact with neighboring jurisdictions, cognizant state and federal agencies, the railroad, the shipper, industry response organizations, and other involved partics. Although the main means of communicating with ficld personnel, dispatchers, or fire alarm offices is generally primary and back-up radio equipment and channels, cellular telephones are being used more and more as a supplementary system. The emergency operations center and key local, regional, and state agencies often communicate with each other over dedicated hot lines, which are backed up by commercial landline and radio systems.

Civil authoritics are responsible for choosing the location of any joint communications center, typically located off railroad property.

\section{Guidance}

1. Supply incoming mutual-aid forces with portable radios tunable to local frequencies. The radios used by responders from neighboring jurisdictions may be incompatible with those of the requesting community.

2. Equip the on-scene command post with up to six extra telephone jacks. Radios have limited range; therefore, responders who report 
to the Incident Commander but who are responsible for their own personnel, should be able to communicate with those who are out of radio range but have aceess to a telephone. An alternative would be to have the ability to add extra telephone lines. Once activated, these lines should be available on a 24-hour basis.

3. Designate at least one dedicated radio band, but not the shared frequency normally used by community response officials, for automatic elimination of all nonemergency communication. In most cases, this band will be the emergency band used by all area jurisdictions. An example of such a shared band is the Central Emergency Coordination Channel used by several states. Valuable minutes can be saved by avoiding frequent band changes caused by excessive traffic on customary channels. All parties involved in responding to a hayardous matcrials emergency should have access to and be trained in the use of this band. Protocols should be developed for getting and giving up exclusive use of this channel. Prescripted messages may be useful for this purpose. The protocols should be included in mutual-aid compacts.

4. Designate an internal railroad radio band for emergency communications only. The designated band should be in addition to the one shared with civil authorities.

5. Provide for telephone multiconferencing. Large numbers of publicand privale-sector responders with varied expertise are likely to be involved in hazardous materials cmergencies; therefore, quickly activated telephone multiconferencing should be available.

6. Regularly inspect and test communications equipment. Communications equipment frequently fails to work because of bad wealler, difficult terrain (for example, hills or mountains), or poor maintenance (for example, weak batteries). Steps should be laken 10 ensure that communications equipment will operate when needed.

7. Provide cellular telephones or hand-held radios. In response vehicles, cellular telephones and hand-held radios provide not only backup communications capability, but also the opportunity to extend telephone communications to locations away from the response vehicle. For example, a cellular telephone or hand-held radio transmitter/receiver can be used to transmit instructions on how to conduct repairs, thereby increasing the flexibility and range of initial response to the emergency. Pagers may also be useful. In large railyards, pagers are commonly carried by yardmasters or other designated personnel such as duty officers. 


\section{C.4 Equipment Inventories and Classification}

Section $C$ above lists emergency supplies and equipment that communitics and railroads may wish to acquire.

\section{Guidance}

1. Classify all personal protective equipment, including chemical protective clothing, by EPA category (levels $A$ through $C$ ). Because this classification system is based on the suitability of the equipment for the emergency (that is, on the level of protection provided), it provides for different levels of protection yet avoids unnecessary use of and possible damage to high-level protective gear. The use of standard terminology when requesting mutual aid or other outside assistance and when communicating with response organiations also prevents miscommunication of equipment needs and consequent crrors in supply.

2. Regularly update inventories of emergency equipment and supplies that are on hand at the railyard or jurisdiction, or available through supplemental support agencies, jurisdictions, or private organizations. Totals should agree with inventory lists, since theft or inventory errors could mean that critically necded supplies may not be available during an emergency. Inventorics should indicate storage locations and any special accessing information. At a minimum, all information should be verified and updated annually.

3. When compiling inventories' of emergency equipment and supplies, coordinate with public and private response organizations to identify both gaps and redundancies. Use the inventories to develop procurement prioritics.

4. Establish central depots for equipment used in responding to railyard emergencies involving hazardous materials. When established 10 serve a community-wide or area-wide hazardous materials response team, such depots provide quick acess to a wide varicly of specialized resources.

5. As soon as possible after the first responding unit arrives on the scene, provide the Incident Commander with a list of what emergency equipment and supplies are available, where they are located, and how quickly they can be operational. The list should include an up-lo-date inventory of all on-site emergency equipment and supplies, waybills for all affected railears, and any dala already obtained from CHEMTREC, the shipper, or other qualified source. For large communities, such information should be available in the command van, either on a computer screen or as hard copy. For small communities, the information should be supplied routincly to fire and rescue personnel. This information should also be provided to responders designated by the Incident Commander. 


\section{C.5 Inspection and Maintenance}

Inspection and maintenance of railroad equipment and supplies varies widely. SOPs may specify general inspection and malntenance intervals, bul most emergency plans do not address these issues.

All communilies inspece on-site fire hydrants and exlinguishers regularly. Command vans are used routinely in fire and rescue operations; therefore, their operational readiness is confirmed almost daily.

\section{Guidance}

1. Conduct maintenance checks, especially of equipment requiring calibration, at least quarterly; semiannual checks may be sufficient for some equipment. Inspectors should be trained to ensure that all equipment, especially batleries, is operational.

2. Document maintenance checks in an equipment data base. The data base should contain all information needed to confirm operational readiness (for example, inspection dales, problems uncovered, and corrective actions laken) and provide a paper trail for any later legal procecedings.

3. Inspect all emergency operations facilities regularly to ensure their operational readinciss. Fixed emergency operations facilities are rarely activaled and herefore need regular inspection. Inspectors should be traned to document inspections, and to record their findings in an equipment data base.

4. Inspect all chemical protective chothing upon receipt and after each use. Record dates of use, user, and inspection in equipment data basc.

\section{C.6 Water Suppression Support}

Many railroads provide local fire deparments with maps showing the locations of on- and off-sile fire hydrants. Often these maps are submilled with railyard emergency preparedness plans. Some railroads have evaluated their water supplies and the hookup needs of civil responders, and have undertaken major upgrades to their on-sile hydrant systems. Typically, upgrades focus on increasing water pressure and improving access to yard localtons where fires might originalc.

Some railroads have equipped lheir railyards with lined ditching systems and containment pits 10 protect storm runoff sewers and underground water supplies from contamination. These also reduce the legal liabilities of railroads in the event of a hazardous malerial release. Some major railroads have upgraded the concrete containment pits adjacent to their isolation tracks by connecting them to water treatment facilities. Specially railroads that handle large volumes of hazardous 
material have also used such systems successfully and are in compliance with environmental requirements.

All communities regularly inspect on-site fite hydranls and extinguishers, and some assist in designing major additions to on-sile water supply systems.

\section{Guidance}

1. Evaluate water suppliess and the hookup needs of fire and rescues equipment. Through regular contact, railyard safely olficers and/or designated first responders should be aware of the capabilities and necds of civilian responders.

2. Improve railyard and nearby off-site hydrant rystems. Communilices and railroads should improve connections to olf-site hydrants. Hoses laid over tracks may be cul or may, at a minimum, interfere with yard operations. When costs and the layout of the hydrant system permil, railyard hydrants should be added or upgraded, as needed, with close coordination and cooperalton between the railroad and communily.

3. If emergency equipment cannot be kept completely away from ongoing railroad operations, high-celearance tray platforms or buried piping of large diameter should be installed at strategic: points along the mainline track. Hoses from olf-sile: hydrants can then pass over or under the roadbed. 


\section{I) AIILR'I' ANI) NO'IIIITSAIION}

\section{A Alert}

"Roulc alerling," or driving vehleles equipped will sirens and publle address

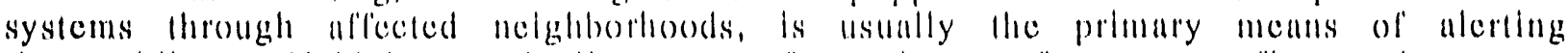
the publle. Vehicles lypically come from law enforecment, fite and rescue, emergency services, or ollier civil agencies. Allhough door-to-door alering plays an important role in some locallons and under certain circumstances, route alerting is typically undertaken fliss and is olten the only lechmigue used. In some cases, the sirens of the locul public warming system maly also be used and/or the EBS may be activaled, In one case, a used siren is belng refurbished and installed for a communily adjacent to a rablyard in Alexandria, Virglnia. The siren's lone for alerting the public 10 a rallyard emergency will be dilferent f'rom that of oblher emergency sirens used for weulled or civil defouse warmings.

liew milroads operale lheir own fixed locallon sirens. llowever, railesad personnel, as well as police oflicers, firefighters, sheriff's personnel, and other emergency workers mal parlicipalle in hese inetivilies.

Occupants of buildinges adjacent to lhe rablyarl may be all particular risk in a hazardous materials emergency. Oflen, milyards have litlle or no contact with either the owners of the oceupants of these buildings, and emergency plans contain no

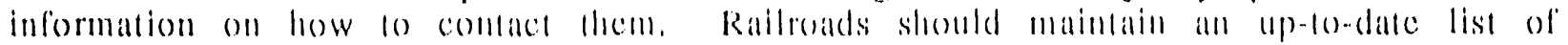

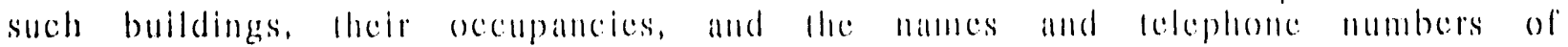
managers and custodians.

\section{Guidance}

1. Esstablish procedures and means for alderting the public that an emergency has occurred and for issuing emergeney instrustions. Develop standard forms and prescripled messinges, and train personnel on the procedures and equipment to be used for communicantug essential information to the publice (Sese Secse li.2 and $d)$,

2. Maintain and update lists containing the addresses of all builaingss

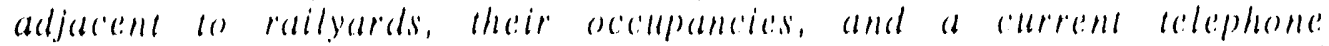
number lo be wsed in alerting building managers or anstodial personnel.

\section{2 Notification}

Many major railroads have formalized hedr checklists and infermal and external notification procedures to be followed in emergencies involving hazardous matcrials. When a hazardous or potentially havardous situation is discovered, railroad personnel are trained to notify the shipper (if possibles oblace specified railrond personnel; natomal response organizalions like llae Nallonal Response 
Center (NRC), CHEMTREC, and AAR's Burcau of Explosives; and local elvil responders. Employecs of small rallroads are also truined 10 know which railroad officials to contact if a hazardous or potenlially hazardous siluation is discovered.

Notification of the NRC satisfies federal legal requirements and facillates access to a federal on-secte coordinator and mullagency reglonal response team. Notification of CHEM'TREC facilliales acess to a CMA CHEMNE'T loam or a CHLOREP team. The following teams are avallable natonwide.

1. CHEMNET, Started in November 1985, the CHEMNET mutual-aid network (sec Fig, 1) now has more than 50 participating companies teams, 23 subseribers, and four emergency response contractors. Participating companies include the nation's largest chemical producers and transporters. Subscribers receive services from participaling companles and then reimburse them for response and cleanup costs. Further expansion is expected.

2. CHLOREP, Thirty-live companies and their 70 producing and packaging plants are involved in this 24-hour mutual-aid program. More than 800 transportation and lixed-facility accidents have been handled since il was starled in 1972.

3. PSTN (Pesticide Salely 'T'am Network). This network has 15 member companies and more than 45 salety teams with expert personnel and equipment for prompl and efficient cleanup of pesticides alter major incidents (FEMA and DOT, 1986).

Any of these emergency response teams can supplement railroad and community response teams or provide help when the railroad or community does not have a response team.

Although civil authorities are generally notilied via a 911-lype call to the local community 24-hour warning point, the local fire department may identily a special alert telephone number or official contact for emergencies involving hazardous materials as part of the local emergency response plan. Even in the very smallest communities, firc and police personncl can be notilied on a 24 -hour basis. However, in small communities, the limeliness and magnitude of the response may suffer if the community dispatcher is not immediately available to personnel at the warning point, or a small railroad's oflice is closed. These siluations are not unusual outside normal business hours.

Each year, fire departments nationwide receive thousands of false alams and hoax calls. Time and resources are wasted because a response is needed for confirmation. To prevent such siluations from disrupting communications betwecn railyards and civil responders, some railroads have adopled the following procedures:

1. Call Verification, Code words or messages known only 10 the authorized officials are used. Community officials then know that they are dealing with authorized railroad spokespersons. This approach can be used even in communilies with 911-lype systems 

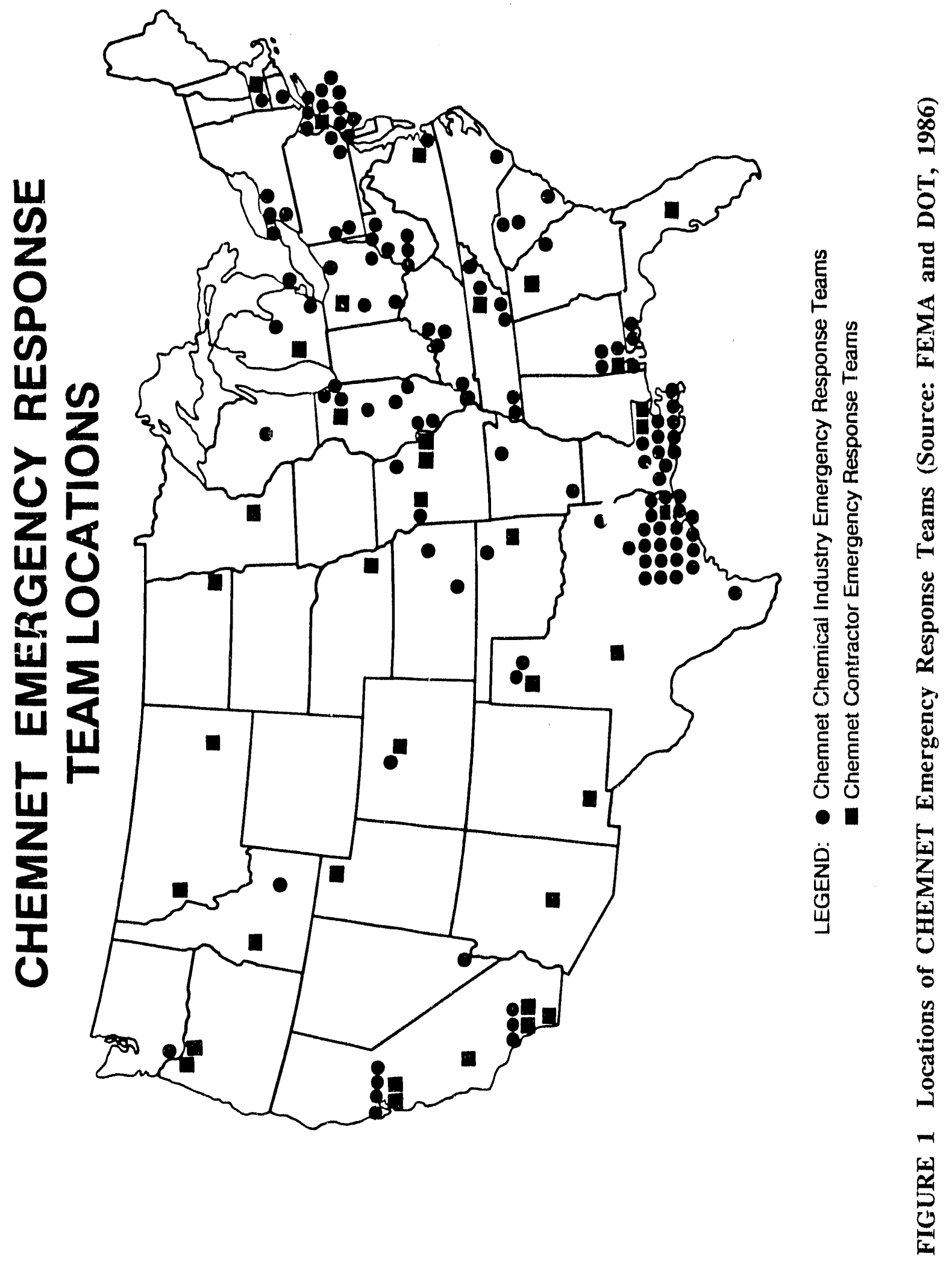
that display the telephone numbers of originating callers on the dispatcher's screen. An unauthorized employec could be placing the call. Even if the caller is unaulorized, however, the caller's informalion has to be treated as a true emergency.

2. Shared Radio Frequencies. Acesss 10 a radio frequency is limited to railroad and local community emergency response oflicials. Railroads can lhereby prevent unauhlorized individuals from posing as ralroad cmployecs. Sharing a radio frequency with civil authorilies is parlicularly useful for nighttime through-train operations by a small railroad when its rallyard office is closed. Such molilication systems also provide backup when commercial landlines ate out of service. If equipped with these frequencies, locomolives in or near he railyard can be warned or asked to help.

Few communilies have established emergency nolificalion procedures specifically for railyard emergencies involving havardous materials. Rather, most communities use 911 systems thall automatically route emergency calls 10 a central dispatch center. The conversalion is recorded, and the telephone number from which it was placed is displayed on the dispalcher's work station. Calls reporting potential hazardous malorials emergencics are quickly forwarded fo a fire alarm office for immediate dispalching.

The closest fire and rescue unil responds to the call. Once at the Incident Command Post, or even while on the way, the senior fire oflieer or a designee assumes responsibility for conlacting and summoning responders from other service or special-skill organizations. At this point, the railroad has no further responsibility for nolifying civil responders. However, the railroad is still responsible for making all requited legal nolifications, nolifying other railroad personnel, the railroad hazardous materials team (if any), the shipper, and damage control and cleanup contractors. Any or all of these parties may be needed for hazard containment activilies under the direction of the Incident Commander.

If the preliminary report indicates that hatadous materials may be involved, a hazardous material response is typically intiated. If available, units specializing in heavy rescue and hazardous malerials emergencies respond at the same lime as the closest fire and rescue unit. These specialized scjuads are often headquartered at a centrally located firchouse that serves all or a defined sector of the community. The closest unit typically arrives within three 10 four minutes after receiving the call. Taking charge is the ranking officer and after assessing the siluation, he or she decides whelher specialized support is needed. If not, specialized units en route to the scene are told by radic 10 relurn 10 their quarters.

If the ranking officer determines that the call is a hazardous materials emergency, additional specialized units and higher ranking officers may be requested. The highest ranking oflieer of all responding units becomes the lncident Commander, If the Incident Commander determines that the siluation is a major emergency, he of she directs the dispalcher or fire alarm office lo notify the senior fire officer and responders from ollier service or special-skills organizations in the community, For example, the heads of environmental services or local water and 


\section{Alert and Notification}

sewer departments may be notified. Neighboring jurisdictions that could be affected are also notified.

If certain federal, statc, or industry officials should be notified, th community's emergency preparedness coordinator generally undertakes that task. Local circumstances determine whether he or she contacts, among others, CHEMTREC, local chemical companies, the National Agricultural Chemical Association, the U.S. Coast Guard, or appropriate state and regional agencies. Examples of regional agencies are sanitary, irrigation, or river basin districts. Contaci lists and checklists should also include the current telephone numbers of contacts at manufacturers of the hazardous materials most frequently handled at the railyard. These contacts can generally provide detailed information on the characteristics of the hazardous materials involved in the emergency. As part of the planning effort underway to comply with SARA, Title III, many communities now routincly compile and regularly update contact lists. However, these lists do not always contain the telephone numbers of contacts at manufacturers of the hazardous materials most frequently handled at the railyard.

Large communities are more likely 10 receive requests for mutual aid than to initiate thes. As a general rule, mutual-aid requests are deferred until community resources are ncarly exhausted. If circumstances warrant, the Incident Commander recommends secking mutual-aid assistance. The request is generally initiated at the departmental level under the authority of the fire chicf, police chief, or other department head. The request for assistance from one or more signatory fire, police, or emergency services departments can be made by phone, via the shared local radio frequency, or as spelled out in the mutual-aid contract. General assistance or certain personnel or equipment call be requested.

Community plans usually contain procedures for initiating mutual-aid requests. They should also specify how federal, state, or industry organizations are notified, and assign clear responsibility for such notification.

Those small communities outside metropolitan areas usually use traditional telephone notification systems. In communities without specialized response teams, the responding fire and rescue unit arrives within several minutes of receiving the call. The ranking olficer lakes charge, assesses the situation, and decides whether additional support is needed. Because of their limited resources, small communities are likely to request mutual aid from neighboring jurisdictions and support from county or state governments. As with their larger counterparts, however, mutualaid requests are usually deferred until community resources have been nearly cxhausicd.

Some communities with many plants that manufacture and ship hazardous materials have dedicated hot-line notification systems. Such systems save valuable time and cnable quicker mobilization of equipment, supplies, and expertise. If a hazardous or possibly hayardous siluation develops at any one of the plants, information about it can be quickly and simultaneously communicated to the other plants by dedicated ring-down telephone. There must be at least one 24-hour location designated as an emergency warning point at each company. Such systems also require a mutually agreed upon incident classification system (sec Sec. B.2). Dedicated hot lines are particularly good for small railroads, especially those that 
rely on a major shipper, gencrally a manufacturer of chemicals, for help during emergencies involving hazardous materials. The manufacturer may have an emergency response team or other response capabilities. The adjacent community may be equally dependent on this manufacturer.

\section{Guidance}

1. Designate an appropriate local official, or his or her representative, responsible for notifying public and private response and assistance organizations. Knowing the official responsible for notification will help local responders verify and authenticate the notification.

2. Determine notification procedures based upon emergency classification levels. A minor emergency may require few notifications, while a major one may require notification of a range of regulatory agencies, response organizations, and assistance groups. The situation will vary from one emergency to another; however, procedures can specify which organizations to contact, the person responsible for making those contacts, and the conditions for initiating each type of contact.

3. Where an incident may have dire consequences (for example, all incidents involving Class $A$ poisons, Class $A$ and $B$ explosives, or flammable liquids or gases), establish procedures that require yard personnel to promptly notify adjacent communities and to request at least backup support.

4. Develop and use carefully written prescripted messages for alert and notification of the public. Such messages should be prepared in advance of an emergency and be in a fill-in-the-blank format, thus minimizing preparation time. These messages should conform to mutually accepted schemes for classifying emergencies and action levels. Properly filled out, the prescripted messages clarify the magnitude of the necded civil response and minimize the potential for the community to misunderstand the situation.

5. If communicated by radio, responder notification messages should comply with existing radio protocols. Messages should also contain keywords and information specific for the type of emergency involved. For cxample, they should identify railyard access points to be used by civil responders, and the location where railyard officials and the arriving response team or Incident Commander should meet.*

6. Use a prearranged system to verify the initial emergency report. Developed jointly by fire and rescue personnel and responsible

\footnotetext{
*For access and mecting locations, fire departments prefer to be given specific strect addresses or the names of iniersecting strects.
} 
railyard officials, such systems can identify false alarms and hoax calls placed by unauthorized individuals posing as railroad personnel. Alternatives include (a) contacting a designaled railyard spokesperson or requiring verification of the call by the spokesperson; (b) using carcfully written messages or code words known only to the communicating officials; (c) using dedicated radio frequencics accessible only to railroad and community emergency response officials in the immediate area; or (d) matching the telephone number from which the call was placed with the number of a predesignated hot line located in the office of the yardmaster, train master, or other responsible railyard official.

Sharing a dedicated radio frequency also climinates total reliance on landline telephones, and may increase the security of transmissions. Emergency response plans should include procedures for clearing radio traffic and establishing a railroadcommunity link on the dedicated frequency. (See Sec. C.3)

7 Develop checklists for alert and notification of responders and authorities, and maintain appropriate records documenting that such notifications were made. This ensures that appropriate partics are notificd and assists in inyestigation and follow-up. Checklists need not be lengthy or complex. Some communitics use a one-page form that documents (a) the name of the person initiating the contact, (b) the time of the contact, (c) the name of the person receiving the call, and (d) the names of the persons responding 10 the emergency and the time they arrive on the scenc (if appropriate). To facilitate notification and follow-up, the forms sometimes list telephone numbers for the agencies or departments most likely to be involved. Include the telephone numbers of contacts at manufacturers of the hazardous materials most frequently handled at the railyard. Railroads should consider developing a similar form to document initial notifications.

8. Install dedicated hot line notification systems to speed mobilization of equipment, supplies, and expertise. Such systems are being implemented by communities having high concentrations of facilitics that produce, process, or store hazardous materials. Using a dedicated ring-down telephone, such systems permit the local fire or police department to quickly and simultancously communicate information about a situation developing at onc facility to other facilities in the area, and, if necessary, request technical assistance. In designing the systems, communities have drawn on the experience and knowledge gained from radiological emergency preparedness planning. To implement them, railroads and communitics must adopt mutually agreed upon cmergency classifications and notification procedures (sec Sec. B.2) and train personnel in their use.

Dedicated hot lincs can also help railroads promptly notify companies with special needs, such as pipcline companics whose 
rights-of-way and submerged pipclines cross the railyard at or near

the scene of the emergency.

Small communities with railyards and several nearby hazardous matcrials facilities are likely to need financial assistance from those facilitics to develop such communication systems. Large communities with many hazardous matcrials facilitics also may want to request some kind of cost sharing with these facilities.

9. Provide civil responders and the NRC with the necessary information. The designated responder at the railyard should be trained 10 provide civil responders and the NRC with clear and concise information on the following:

a. Emergency location in railyard.

b. Time of discovery.

c. Nature of the problem, being as specific as possible for example, lcaking valve, punctured vessel, or derailment with possible damage to railcar).

d. Data already developed concerning the hazardous matcrials involved from consulting placards, waybills, shipping papers, consist lists, AAR guidebooks, CHEMTREC, and the manufacturer.

c. Location of injured and potentially threatened personnel.

f. Number of cars involved.

g. How many cars are apparently empty and how many fully laden.

h. Presence of noninvolved railcars containing hayardous matcrials near the scenc of the emergency.

i. Responsc actions already taken by the railroad (for example, locomotive placement, railcar inspection, and isolation efforts). These actions should be consistent with the most cautious recommendation obtained to that point, whether from written guidance or the shipper or manufacturer. For example, standard operating procedures for rerailing involved and damaged cars should not be relied on before the cars are inspected by an expert, even if both the waybill and the consist list indicate the cars are "emply" (sec Sec. G.2).

10. Include chemical-specific information at the time of initial notification of a hazardous materials emergency. If first responders are given al least the chemical name and its four-digit identification number, they can save valuable time by reviewing hazard information while en routc. 


\title{
E POPULATION PROTEC'TIVE ACTIONS
}

Many railroad plans, procedures, and training materials include instructions for immediately correcting minor problems with railcars containing havardous materials. If implemented properly, these measures can protect the public by not allowing minor emergencies to become major ones. For major cmergencies, most railroad plans correctly lcave decision making and implementation of actions to protect the public to civil authorities. However, in fast-breaking emergencies involving hazardous matcrials, railyard officials may recommend cvacuation of the public when initially notifying civil authorities. The plans of some major railroads discuss this responsibility. Protecting the public during a hazardous material emergency also requires controlling access to the scene of railyard emergencies. (See Sec. A.3)

Few communities have been unfortunate enough to have becn faced with the difficult decision of whether to relocate citizens away from the danger zone of a hazardous matcrials emergency. This decision is much more difficult to make than that required by approaching natural hazards like floods or tornadocs. The danger from a hazardous materials emergency may be less obvious -- even invisible. Whether property damage is imminent is unclear. Therefore, the likelihood of physical harm is hard 10 assess. Also, hazardous materials emergencies are unpredictable, which makes it difficult to define the hazard area. Metcorological conditions, such as wind speed and direction or atmospheric stability, may vary, thereby affecting the size and location of the hazard area and the population at risk.

\begin{abstract}
In many cases, the measure most likely to minimize total personal injury may not be evacuation. Sheltcring (or protecting-in-place) in a home or other enclosed structure may be the most prudent alternative. Whether it is, will depend somewhat on the properties of the matcrials involved, but also on several other factors. The Handbook of Chemical Hazard Analysis Procedures (FEMA, DOT, and EPA, 1989) discusses the factors to be considered when deciding whether to protect-in-place or cvacuate nearby persons. Community emergency preparedness personnel will find this information extremely helpful in planning for potential emergencies.
\end{abstract}

If authorized community officials decide that protective actions are needed for persons beyond company property (that is, beyond the designated on-site sectors), SOPs for sheltering or cvacuation will be activated. Most communitics are linked to the EBS in their area; this linkage cnables announcements of protective actions to be broadcast almost as soon as they have been declared. In many locations, however, arrangements for broadcasting cmergency announcements are informal and not supported by provisions for an accompanying tone or siren designed 10 alert the public to turn on an EBS station (sec Secs. D.1 and E.3). 


\section{E.1 Decisionmaking}

Historically, the plans of large railyards, like those of their adjacent communities, have focused on cvacuation rather than protecting-in-place (also referred to as sheltering-in-place) as the mechanism for limiting exposure of nearby persons from a hazardous material relcase. However, the Emergency Response Guidebook (DOT) and training matcrials for active response teams like those of Houston, Texas (Houston Fire Department, 1987) have a slightly different cmphasis. Based on recent studies, these sources have concluded that for some chemicals and in some circumstances, sheltering people may be better than evacuating them. Because all situations are different, careful consideration should be given to all population protective action options. The DOT guidebook states:

Evacuation is, by itself, a process with significant risk for the persons being cvacuated. Therefore, protecting-in-place should always be a first consideration if the building can be closed up tight and airconditioning or incoming fresh air can be shut down. In the case of short-term spills and cold toxic vapor clouds, the material may be deflected or reflected by a multistory building and pass by without affecting the occupants of the building. People in the upper floors of a tall building in the evacuation sector may often be safer by remaining where they are. However, the heating and air-handling equipment in the building must be shut down to keep out the hazardous vapors. It is vital that communications be maintained with competent persons inside the building so that they may be advised about changing conditions. Those persons protected-in-place should be warned to stay far from windows in direct line-of-sight of the seene because of the danger from glass and projected metal fragments in a fire and/or explosion.

The DOT Guidebook also provides a Table of Isolation and Protective Action Distances for hundreds of chemicals, additional descriptions of evacuation and in-place protection, and a list of factors to consider in deciding on appropriate protective actions. (Sec Table 4)

Railroad plans and training programs should thereforc discuss protecting-in-place as a possible action to protect the public in fast-breaking emergencies.

Rescarch sponsored by the EPA (Ujihara, 1989) also shows that sheltering is preferred if evacuation without inhalation or other exposure is impossible during short-term, rapid relcases of fast-moving cold toxic vapor clouds, that is (p. 12):

Sheltering in place provides protection during a toxic chemical emergency because closed structures supply a reservoir of clean air and serve to shicld the occupants from direct exposure to the contaminated air outside. Because of infiltration effects, sheltering in place would probably not climinate the threat entirely, but at least it would reduce the concentrations to which building occupants would be exposed were they to go outside. ... Because it takes time for authoritics to respond to an emergency, sheltering in place can be an effective interim measure while emergency personnel assess the situation.... 


\title{
TABLE 4 Factors to Consider in Selecting Actions to Protect the Public
}

\author{
The Hazardous Material \\ - Degree of health hazard \\ - Amount involved \\ - Relcase containment / control \\ - Rate of vapor movement

\section{The Population Threalened} \\ - Location \\ - Number of People \\ - Time to evacuate or protect in-place \\ - Ability to control cvacuation or protect in-place \\ - Building types and availability \\ - Special institutions or populations, e.g. nursing homes, hospitals, prisons
}

\section{Weather Conditions}

- Effect on vapor and cloud movement

- Potential for change

- Effect on evacuation or protection in-place

Source: U.S. Department of Transportation, 1990.

If suitable supplies were kept on hand, many railyard buildings could serve as shelters. Instructions for implementing sheltering are provided in the Handbook of Chemical Hazard Analysis Procedures (FEMA, DOT, and EPA, 1989, p. C-7).

An example of a railyard emergency requiring on-site sheltering is severe puncturing of a large tank car fully loaded with an extremely toxic chemical and positioned upwind of personnel in work areas and at the railyard office. Commonly shipped examples of such chemicals are chlorinated or brominated hydrocarbons, such as chloroform, bromoform, trichlorocthane, and tetrachlorocthene. A large, cold toxic cloud could form as a result of rapid decompression and relcase of cargo. High-density, low-flammability vapors may be involved. In this casc, evacuation with exposure could cause more death and injury than sheltering in the railroad office, especially if dispersion is hampered by a depression or other local variation in the yard terrain.

Also very dangerous are highly water reactive and toxic chemicals like methyl isocyanate, thionyl chloride, and phosgene, and condensed acids and alkalis like hydrochloric acid or anhydrous ammonia (sec Sec. F). These chemicals can be fatal to railyard personncl attempting to evacuate without protective clothing and respirators. In such cases, the evacuation of railyard personnel could be more safely accomplished if properly protected rescue workers were to bring such equipment to an on-site building serving as a shelter. 
Generally speaking, the most difficult decisions facing responsible local officials are whether and when 10 initiate public protective actions. Many factors affect these decisions, including (1) the seriousness of the hazard; (2) the state of the hazardous material (solid, liquid, or gas); (3) meteorological conditions like local temperature, wind speed and direction, and moisture conditions (rain and humidity); (4) the local terrain (flat area, hill, or valley); and (5) the overall integrity of the affected containment vessels, which may be very uncertain if the vessels are damaged (sec Sec, H.1) or have contained a wide variely of substances.

A number of resources are available to assist decision makers in obtaining the information needed 10 make these decisions. Several of these resources are newly developed or recently revised. They include the references described in Secs. A, F.1, and G.1 which provide detailed information on the physical and chemical characteristics of hazardous materials and effective response strategies for those matcrials involved in an emergency. They also include lwo computer-based information systems used by railroads, ICARIS and CERIS, Both systems are also available to communities at low cost through the AAR. ICARIS has an evaporation and dispersion model in addition 10 a hazardous materials data base and can be accessed via modem.

A third computer-based resource, CAMEO, is used by an increasing number of communitics. (CAMEO was discussed in Sec. C.1.) From an extensive communityspecific and metcorological data basc, CAMEO plots plume footprints on city or railyard maps, identifics hazard sectors, and provides detailed readouts on the specific chemicals involved.

A fourth resource, the Handbook of Chemical Hazard Analysis Procedures (the "brown book") issued by FEMA, DOT, and EPA, provides site- and scenario-specific analysis, as well as documentation for a companion computer program, Automated Resource for Chemical Haxard Incident Evaluation (ARCHIE) (1989). This document supplements Technical Guidance for Hazards Analysis: Emergency Planning for Extremely Hazardous Substances (the "green book"), also issued by these agencies (1987). While the "green book" provides an overview of the entire hazard analysis process and a simple method for screcning toxic gas hazards, the "brown book" provides information on fire, explosion, and reactivity hazards, as well as on toxicity. The ARCHIE compuler program is a 1001 for calculating the consequences of accidental releases, given detailed information about the chemical and physical characteristics of the release. Because of its data requirements, ARCHIE is best used as a planning tool. However, the information it calculates can be extremely helpful to emergency personncl in reaching appropriate protective action decisions. For instance, ARCHIE calculates not just the geographic extent (area), but also the time of onset and the duration of exposure of unprotected persons to a loxic plume. Emergency personncl could consider this information, along with other factors in reaching a protective action decision. Such other factors might include, for instance, the lime required 10 mobilize an evacuation and the length of time in place protection would be effective. The "brown book" also includes a discussion, "Overvicw of Shelter-in-Place Concepts," that describes these and other factors 10 be considered in deciding on or implementing in-place protection. (Sec Fig, 2) 
FIGURE 2 Recommended Shelter-in-Place Instructions (Source:

Handbook of Chemical Hazard Analysis Procedures, FEMA, DOT and EPA, 1989)

1. Close all doors to the outside and close and lock all windows (windows somctimes seal better when locked).

2. Building superintendents should set all ventilation systems to 100 pereent recirculation so that no outside air is drawn into the structure. Where this is not possible, ventilation systems should be turned off.

3. Turn off all heating systems.

4. Turn off all air-conditioners and switch inlets to the "closed" position. Scal any gaps around window type air-conditioners with tape and plastic shecting, wax paper, or aluminum wrap.

5. T'urn off all exhaust fans in kitchens, bathrooms, and other spaces.

6. Close all fircplace dampers.

7. Close as many internal doors as possible in your hom: or other building.

8. Use tape and plastic food wrapping, wax paper, or aluminum wrap to cover and seal bathroom exhaust fan grilles, range vents, dryer vents, and other openings to the outside to the extent possible (including any obvious gaps around external windows and doors).

9. If the gas or vapor is soluble or even partially soluble in water .- hold a wet cloth or handkerchief over your nose and mouth if the gases start to bother you. For a higher degree of protection, go into the bathroom, close the door, and turn on the shower in a strong spray to "wash" the air. Seal any openings to the outside of the bathroom as best as you can. Don't worry about running out of air to breathe. That is highly unlikely in normal homes and buildings.

10. If an explosion is possible outdoors - close drapes, curtains, and shades over windows. Stay away from external windows to prevent potential injury from flying glass.

11. Minimize the use of elevators in buildings. These tend to "pump" outdoor air in and out of a building as they travel up and down.

12. Tune into the EBS on your radio or television for further information and guidance. 
These and other resoures provide emergency services personnel with the technical information to make recommendations about possible protective actions. Such recomnendations are then considered by the elected offictal responsible for choosing among profective actions. The offlicial is usually the mayor, counly bourd chairman, or first selectman, or his or her designec, as provided for in an approved emergency preparedness plan. The official gencrally declares an energency, which legalizes extraordinary measures. The Incident Commander is responsible for implementing protective actions as well as developing, in coordination wilh other public- and privale-sector response organizalions, a plan for control, contanment, and mitigation of lhe emergency.

To help civil authorlics prepare for making protective acton decistons, railroads often provide them with information on the havardous materials most frequently handled by the railroad (sec Sec, B.1). Some railroads also follow up to ensure that their knowledge and viewpoints are considered in developing lac protective action strategies contained in emergency plans and activated in actual emergencies, The passage of SARA, Title III, increases the likelihood of further participation from lice private sector, Already, some railroads are teaming up with local shippers and receivers of hazardous malcrials to help communilies develop alternative protective action strategies. Also, under the CMA's CABR program, manufacturers of hazardous materials are participating in a growing number of joint excreises that focus on appropriale protective strategies under various incident scenarios (CMA, 1991, p, 7), Likely by-products of such activitics are improved coordination, cooperation, and communication.

Railroads also assist communities, manufacturers, shippers, and ofher experts by providing them with the incident-specific informallon needed lo determine appropriate protective actions. As stated elsewhere (see Secs, D.2 and G,1), even wilh chemical-specific informalion, it is still advisable for the railroad and/or community involved to immediately contact the shipper, the NRC, or the closest manufiacturess of any acutely toxic matcrials being released. They should try lo obtain information useful for deciding whether to evacuate or shelter or, possibly, whether to do some of cach. For example, the AAR Guidebook (1989), p. 10-A) recommends that the "... shipper or nearest manufacturer of the material should be called for assistance in any incident involving Poison A materials." Manufacturers, shippers, and the NRC Inust be informed about container damage, probability of release, anount and rate of ongoing releases, terrain, and local wealher, Especially important with respect to weather conditions are precipilation, humidity, temperalure, and wind suecd and direclion.

\section{Guidance}

1. Consider gaining access to or acauiring hazard information systems like CAME(O), ICARIS, and CERIS, and wise them for training as well as response activities. Although small communities may too have the resources to implement systems as complex as CAMEO on llicir own, other arrangements may be possible. For example, one or more small communities could coordinate with county or regional agencies 10 develop a joint system. 
2. Provide communities adjecent to malyards with lists of the rablyard's most frectuently handled hazardoms malerials. For use in protective action planning and truining, such lists can be prepared firom internal summaries of rallroad tralifis, At a minimum, lles lists should be updated anmuilly. (See also Sece, B, 1)

3. Participale in community mestings and other formms where planning strategles for protective actionss will be discrussed. Al such meetlings, rallroads should contribule expert dala on calcgories of minor emergencies (for example, a valve leaking from a seat) and major emergencies (lor example, a punciured tank car), Such categortes can help in developing stralcgies to protect the public. Once an official policy on such strategies is adopled and documented, the rallesad should obluin and kecp a copy at an appropriate rablyard location. Rablyard personnel should be instructed lo eonsull this document in last-breaking silualions.

4. Consider sheltering as an alternative that is often safer than evacilation. Rullyard and communlly emergency preparedeness plans should include shellering as an allermative for corlan hazardous malcrials (lor example, medhyl isocyanate, chlorine, and phosgene).

5. Designate one or more buildingss in the railyard as shelters, indicate: their loceations on site mapss and in emergency plans. conduct appropriate training, and stock them with appropriate: supplies including towels, thick tape, and other materials for temporarily sealing doors and windows. A public-address system or bullhorns can be used to quickly advise railyard personnel localed outdoors 10 seck sheller, One railyard shelter (ideally the railyarl command conter) should be cyupped to communteate with the aldjacent community.

\section{E.2 Evacuation and Profecting-in-Place}

Whether or Hot compuler systems like CAMEO, ICARIS, or CERIS are Used, circumstances may warrant implementation of various prolective actions. For example, railyard personnel may be instructed to seck shellet in designated buildings or 10 evacualc the secne; likewise, the general public mal be instructed 10 sheler in place or to evacuate locations within a specilied distance of the entergency scenc. Such localions may be cilher downwind or in a direction likely to be affected by a change in wind direcilon.

The local radio station may be asked to broalcast essential entergency information for area residents not likely to be reached by slandard molificalion procedures. One example is people living in the affected neighborhood, bul working elsewhere. However, unless a signed EBS agrecment is in place, the station is not obligated 10 broadcast the needed informalion. Because such messages may prove indispensable 10 emergency response eflorts, formal EBS agrecments should be effected with one or more local or regional radio and celevision slations. 
Radio messages are likely 10 include such essentlal information as (1) the area covered by the order to shelter-lilplace or evacuate, whether by neighborhood or by boundarles defined by well-known landmarks; (2) special instructions for sheltering in place safely or for properly sccuring a home before leaving it; (3) lists of clothing and supplics to lake along; (4) ovacuation routes to follow, perhaps by neighborhood; (5) areas to avoid; and (6) designaled reception and care shelters, including those with facilities for handicapped and other special-needs populations. In small communities, lie local radio station may be asked to suspend normal programming in addition to broadcasting essenlial emergency information.

Timely broadcast of essential cmergency information requires advance planning, One way 10 ensure that the public understands the messages is to prepare and distribute emergency information brochures in advance (sec Sec. 2.10). Another way is to develop clear, prescripled messages designed for insertion of event-specific information. Such advance planning can save vital minules during last-breaking emergencies.

During implementalion of protective actions, many communilies find that procedural checklists used by each of the sector oflicers ensure that the necessary steps are taken. Checklists may contain such direclives as:

1. Provide standby resourecs to clear impediments to evacuation, if needed. Such resources might include low trucks lo move cars involved in aceidents.

2. Reroute trallic if designaled evacuation roules become too congested.

3. Control access to cvacualed areas.

4. If local shelters reach capacily, arrange with nearby communities or the American Red Cross to shelter evacuecs. If this siluation is likely to develop, execute wrillen agreements wilh nearby communily shellers for inclusion in the local emergency preparedness plan.

5. Arrange with hospilals and nursing homes, preferably through written agrecments, 10 aceopl any evacualed illvalids and handicapped people.

Such provisions may already be in place for local natural disaster response plans. However, the means for exceuting lhem may not be described in sufficient detail, or the measures may not be fully consistent with the probable scope of a railyard emergency involving hazardous matcrials. For example, likely cvacuation areas and routes, or participating personnel, may need to be different for railyard cmergencics.

\section{Gu i d ance}

1. Enter into formal agreements with at least one radio and one television station in the area to provide for broadcast of emergency 
Information messages as soon as they are provided. These stations would then serve as the designated EBS stations for the area. The full extent of their responsibilltes in this role can be obtained from the Federal Communicalions Commission.

2. Provide advance indication of the type of information that would be included in emergency radio notifications through community-wide distribution of an emergency preparedness brochure. The brochure should provide prescripted EBS messages that give instructions on protective actions for all expected emergency situations (sec Sec. 2.10). The messages should have a fill-in-lhe-blank format to facilitate communicating the particular areas subject to sheltering in place or cracuation. Communitics should consider supplementing the emergency information brochure by presenting emergency response information and cvacuation route maps in line local telephone directories.

\section{E.3 Reentry}

Deciding when evacualed areas can be salely recntered can be especially difficult in rallyard or other railroad encrgencies. Unrecognized threats have occasionally led to recvacuation of areas previously announced to be safe for recntry (Woodhousc, 1986),* For example, an area can be wrongly decmed safe because (1) a leaking or damaged tank car apparently becomes emply; (2) a potential fire hazard is climinated; or (3) addilional release of a substance is belicved unlikely. Only one individual, such as the Incident Commander, should be authorized to decide and authorize recntry. However, that decision should be made only after full consultation with expert responders regarding the amount of mitigation and control actually achieved. Such consultation should cover al least the following elements for both railyard and community reentry:

1. The affected lank car or other transport vessel should have been carefully inspected by qualified personnel, such as a representative of the AAR's Burcau of Explosives, or should have becn completely unloaded.

2. The extenl and depth of the spill should have been fully charted.

3. Excavations, dikes, and substance removal should be adequate 10 protect water supplies, storm sewers, and recutering personnel.

\footnotetext{
* Miamisburg, Ohio, was in a state of emergency for five days in 1986 when a railroad tank car containing 2000) gallons of white phosphorus caught fire after it and several other railcars derailed. The fïre chief immedialcly ordered evacuation of $12,0(0)$ persons, Later, with the fire seemingly under control, pressure mounted to allow Mlamisburg residents to return to their homes. The Miamisburg city manager refused to rescind the evacuation order. When the concrete abutment on which the tanker was resting unexpectedly gave way, the fire reignited. The second evacuation involved 30,000 people. The calutious approach of the community officials was vindicated.
} 
4. The ambient concentration of the released substance should be below its threshold limit value* or other predetermined level throughout the cracuated area.

5. The affected tank cars or vessels should have been completely isolated from other traffic, and there should be no expectation of hazard-triggering cvents with respect to substances in other rallears in the vicinity of the affected cars.

6. A full accounting should be in hand of cleanup and disposal activities. For example, the decision maker should know the quantities of substance or soll removed, the number and destinations of disposial loads, and the disposal procedures.

7. The need for monitoring beyond the site on an extended basis should have becn determined, and the official responsible for maintaining surveillance should be identified.

Once a railyard is safe, recntry of evacuated railroad personncl is controlled by the Incident Commander. However, the plans of major railroads generally identify a hazardous materials control official or senior operating officer to facilitate coordination with civil authoritics. This individual should be involved in preparations for reentry and related decision making. Emergency preparedness plans should contain detailed discussions of recntry procedures and decisions.

\section{Guidance}

1. Establish a system of expert consultation and assistance on progress being made to mitigate and control emergencies involving hazardous materials. Such systems should enhance responder safety as well as prevent premature authorization of public reentry to an cvacuated hazard zonc.

2. Provide proper controls for authorizing reentry to an evacuated railyard. The railyard emergency preparedness plan should specify which railroad official is responsible for directing reentry into the previously evacuated railyard. However, such recntry cannol lake place until authorized by the Incident Commander. (Sec Sec. A.3) If certain actions should be given highest priority once recntry occurs, those actions should also be identified in the plan.

3. Establish procedures for handling long-term physical and psychological effects on victims.

\footnotetext{
*The concentration amoun: allowed for workers in a specified time period under guidelines of the
} American Conference of Government Industrial Hygienists. 


\section{F RESPONDER SAFETY}

Some fire departments are extremely experienced in hazardous materials response. With more than 10 years of experience with hazardous materials regulations, these responders have become very knowledgeable about emergency equipment and other resources to enhance personnel protection, and have developed sound procedures for handling hazardous materials and reducing personnel exposures. In some cases SOPs that apply to a range of hazardous material emergencies are supplemented by SOPs specifically for railyards.

Other fire departments have far less expertise, having little or no training or experience in this highly spccialized area. These responders are far less knowledgeable about personnel protection and generally have less access to specialized resources.

\section{F.1 Resources}

To minimize exposure, standard turn out gear is being supplemented by protective clothing more resistant to specific chemicals. Neoprene and nitrile gloves, boots and coats are examples of such clothing. Reusable and limited use, Class A full-body protective clothing, and Acid suits are becoming more common, even for fire departments in small urban areas.

For railyard emergencies involving hazardous materials, information provided by the railroad and in the DOT and AAR emergency response guidebooks can help local responders select the most appropriate gear. The most extensive safety information is in the highly informative Emergency Action Guides (AAR, 1984). The volume contains an excellent introduction and guides of varying length for 172 chemicals. (Figures 3-5 compare the amount of safety and first aid information on anhydrous ammonia in the above three sources.)

Of the three, the Emergency Action Guides provides the best single reference for protecting railroad personnel. Although only 142 chemicals are cuicred, these materials account for approximately $98 \%$ (by volume) of the hazardous materials shipped by rail. Nevertheless, the other two guidebooks are quite useful, covering more than 1000 chemicals, and should also be available to emergency response personnel at major railroads and the communities adjacent to their railyards.

As a cooperative gesture, some railroads (small as well as large) have distributed copies of Emergency Handling of Hazardous Materials in Surface Transportation (AAR) and Emergency Action Guides (AAR) to all communities along their rights-of-way, including communities adjacent to their railyards. Major railroads -- particularly those that are already providing lists of chemicals frequently handled in their railyards to adjacent communities -- are providing guidebooks or similar materials such as the appropriate pages from the guidebooks to adjacent communitics. 


\section{ANHYDROUS AMMONIA Nonflammable Gas $R Q 100 \mathrm{Lb} / 45.4 \mathrm{Kg}^{*}$}

\section{GENERAL INFORMATION}

Anhydrous ammonia is a colorless gas shipped under pressure as a liquid and having the pungent characteristic odor of ammonia. It is used as a refrigerant and in making fertilizers, explosives, synthetic fibers, plastics, pharmaceuticals, household cleaners, dyes, and wide variety of other chemicals and products. It is quite soluble in water and dissolves to form an alkaline ammonium hydroxide solution with the evolution of heat. Although it is considered nonflammable under conditions likely to be encountered, it can be ignited with an appropriate ignition source within a relatively narrow range of concentrations in air. Containers may rupture violently due to overpressurization if exposed to fire or excessive heat for sufficient time duration. The liquid product weighs approximately 5.7 pounds per gallon at its low boiling point of $-28^{\wedge} \mathrm{F}$.

The major hazard of anhydrous ammonia spills is that the product will boil or vuporize rapidly upon release to form a substantial vapor sloud or plume that may expose downwind areas to toxic concentrations in air over considerable distances. Also to be noted is that the product is corrosive to aluminum, tin, copper, lead, silver, zinc and other alloys; forms highly explosive products with calcium hypochlorite bleaches, gold, mercury, and silver; is otherwise reactive with a variety of chemicals, and is corrosive to bodily tissues.

Downwind evacuation should be considered if anhydrous ammonia is leaking but not on fire. If bulk container is exposed to direct flame or fire becomes uncontrollable, evacuate for a radius of 2500 feet. If cylinder is exposed to direct flame or fire becomes uncontrollable, evacuate for a radius of 1500 feet.

\section{CHEMICAL/PHYSICAL DATA}

Solubility in Water: Soluble, $51 \mathrm{~g} / 100 \mathrm{~g}$ water at $68^{\circ} \mathrm{F}$ $\left(20^{\circ} \mathrm{C}\right)$

Solubility in Other Chemicals: Soluble in alcohol, chloroform, and ether.

Specific Gravity (Liquid): 0.682 at $-28.1^{\circ} \mathrm{F}\left(-33.4^{\circ} \mathrm{C}\right.$

Boiling Point: $-28.0\left(-33.35^{\circ} \mathrm{C}\right)$

Melting Point: $-107.9^{\circ} \mathrm{F}\left(-77.7^{\circ} \mathrm{C}\right)$

Freeding Point: $-107.9^{\circ} \mathrm{F}\left(-77.7^{\circ} \mathrm{C}\right)$

Molecular Weight: 17.03

Heat of Combuation: $-4440 \mathrm{cal} / \mathrm{g}$

Vapor Preasure: 5 atm at $40.5^{\circ} \mathrm{F}\left(4.7^{\circ} \mathrm{C}\right) ; 10$ atm at $78.3^{\circ} \mathrm{F}\left(25.7^{\circ} \mathrm{C}\right)$

Fash Point Not flammable under conditions likely to be encountered.

Autoignition Temperature: $1204^{\circ} \mathrm{F}\left(651^{\circ} \mathrm{C}\right)$

\section{IDENTIFICATION}

Shipping Names: Ammonia, anhydrous (USDOT); ammonia (IMO)

Bynonyms and Tradenames: Ammonia; ammonia gas; liquid ammonia; Nitro-sil; spirit of hartahorn; Am-fol. Chemical Formula: $\mathrm{NH}_{3}$

Constituent Componente( $(\%$ each): $99.5 \%$ or more pure 19 STCC: 4904210

UN/NA Deaignation: UN1005

MYO Dadignation: 2.3, poison gas
Burning Rate: $1 \mathrm{~mm} / \mathrm{minute}$

Stability: Stable

Corrosiveness: Attacks aluminum, tin, copper, lead, silver, zinc, and other alloys; some forms of plastics, rubber, and coatings; gold and mercury.

Reactivity with Water: Dissolves with evolution of heat to form ammonium hydroxide. Action upon contact is vigorous and also evolves ammonia vapor's.

Reactivity with Other Chemicals: Reacts with acids, amides, organic anhydrides, isocyanates, vinyl acetate, alkylene oxides, epichlorohydrin, aldehydes, strong oxidizers, calcium hypochlorite bleaches, halogens, gold, silver, mercury, acrolein, and numerous other substances.

Physical State as Shippod: Compressed liquefied gas Physical State as Released: Gas or boiling liquid Color of the Shipped Material: Colorless Odor Characteristica: Extremely pungent

Common Uses: Refrigerant; fertilizer; $\mathrm{mfg}$. of explosives, fertilizers, synthetic fibers, explosives, plastics, pharmaceuticals, household cleaners, dyes, and other chemicals and products.

FOR ADDITIONAL ASSISTANCE OR INFORMATION CALL: CHEMTREC (800)424-8300 OR (202)483-7616 OR THE AAR BUREAU OF EXPLOSIYES (202)835-8500

FIGURE 3 Data Related to Safety of Personnel in Emergencies Involving Anhydrous Ammonia, Emergency Action Guides (Source: AAR, 1984) 


\begin{tabular}{|c|}
\hline $\begin{array}{l}\text { ROUS AMMON } \\
\text { lammable Gas }\end{array}$ \\
\hline 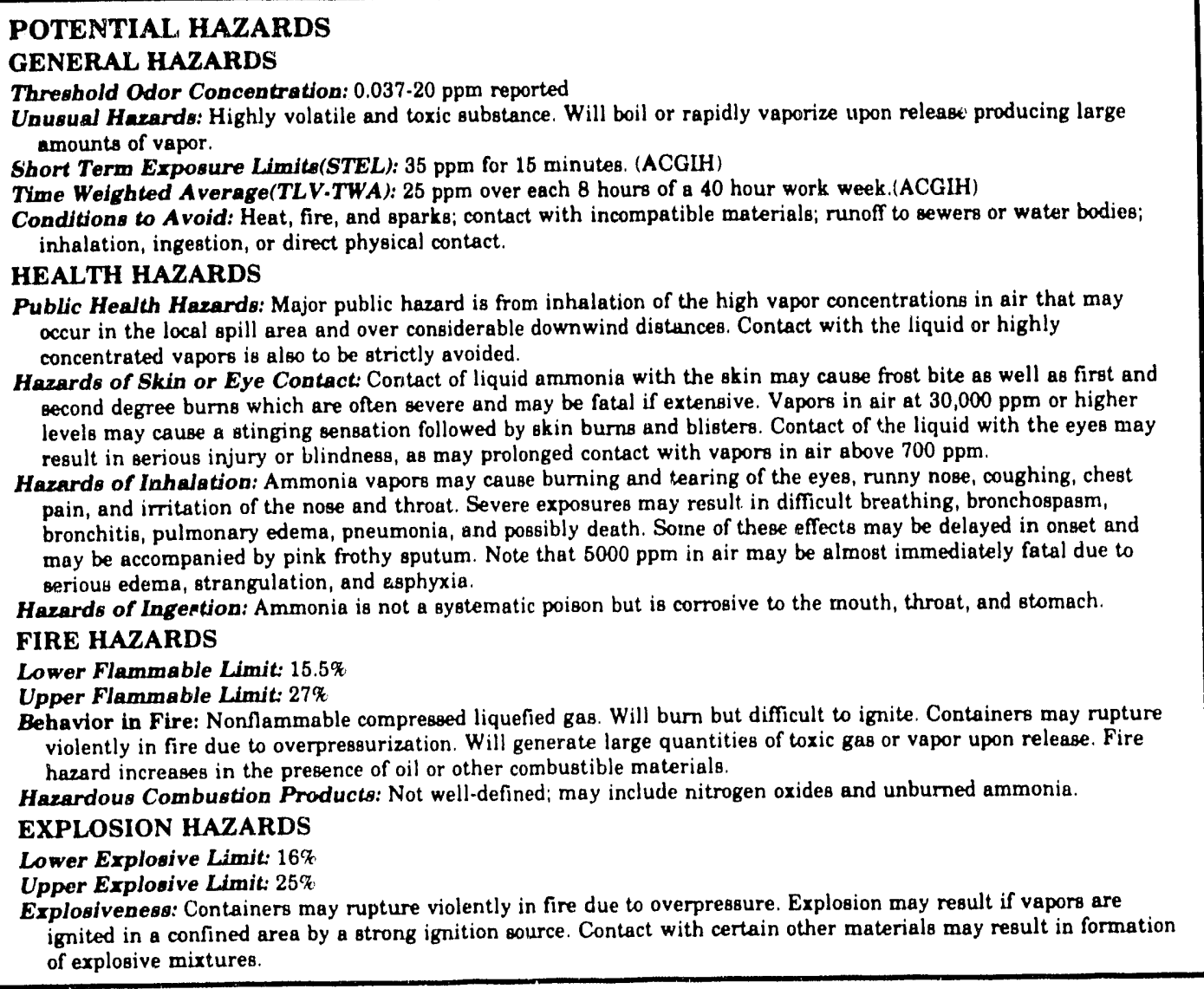 \\
\hline $\begin{array}{l}\text { PROTECTIVE CLOTHING AND EQUIPMENT } \\
\text { Protective Clothing Required: Eupuipment should prevent any possibility of skin or eye contact with the spilled } \\
\text { product. This may include rubber boots, gloves, face shields, splash-proof safety goggles, and other impervious and } \\
\text { resistant clothing. Fully encapsulating suits with self-contained breathing apparatus (SCBA) may be advisable in } \\
\text { come cases to prevent contact with high vapor or fume concentrations in air. Compatible materials may include } \\
\text { butyl rubber, natural rubber, neoprene, nitrile rubber, and polyvinyl chloride. } \\
\text { Respiratory Protection: For unknown concentrations, fire fighting, or high concentrations (above } 600 \mathrm{ppm} \text { ), a self. } \\
\text { contained breathing apparatus (SCBA) with full facepiece (or the equivalent). For lesser concentrations, a gas mask } \\
\text { with chin-style or front or back mounted ammonia canister (500 ppm or less) or an ammonia car iridge respirator } \\
\text { with a full facepiece ( } 300 \mathrm{ppm} \text { or less) within the use limitations of these devices. }\end{array}$ \\
\hline
\end{tabular}

FIGURE 3 (Cont'd) 


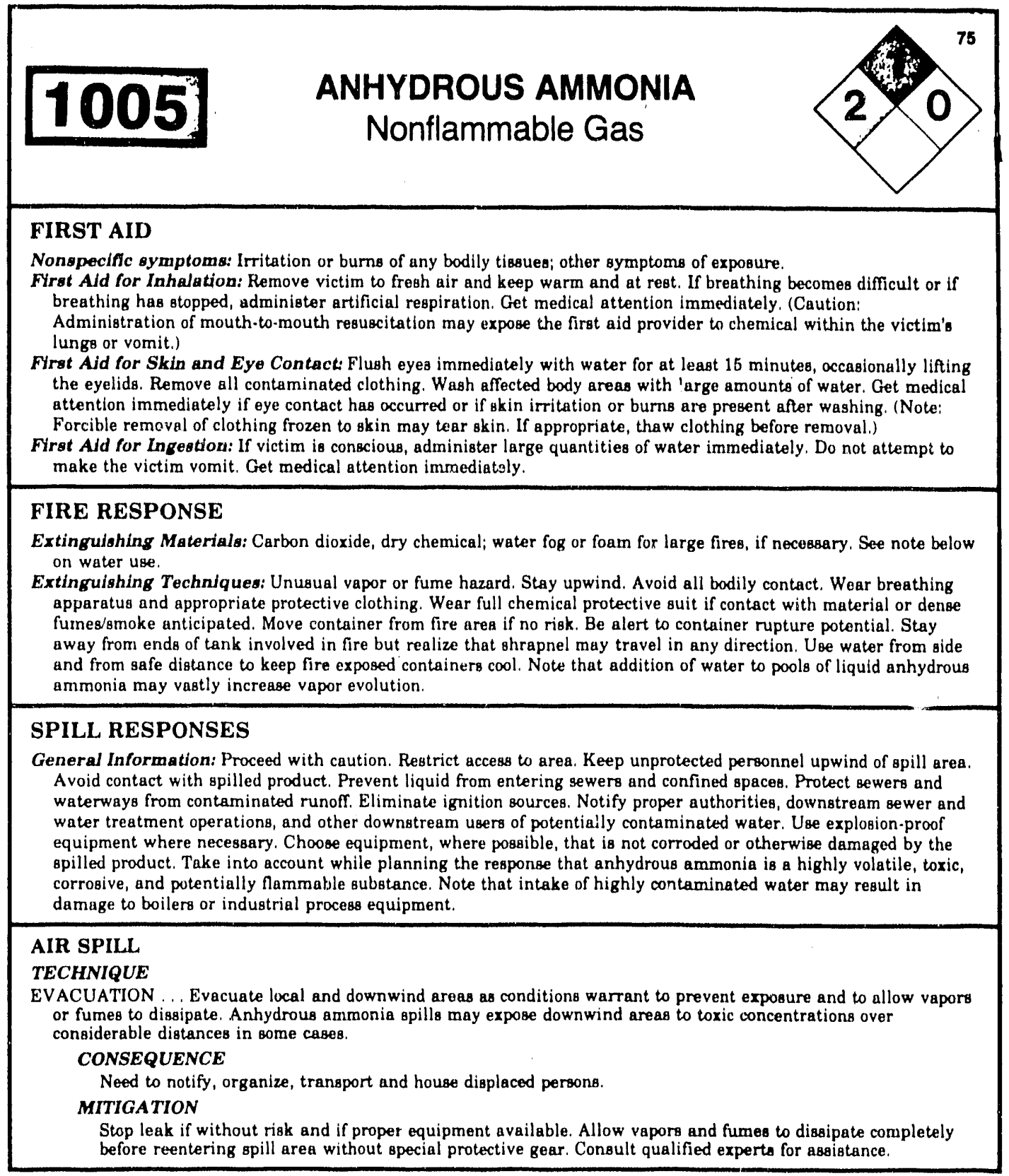

FIGURE 3 (Cont'd) 


\title{
ANHYDROUS AMMONIA (OR) AMMONIA, ANHYDROUS 4904210 NONFLAMMABLE GAS, CORROSIVE, POISONOUS UN1005 ENVIRONMENTALLY HAZARDOUS SUBSTANCE (RQ-100/45.4)
}

\begin{abstract}
Anhydrous ammonia is a clear colorless gas with a characteristic odor. It is used as a fertilizer, as a refrigerant, and in the manufacture of other chemicals. Although it is classed as a nonflammable gas, it will burn within certain vapor concentration limits, and the fire hazard will increase in the presence of oil or other combustible materials. Its "combustibility" is definitely not a common problem in the event of leakage. It is shipped as a liquid under pressure. Contact with the liquid can cause frostbite. It is soluble in water forming a corrosive liquid. Although ammonia is lighter than air, the vapors from a leak initially hug the ground. Il weighs $6 \mathrm{lbs} / g a l l o n$. Long-term exposure to low concentrations or short-term exposure to high concentrations can result in adverse health effects from inhalation.
\end{abstract}

If material involved in fire

Extinguish fire using agent suitable for type of surrounding fire

(Matcrial itself does not burn or burns with difficulty)

Cool all affected containers with flooding quantitics of water

Apply water from as far a distance as possible

Use water spray to knock down vapors

Solid streams of water may spread fire

Do not use water on material itself

Do not apply water to point of leak in tank car or container

If material not involved in fire

Kecp material out of water sources and sewers

Altempt to stop leak if withoul undue personnel hazard

Use water spray to knock-down vapors

Personnel protection

Avoid breathing vapors

Keep upwind

Wear positive-pressure self-contained breathing apparatus

Avoid bodily contact with the material

Wear appropriate chemical protective gloves, and gas-tight goggles

Do not handle broken packages unless wearing appropriate personal protective equipment

Wash away any material which may have contacted the body with copious amounts of watter or soap and water

If contact with the material anticipated, wear appropriate chemical protective clothing

\section{Evacuation}

If material leaking (not on fire) consider cvacuation from downwind area based on amount of material spilled, location and weather conditions

Environmental considerations--land spill

Dig a pit, pond, lagoon, holding arca to contain liquid or solid material

Dike surface llow using soil, sand bags, foamed polyurethane, or foamed concrete

Absorb bulk licluid with fly ash or ecment powder

Neutralize with vinegar or other dilute acid

\begin{abstract}
FIGURE 4 Data Related to Safety of Personnel in Emergencies Involving Anhydrous Ammonia, Emergency Handling of Hazardous Materials in Surface Transportation (Source: AAR, 1989b, p. 60)
\end{abstract}


Environmental considerations--water spill

Neutralize with dilute acid

Use mechanical dredges or or lifts to remove immobilized masses of pollutants and precipitates

\section{Environmental considerations-.air spill}

Apply water spray or mist to knock down vapors

Vapor knockdown water is corrosive or toxic and should be diked for containment

\section{First aid responses}

Move victim to fresh air; call emergency medical care.

If not breathing, give artificial respiration.

If breathing is difficult, give oxygen.

Remove and isolate contaminated clothing and shocs at the site.

In case of contact with material, immediately flush skin or eyes with running water for at least 15 minutes.

Keep victim quict and maintain normal body temperature.

Effects may be delayed, kecp victim under observation.

Compatible protective equipment construction materials include:

Butyl rubber, Natural rubber, Ncoprene, Nitrile rubber, Polyvinyl chloride

\section{FIGURE 4 (Cont'd)}




\section{POTENTIAL HAZARDS}

\section{HEALTH HAZARDS}

Poisonous; may be fatal if inhaled or absorbed through skin.

Contact may cause burns to skin and eyes.

Contact with liquid may cause frostbite.

Clothing frozen to the skin should be thawed before being removed.

Runoff from fire control or dilution water may cause pollution.

FIRE OR EXPLOSION

Some of these materials may burn, but none of them ignites readily.

Cylinder may explode in hea of fire.

\section{LMERGENCY $\triangle C$ CUON}

Keep unnecessary people away; isolate hazard area and deny entry.

Stay upwind, out of low areas, and ventilate closed spaces before entering.

Positive-pressure self-contained breathing apparatus $(S C B A)$ and chemical prolective clothing which is specifically recommended by the shipper or manufacturer may be worn. It may provide litlle or no thermal protection.

Structural firefighters' protective clothing is not effective for these materials.

Isolate the leak or spill area immediately for at least 150 feet in all directions.

See the Table of Intial Isolation and Protective Action Distances. If you find the ID Number and the name of the material lhere, begin protective action.

CALL CHEMTREC $\Lambda$ T 1-800-424-9300 $\Lambda S$ SOON $\Lambda S$ POSSIBLE, especially if there is no local hazardous materials team available.

FIR E

Small Fires: Dry chemical or $\mathrm{CO} 2$.

Large Fires: Water spray, fog or regular foam.

Do not get water inside container.

Move container from fire area if you can do it without risk.

Apply cooling water to sides of containers that are exposed to flames until well after fire is out. Stay away from ends of lanks.

Isolate area until gas has dispersed.

\section{SPILL OR LEAK}

Stop leak if you can do it without risk.

Fully-encapsulating, protective clothing should be worn for spills and leaks with no fire.

Use water spray 10 reduce vapor; do not put water directly on leak or spill area.

Small Spills: Flush area wilh flooding amounts of water.

Large Spills: Dike far ahead of liquid spill for later disposal.

Do not get water inside container.

Isolate area until gas has dispersed.

FIRST AID

Move victim to fresh air and call emergency medical care; if not breathing, give artificial respiration; if breathing is difficult, give oxygen.

In case of contact with material, immediately flush skin or eyes with ruming water for at leasl 15 minutes.

Remove and isolate contaminated elothing and shoes at the site.

Keep victim quiet and maintain nomal body temperature.

Eiffects may be delayed; keep victim under observation.

\section{FIGURE 5 Data Related to Safety of Personnel in Emergencies Involving Anhydrous Ammonia, 1990 Emergency Response Guidebook (Source: DOT, 1990 )}


The guidebooks are also useful to hospital personnel when treating persons contaminated or injured in railyard emergencics. The plans of some railroads require that the appropriate section from Emergency Action Guides be brought to the hospital with any contaminated or injured individual. Other plans require only that the chemical name be provided. Railyard plans should require that at least two copics of the appropriate sections from Emergency Action Guides for the chemicals most frequently handled) should be available at the yard: one for use at the yard and one or more to send to the hospital with contaminated or injured individuals. The sections on individual chemicals in Emergency Action Guides are very comprehensive, especially with respect to treating injuries.

Railyards that handle liquefied petroleum gas and other materials pressurized for transport should also have an explosimeter available for personnel safety as well as for incident assessment. Additional support equipment (for example, weather data services, telescopes, proteclive gloves, splash goggles, emergency showers, and eyewash fountains) should also be on hand. Gencrally speaking, these resources are more readily available at the railyards of large railroads than small ones.

Beyond this, the Incident Commander and his or her subordinates are responsible for ensuring the safety of response personnel. Decontamination supplies should be brought to the site by the hazardous matcrials team in its response vehicle, and should include a garden hose, a safety drench shower, a catch basin with a salvage cover or plastic shecting, and disposable bags or drums.

Small communities can sometimes overcome resource limitations by working with railroads and other privale organizations within their communities to identily specific equipment needs and develop mechanisms for accepting private donations. Railroads have donated acid suits, microcomputers, videotapes and other training materials to local communitics. With fewer railroads maintaining their own response teams, such gestures may become more common in the fulure.

\section{Guidance}

1. Ensure that protective gear appropriate to the specific hazardous materials involved in the emergency is issued to all responders authorized to enter the hazard zone. Both public and private personnel need such protection.

2. Work with local organizations to identify equipment needs that cannot be met with current community resources. If necessary, seck private donations or enter into mutual aid agrecments to ensure that such equipment will be available in the event of an emergency.

3. If the railyard handles hazardous materials pressurized for transport, keep an explosimeter on hand and train personnel in its use. An cxplosimeter may help in decision making. For example, it is dangerous to use a locomolive, which is an ignition source, to move nearby railcars away from the scene of an emergency without using an explosimeter to cvaluate the potential for an explosion. 
4. Make use of existing training materials on personnel safety. Videotapes are available through lending libraries arfiliated with the CMA, AAR, the American Short Line Railroad Associalion, and FEMA. The Hazardous Materials Information Exchange (HMIX), (accessible through 1-8()()-PLANFOR), also contains a comprehensive listing of such videotapes and other training materials.

5. Keep copies of at least three of the basic hazardous materials guidebooks at railyards. Railyards should have copics at their railyards of Emergency Action Guides and Emergency Handling of Hazardous Materials in Surface Transportation, as well as the Emergency Response Guidebook. (Each has useful information not found in the others.) Or, at a minimum, they should have copies of Scc. I of Emergency Action Guides and the appropriate sections from the three guidebooks for the hazardous materials handled by the yard. At least two copics of the relevant emergency action guides should be on hand: one for use at the secene of the emergency and onc or more for accompanying contaminated or injured individuals sent to the hospital (See item 8 below).

6. Share appropriate information on personnel safety with railroads and adjacent communities. Copies of the AAR guidebooks - cither the cntire guidebooks or only appropriate sections (including Sec. I of Emergency Action Guides' -.. should be sent to the communilies adjacent to railyards. These materials can accompany the lists of hazardous materials most frequently handled in the yard. Major railroads and small railroads, particularly if they interconnect, should also explore ways of sharing safety information and training materials. Such cooperative gestures can increase preparedness and lead to other cooperative activities like medical drills.

7. Conduct regular training sessions on personnel safety. The guidebooks mentioned above contain important safely and medical information that should be cmphasized in training sessions for railyard employecs and civil responders. The sessions should also stress use of appropriatc protective gear and clothing during any response activities and kecping exposures to hazardous malcrials "as low as reasonably achicvable" (ALARA). (See Sec. F.2 for a further discussion of ALARA.) If possible, community responders should be invited to attend railroad-sponsored training sessions. Joint participation increases common knowledge, trust, cooperallion, and teamwork.

8. Send relevant information on the hazardous material involved to the hospital with all contaminated and injured individuals. Emergency responsc plans should provide for sending the appropriate emergency action guides to the hospital with contaminated or injured individuals. 


\section{F.2 Standard Operating Procedures}

The emergency preparedness plan for the city of Houston, 'Texas illustrates the types of SOPs that can enhance responder safety. (Houston Fire Department, 1987). The emergency secne is divided into operational sectors for which a commanding officer is responsible for implementing the sector activities described below.

1. Access sector. In the access sector, security personncl control traffic flow (vehicles and pedestrians). Everyone bul authorized responders are prevented from entering the hazard zone. If practical, physical barticades are used.

2. Contaimment sector. Containment sectors are designated when chemical spills require impoundment of runoff. Typical activilies for this sector include trenching, diking, sandbagging, or laying booms 10 contain the substance within a defined perimeter. Workers must have appropriate protective clothing and gear. They can be fïre personnel or privalely employed technicians who were sent to the secne under mulual-aid compacts or who are under contract 10 the owner of the site for example, the railroad that owns the railyard).

3. Decontamination sector. In this sector, responders and any other personnel leaving the hazard zone are monitored, decontaminated, and given first aid, as necessary. Such services should be available for emergencies involving explosives, corrosives, or human or environmental toxins. Under federal administrative regulations (29) CFR 1910.12(0), such services must be in place when conditions warrant before any personnel are sent into the hazard zone.

4. Hazard sector. During emergencies, hazard sectors exist, wheller formally established or not. They encompass the immediate emergency site and the surrounding area where responders may be in immediate danger. The objective is 10 stabilize the emergency within this defined area. Designated by the Incident Commander, the size and shape of the hazard zone depends on the hazardous malcrial involved. Specilic criteria (for example, evacuation distances suggested by hazardous materials guidance) are used 10 establish lhe length of a precautionary action radius from the emergency site. Within the hazard sector, responders must have appropriale protective clothing and gear. They should work in pairs and have a back-up person immediately available for each individual involved.

5. Emergency medical services sector. This sector becomes necessary only when an emergency results in numerous injurics. Because of the life-threatening nature of many hazardous materials, exposed individuals should receive prompl allention from medical or paramedical personnel. Triage, treatment, and transportation should be available. When victims are transported to the hospital, they should be accompanied by a description of ingestion and inhalation symptoms. Because of delayed reactions, exposure symploms are not 
always immediately apparent. Victims should also be accompanied by information and recommendations about medical treatment that are specilic for the substance involved. For rallyard emergencies, such information is generally found in the shipping papers or in the Emergency Actlon Guides (AAR, 1984). If the transport vehicle becomes contaminated, it should be decontaminated immediately afterwards.

6. Rescue sector, If there are trapped or injured persons in the hazard sector, a rescue sector should be established. Rescue operations should be staffed by trained rescue personnel with appropriate protective clothing and gear. However, members of hazardous materials response teams should not be diverted from their main tasks in other sectors unless their special protective clothing is necded.

7. Level II staging sector. Such sectors are necessary only for major cmergencies requiring large numbers of fire companics and other resources. An outof-the-way staging area for these resources facilitates assembling large quantities of equipment and deploying personncl. Close communication and coordination must be maintained between this sector and the Incident Commander.

8. Protective action zone. Citizens within this zone, which lies beyond the hazard sector, are in danger and must be sheltered or cvacuated. The size and shape of the area depends on the nature and quantity of hazardous malcrials involved. The zone may be defined by a radius of particular length around the hazard sector (for a potentiat explosion) or an area downwind of the relcase for toxic or flammable vapors or clouds). The size and shape of the zone should account for potential shifts in wind direction.

Federal administrative regulations (29 CFR 1910.120) require designation of a safety officer, who is to assist opcrations in all sectors. The safety officer is responsible for identifying and evaluating hazards at the emergency scene and for correcting unsafe actions and conditions. This individual should work closely with the Incident Commander, who is sometimes the same person. Within this overall structure, supporting roles are assigned to local public works and health departments.

One major railroad kecps exposures "as low as reasonably achicvable" (ALARA) and speeds up the response by using vapor and oxygen concentration monitors in conjunction with a guide that indicates dangerous exposure thresholds for $96 \%$ of the hazardous materials transported by rail. Also available are one or more sets of protective clothing and positive-pressure self-contained breathing apparatuses for approaching the scene of an emergency safely to assess the degree of hazard. Appendix B in 29 CFR Part 1910 (OSHA, 1989) contains additional information about what levels of protection and protective gear are required under what circumstances. 
Controlling personnel exposure at the acess sector is another example of the ALARA concept. Individual team members should be logged in and oul, and only those with specilic mitigation responsibilities at the immediate entergency secne should be authorlaed to enter the hazard sector. Such individuals can include rallroad personnel. How long each individual remains in the hazard sector should be strictly controlled through written logs, especially if there are localized, elevated concentrations of loxic or corrosive gases. Although the Incident Commander can be responsible for such aceounting, he or she may find it preferable 10 delegale this responsibility to the "Access Sector Officer."

\section{Guidance}

1. Set up operations-oriented SOPS for response sectors. Each sector should have its own designaled oflifer in charge.

2. Use a checklist system for actions to be taken in each designated response sector. Such checklists are particularly necessary if the tasks to be performed by emergency personnel are different from the lasks performed or the procedures followed for natural disasters.

3. Establish a warning system for emergency evacuation of teans operating in the hazard zone. An emergency warning system must be in place because critical situations may develop, and communications between those in command and the operating teams may fail. A $3($ )-second blast from an air horn or electronic siren can be lhe signal for leams to leave the hazard \%one immediately. The warning system should be positioned so that the signal can be heard throughout the havard zone.

4. Evaluate progresss. During implementalion of the chosen option, the Incident Commander should check on the progress being made. If what is supposed to be happening is not happening, he or she must again review the siluation, identify problems, and select another option.

5. Monitor the emergency scene to determine whether concentrations exceed hazard limits. Major railroads should consider having a highly trained individual and appropriale protective gear on hand for detcrmining early in a relcase whether concentrations are dangerous 10 personncl.

6. Assign and train individuals to help response personnel with the difficult task of putting on and taking off Level A protective clothing. Before helping 10 don and again before the wearers enter the hazard zone, the helpers should carcfully inspect lhe suits. To prevent damage to the expensive, gas-light rippers, only the helpers should open and close hem. 
7. In training sessions, stress that water is not the only or always even the correct answer for openflame rillations involving hazardous materials. Inded, waler may somedimes increase the danger. For example, hydrogen lluoride gas becomes highly corrosive when mixed will waler. Decidling wheller and how to use water can be especially difficull when a burning railear (or a railcar with a burning substance on board) has not been isolated from other railcars llan may combin or be leaking waler-reachive hazardous matcrials.

8. Train responding personnel on the importance and meaning of keping exposures to hazardous materials as low as reasonably achievable (ALARA). Training malerials should explain how to sel up aceess and decontamination sectors, the use of appropriate protective gear, and the need for mainaining logs of worker times

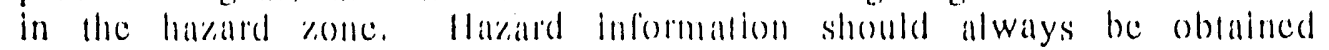
from a sale distance, Evaluators should position themselves upwind and use binoculats.

9. Maintain logs of responders working in the hezard zone. The name of each responder and how long he of she remaned in the havard zone should be recorded. This cill be accomplished wilh a sign-ind sign-oul sheel.

10. Conduct personnel monitoring and decontamination as near as possible to the checkout point from the acicess zone becauses skin can be exposed at any point before removing protective gear and washing down. If llie nearest showers are fiar from the railyard, a mobile washdown facility should be on hand. For example, a lanker truck could be equipped wilh shower slalls or decontaminalion supplies like lhose montioned above. Railroads should be encouraged to provide encegency showers and eyewash fountans al their railyards.

11. To promptly administer correst and perhaps lifesaving medical treatment, personnel in areas of likely exposure sthould know what hazardous materials are involved and recognize exposure symptoms. Everyone involved should also know llan symploms can be delayed. This recommendation pertains especially 10 those operating in the rescue sector, including paramedics. T'o assist emergency medical staff, the following information should accompany injured or contaminaled victims being transported lo the hospital: (a) a description of the exposure, including an estimate of the amount of exposure and the concentration of the hazardous material; (b) a list of observed exposure symptoms; and (c) informalion about treatment allermalives specific for the havardous mallerial involved, as provided in standard guidebooks, especially the Emergency Action Gimides (AAR, 1984). 


\section{F.3 Operating Procedures Specifically for Railyards}

In the most complete EOPs, responders follow SOPs specifleally for rallyards. Some of these procedures deal primarily with loglstics and operations. Delalled maps may be included that show the localtons of isolation tracks and adjacent local strects (sec Fig, 6), Ohler SOPs can be oriented more toward safely (see Flg, 7). Railyardspecific SOPs can be supplemented by emergency response training activities (sec Sec. H) that greally enhance the workability of the plans.

Houston, 'Texas, which has 34 rallyards within lts boundaries, has developed such rallyard-specific procedures (sec Fig. 7) in addition to the SOPs that apply to a range of hazardous materlals cmergencles. These railyard-specific procedures lend to be oriented primarily toward salety, dealing with such actlons as moving railcars, stepping over rails, and crossing linrough lines of stationary ralloars.

The EOPs of major rallonds usually contain instructions and procedures for protecting railroad personnel all or near the scencs of emergencies involving hazardous materials. Instructions such as "stay upwind," "avold contact or inhalation," "warn olhers," and "ciminale ignilion sources" are almost always included. Major railroads have also begun 10 develop training materials 10 enhance the competence and safely of yard personnel in handling hayardous materials emergencies in railyards. Conrail has developed a training program called operation EYE - Employees in Yard Emergenciess that focuses on the procedures yard personnel should use when fiaced with hazardous material incidents. Figure 8 shows a foldout card developed for that program. Santa Fe has developed a 12 -minute videolape, also called Operation EYE - Employees in Yard Emergencies, which presents basic safely rules and instructions in a highly interesting and understandable manner (Alchison, Topeka and Santa Fe Rallway Company, undated). Important points cmphasized in the videotape, but not included in the card, are:

1. Kecp an eye on malcats containing hazardous matcrials.

2. Use a helper wearing full-body cnclosure gear and a positivepressure aelf-eontaned breathing apparatus for inilial status reports from the emergency scene.

3. Identify, by matcral, any other ralcars containing hazardous materials. Include those that are apparently empty or that have placards indicaling residues only.

4. Identily for medical personnel the exact hazardous materials involved in any exposures.

5. If necessary, evacuate railroad personnel or the public. The decision to evacuate should be based on the fact or probability of a release and its likely elfects.

6. If supervisors are comporarily unavailable, the individual discovering the siluation should notify local civil authoritics. 


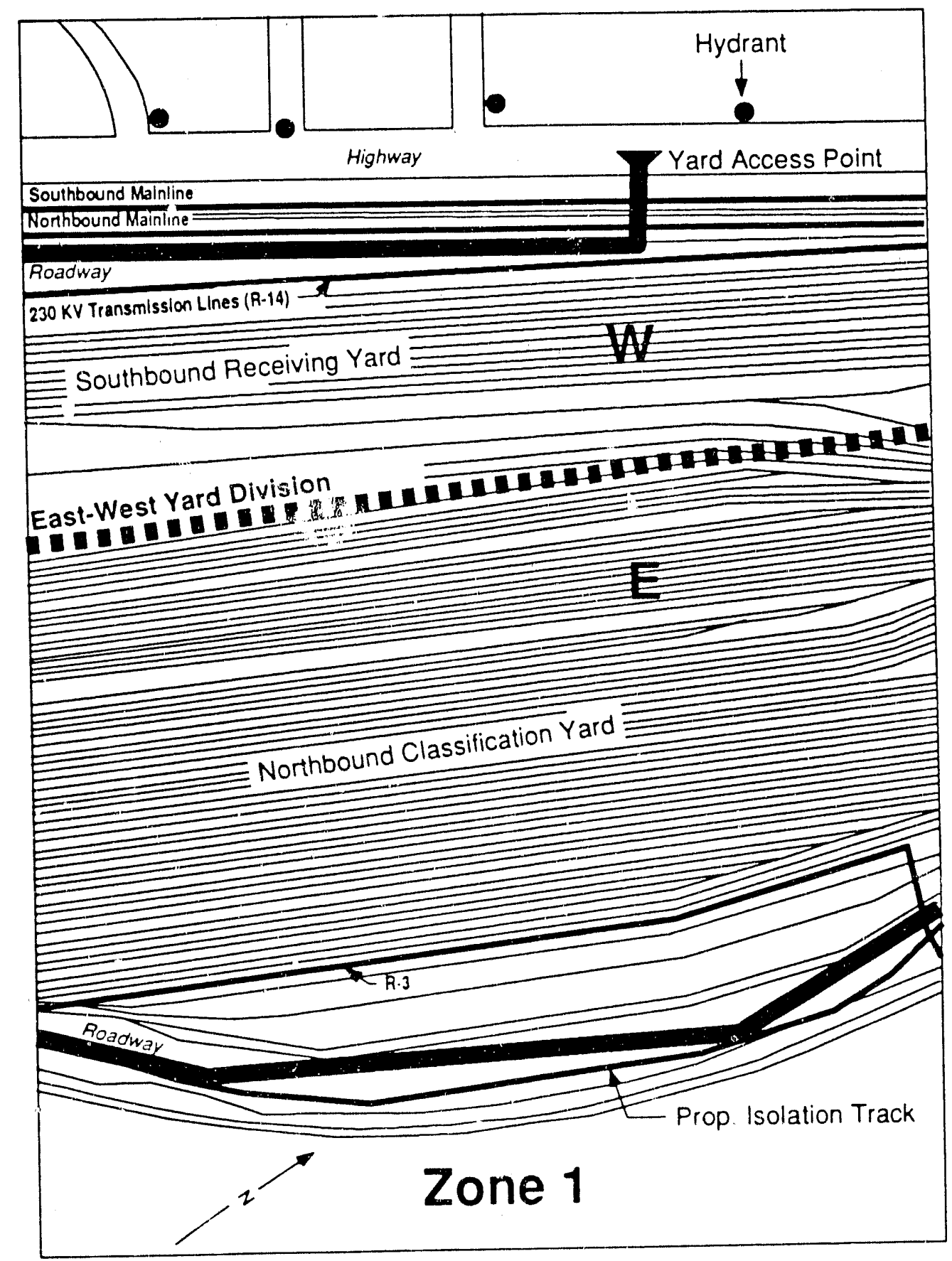

FIGURE 6 Map of Sample Railyard Zone (one of six) Showing Ysolation Tracks, Internal Roadways, and Yard Acess Point iSource: Adapted from Alexandria, Virginia, Fire Department, 1984) 


\section{SUPPLEMENT TO GUIDELINES AND PROCEDURES FOR HAZARDOUS MATERIALS EMERGENCIES (SP-8)}

1. Railroads will report as much of the following information as possible to Fire Alarm for railyard emergencies:

a. Type (fire, sniil, leak, derailment) and magnitude.

b. Name of railyard.

c. Location of railyard.

d. Chemical name and four-digit identification number of chemical.

2. Fire Alarm will dispatch the Hazardous Materials Response Team (HMRT), along with the appropriate firc companics.

3. All information supplied to Fire Alarm from a railroad will be passed on to responding companies during the initial dispatch.

4. Fire Alarm will relay all follow-up information from the railroad to responding fire companies.

5. Fire officers will review hazards of the chemical in DOT's Emergency Response Guidebook en route to location.

6. All fire compinies shall stage at the designated railyard location (or upwind if the railyard location is untenable).

7. Fire companies will not enter railyards that are preceded by double asterisks in the railyard list without guidance of a railroad official. (This does not include structural fires in the railyard.)

8. If a railroad official is not on scene at the time of Fire Department arrival (except at railyards preceded by double asterisks in the railyard list), the following procedures shall apply:

a. Fire personnel shall not enter the railyard until the chemical has been identified and its hazards known.

b. If the railcar cannot be seen from the staging area, the commanding officer will request the location of the railcar from Fire Alarm. Fire Alarm will contact the railroad and obtain the railyard section (south end, mid-yard, etc.), track number, and railcar number.

c. A minimum number of men in full protective clothing and positive-pressure selfcontained breathing apparatus will be committed for size-up; but no fewer than two men.

\section{FIGURE 7 Procedures for Ratyard Emergencies (Soures: Housten Fire Department, 1987)}




\section{SUPPLEMENT TO GUIDELINES AND PROCEDURES FOR HAZARDOUS MATERIALS EMERGENCIES (SP-8) (ront'd)}

d. HMRT will be committed for size-up when special protective clsithing is needed for complete protection against the hazards (for example, poison gas) or when special monitoring is needed (for example, radioactive materials).

e. Personnel entering railyard shall remain alert for moving railcars.

9. A command post will be conspicuously located outside the Hazard Zone.

10. The ranking railroad official will serve as advisor to the commanding officer and will direct railroad employees.

11. At least one power unit will be available to move railcars as needed.

12. Fire personnel shall avoid steppirg on track rails; always step over the rail.

13. Fire personnel shall not crawl under a railcar or under the couplings when crossing from one side of a line of railcars to the other side. Use the "running board" and grab rail located above the coupling on either end of a railcar to cross a line of railcars.

April, 1984

\section{FIGURE 7 (Cont'd)}


OPERATION

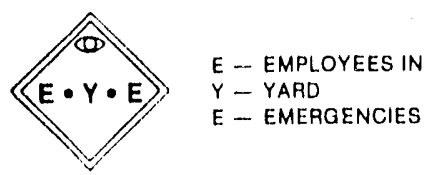

KEeping your EYE ON HAZARDOUS MATERIALS

HAZARDOUS MATERIALS PLACARDS ARE WARNINGS

BE ALERT

OBSERVE SAFE HANDLING, REPORT UNSAFE

CONDITIONS

When things look $B A D$

B - BACK OFF - WARN PEOPLE AWAY

A - AVOID INHALATION OF G.ASES, FUMES, SMOKE

D - DON'T TOUCH OR WALK INTO MATERIALS OR LIQUID.

NOTIFY SUPEAWISION AI ONCE

GIVE LOCATION, DETAILS

IN THE EVENT OF EXPOSUAE OR INJUAY

ARGANGE FOR MEDICAL CARE AT ONCE.

BASIC FIRST AID

1. MOVE VICTIM TO FRESH AIR

2. IF NOT BREATHING GIVE ARTIFICIAL

RESPIRATION. (SEE YOUR SAFETY RULE BOOK)

3. IF CONTACT WITH MATERIAL, IMMEDIATELY FLUSH SKIN OR EYES WITH RUNNING WATER FOR AT LEAST 15 MINUTES.

4. CAREFULLY REMOVE AND ISOLATE CON TAMINATED CLOTHING AND SHOES.

5. KEEP THE INJURED PERSON QUIET AND MAINTAIN

NORMAL BODY TEMPERATURE.

6. REMOVING MATERIAL FROM SKIN IS OF EXTREME IMPORTANCE. EFFECTS MAY BE DELAYED IMPORTANCE. EFFECTS MAY BE DELAYE
KEEP THE VICTIM UNDER OBSERVATION

INFORMATION NFEDED BY EMEROENCY FORCE?

1. LOCATION OF INCIDENT.

2. BEST ENTRY INTO AREA.

2. BEST ENTRY INTO AREA.

3. IDENTIFICATIC
LOCATION

4. HAZARD CLASS (FROM PLACARD OR SHIPPING PAPER)

5. HAZARDOUS MATERIAL IDENT. NO. (FROM PLACARO OR SHIPPING PAPER)

6. EXACT NAME OF COMMODITY (FROM SHIPPING PAPER, TANK STENCILLING, OR COMPUTER INQUIRY

7. WATER SOURCES.

FIGURE 8 Foldout Card Entitled Employees $i$ (Source: Conrail Corporation, undated)

FULL DETAILS INCLUDING PLACARDIDENTIFICATION NUMBER INFORMATION IN YOUR HAZARDOUS MATERIALS CT.225

EMERQENCY TELEPHONE NUMBERS

YARDMASTER

SUPERVISOR

TRAIN OPERATIONS

(Source Conrail Corporation, undated) 
Some railroads are also using commercially available training courses for specific chemicals. Such courses are available on modular videotapes, with their main points reinforeed through handouts and self-quizzes. The modules are designed to motivate employecs to follow effective safety procedures, to prepare them to respond quickly and effectively to emergencies involving specific chemicals, and to enable them to spot and remedy dangerous situations. Because the modules are for specific chemical groups, railroads and communities can sclectively acquire those modules dealing with their most frequently handled chemicals.

Section I of Emergency Action Guides (AAR) discusses personnel safety, including procedures for inspecting personal protective clothing (p. IX):

A word of caution: Responders should inspect all equipment, before donning. Any defective part should be fixed or replaced. Don't wear cracked or damaged clothing. This pre-donning inspection should include checks for:

- Cracks, britlleness, pinholes, or lears in the fabric;

- Zipper failurel;

- Cracks on the facepiece, rubber surface, and seal; |and|

- Condition of valves, canisters, warning devices, and hoses.

In practice, however, most personnel do a quick visual inspection as the suit is donned. More thorough inspections are conducted during daily or periodic maintenance checks and after each use of the suit (McRac, 1989).

Gas concentration monitors (sec Sec F.2) and instruction booklets for specific tasks can also cnhance personnel safety. The tank car repair booklet supplicd to appropriate railyard personnel by Southern Pacilic Transportation Company and St. Louis Southwestern Railway (undated) is a good example of both. Designed to prevent minor emergencics from becoming major ones, the instructions cover repair of leaking tank cars, including how to decide what protective clothing 10 wear and when to contact the hazardous materials control officer. (Protective gear may not be necessary if the secne has been monitored first.)

The booklet also classifies tank car repairs as basic or advanced. Only personnel familiar with another Southern Pacific and St. Louis Southwestern publication, Introduction to Tankcars, should altempt basic repairs. Repairs should not be attempted until (a) the contents of the railear have becn determined using waybill or computer inquiries, (b) the hazard presented by the material (from computer response to inquiries) has been determined, and (c) personnel are wearing and using necessary protective equipment. Examples of basic repairs include:

1. Replacing a burst safely vent rupture disc.

2. Closing lank car valves, and tightening caps or plugs.

3. Securing a manway cover and filling a hole, and replacing the gaskets. 
4. Securing the gauging device on IPG (liquefied petroleum gas) lank car.

Personnel trained by the railroad's hayatho thaterials control officer and qualified to use positive-pressure self-contained bifuthig apparatus can attempt the following advanced repairs. These repairs should never be attempted by emergency response personnel untrained in the specific hazards and procedures.

1. Repair any leak involving toxic gases or products that generate toxic vapor. Such materials require use of self-contained breathing apparatus.

2. Vent an acid car.

3. Disassemble liquid-linc fillings.

4. Replace a boltom outlet cap gasket.

Two procedures adopted by the Houston Fire Deparment (1987) should be considered for inclusion in the railroad repair procedures. First, a warning system (for example, an air horn) should be in place 10 alert (and possibly cvacuate) railyard personncl if something dangerous unexpectedly happens or a dangerous mistake is made during repairs. Second, the repair should be monitored to ensure that the situation is improving, or at least not deteriorating.

Piocedures and resources to chlnance personncl safely necd not be sophisticated or costly. At small railroads. officials who give safety a high priority have shown that inexpensive and sometimes makeshift measures can detect situation; dangerous 10 railyard personnel and make safe responses casier. For example, liquid dishwashing detergent and water in a bucket can be used to detect leaks; wind socks and binoculars can monitor personnel safety and incident assessment; and instructional materials like the foldout card in Fig. 8 can be carried in employec wallets.

Small railroads and their adjacent communities may not need the entire contents of Emergency Action Guides (AAR). They may only need the introductory material and excerpts that cover the havardous materials most frequently handled at their railyards. For example, if a small raiload specializes in handling propane, while also handling a few other hazardous materials, it could provide adjacent communities with copies of the emergency action guide on propane and any other relevant guides, plus the introductory section of the guidebook. Some small railroads have distributed copics of Emergency Action Guides to emergency response agencies in the countics along their rights-of-way; others have donated acid suits lo local communities. Such cooperative gestures provide a basis for mulual preparedness activities and improved railroald-community relalions.

For members and governmental organiations, the Association of American Railroads charges $\$ 125$ for its Emergency Action Guides with plasticiaed pages. Nonmembers are charged $\$ 150$. The version with paper pages costs $\$ 55$, regardless of membership. 


\section{Guidance}

1. Develop SOPs specifically for railyards, and train emergency response personnel in their use. Such procedures can parallel more generally applicable procedures for hazardous malcrials emergencies and still be labelled as railyard specific.

2. Acquire videotapes like Operation EYE to train employees for yard emergencies. This videolape is recommended for national distribution by the CMA, the AAR, FEMA, and the American Short Line Railroad Association (sec Sec. H). As major railroads develop additional programs 10 enhance the emergency preparedness of their personnel, they are urged to make them available to small railroads.

3. Ensure that any damaged tank car or other transport vessel containing residual product is carefully examined by competent personnel before it is moved or its product is removed. Representatives of AAR's Burcau of Explosives have the appropriate training for this task. For example, it may be dangerous to move the vessel from a northern railyard to an area with a warmer climale or to allow the vessel to remain unmonitored in hot sunlight after a nighttime emergency. The danger is especially great for vessels that originally contained liqueficd gases. Increasing ambient temperatures may result in leaks caused by expansion of any gas left in the container. The likelihood and severity of such leaks or a rupture may also be a function of the nature and degree of container damage (see Sec. G).

4. Structure response and repair operations for maximum safety of railyard personnel. For example, obtain assessment data upwind and from a safe distance, kecp an explosimeler on hand if pressurized matcrials are handed, and equip vehocles used for public notification with enough respirators.

5. Install or have a portable employee warning system for example, an air horn) if railroad personnel respond to minor emergencies and repair tank cars in the railyard. The warning system will help intiale evacuation or protection-in-place if response or repair activities lead 10 dangerous siluations. The progress of repairs should be periodically evaluated to cnsure that the situation is improving, or at least not worsening. Warning systems are also useful for alerting employees immediately after an emergency occurs. 


\section{(; INCIIENT ASSESSMENT}

\section{G.1 Information and Resources}

Large railroads have staft members who are experts in hazard control, hazard mitigation, and damage assessment. However, these emergency response roles are often in addition to their regular full-time responsibilitics, and their duty stations are often distant from the site of an emergency. Thus, railroads usually have a designated responder at each railyard to be responsible for the initial response. Although such individuals have been trained in hazard identification, verification, and mitigation, they usually need the advice and assistance of civil responders and oth:r off-site resources, such as (1) CHEMTREC, (2) the shipper, (3) the AAR's Burcau of Explosives, or (4) local or regional emergency information resource networks (for example, the Houston Channel Industrics Mutual Aid Organization).

Once the harardous material has been identified, CHEMTREC immediately provides information on the nature of the materials and the steps to be taken in handling the early slages of a problem. CHEM'TREC then contacts the shipper (if the shipper is a manulacturer of chemicals) for more detailed assistance and appropriate follow-up, including, when possible, assistance at the scene of the emergency. Direct contact with the shipper is advisable even after standard references (sec below) have been consulted. Indecd, small railroads with relatively limiled experience in handling hazardous materials may instruct their personnel to rely on higher-level information, that is, to verify all hazards through CHEMTREC and the manufacturer. According to the 199() Emergency Response Guidebook (DO'T, 1990, page v):

The information from this guidebook should be augmented by expert technical advice as soon as you have assessed the siluation and have seen to the immediate needs of the people involved. The shipper or manufacturer of the material can usually be contacted through CHEMTREC for assislance...

To cnsure prompl and effective responses, CHEMTREC maintains links with (1) private-sector response teams, including those from the Chlorine Institule and the National Agricullural Chemical Association; (2) appropriale federal agencies, including the DO'T and the U.S. Department of Energy; and (3) the AAR's Bureau of Explosives.

Those answering the CHEMTREC 24-hour emergency number (80()-424-930()) have been chosen for their ability to remain calm in stressful siluations. They have been strictly instructed not to deviate from the information prepared for their use by industry technical experts. Thus, unfounded personal speculation regarding the reported emergency is avoided.

Under most SOPs, the responsible official at the railyard (that is, the trainmaster, yardmaster, or general foreman) will immediately consult the shipping papers when a leaking or otherwise damaged railear has been identified by number. Estimating hazads from placards is not advisable. The placard's code number may be too general, or the placard may be lost, stolen, or out of sight. Although placards provide responding railyard staft with supporting verification and some lechnical 
information, they should be supplemented by consulting the shipping papers and one of the above guidebooks.

Additional help can be obtained from the Emergency Action Guides and Emergency Handling of Hazardous Materials in Surface Transportation (AAR). The former guidebook is available in hard copy and also with downwind modeling capabilities through ICARIS. The latter guidebook is available in hard copy and in personal computer form via CERIS. These two computer-based scrvices are offered at low cost by the AAR. Also valuable as a resource is the Emergency Response Guidebook (DOT) (sec Secs. H.1 and H.2). If in their possession, civil responders often consult these sources on the way to the emergency scene. These documents are usually available from CHEMTREC, the yardmaster's office, or the conductor on the train. The railroad also contacts CHEMTREC, either from the yard or head office. Hard copies of CHEMTREC information are obtained via modem through the CMA's Hazard Information Transmission program (202-887-1255). These can be printed at the railyard or sent via telefacsimile machine from the railroad's head office.

Once at the scene, civil responders first identify the commodity involved in a hazardous materials cmergency, then determine appropriatc countermeasures. They generally rely on placards, labels, and stenciled markings on railears, as well as shipping papers. Indeed, they generally request copies of the waybill or shipping papers as soon as they arrive on the scenc. Most large railroads routinely attach computer-generated hazardous matcrials information to the shipping papers of all hazardous cargoes. Often taken from standard references, this information includes important physical properties (for example, flash point, vapor density, and specific gravity) and recommended procedures for personal protection, mitigation and containment.

Flowcharts tailored to each hazard class can assist first responders in deciding on the most apppropriate course of action. Figure 9 is a flowchart for emergencies involving Explosives "A." An carly recommendation for cvacuation or sheltcring-inplace, based on such a flowchart, can be included in the message that notifies community emergency response organizations (sec Sec. D).

\section{Guidance}

1. Provide railroad personnel with intial instruction and periodic: refresher training in the use of basic sources of information for immediately identifying and learning about the hazardous materials involved. Al a minimum, train and yard crews, and supervisory personnel should be trained in the use of AAR's Emergency Handling of Hazardous Materials in Surface Transportation and Emergency Action Guides and DOT's Emergency Response Guidebook. Familiarity with these references and their proper use can save vital seconds during serious emergencies. Allhough casy 10 overlook, such training is invaluable and can be conducted internally at very low cost. The training should cmphasize how to quickly locatc information on specific chemicals and the importance of assessing damage to containers for an indication of current or fulure hazard. 


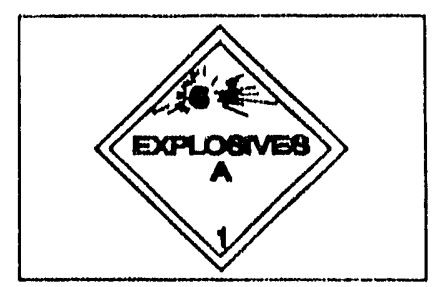

EXPLOSIVES "A"

EXPLOSIVES "A" (EXP) are capablo of oxplosing or dotoriating in mass whon involvod in fire or subjectod to strong impacts or shocks. When involvod in fires, all persons should bo evacuated for a distance of one millo. When not on fire, they should be protected from being struck, crushed, exposed to firo, or contact with corrosive materials. Examples of Class A explosives: high explosives; explosive bombs; Initiating oxplosives; black powder

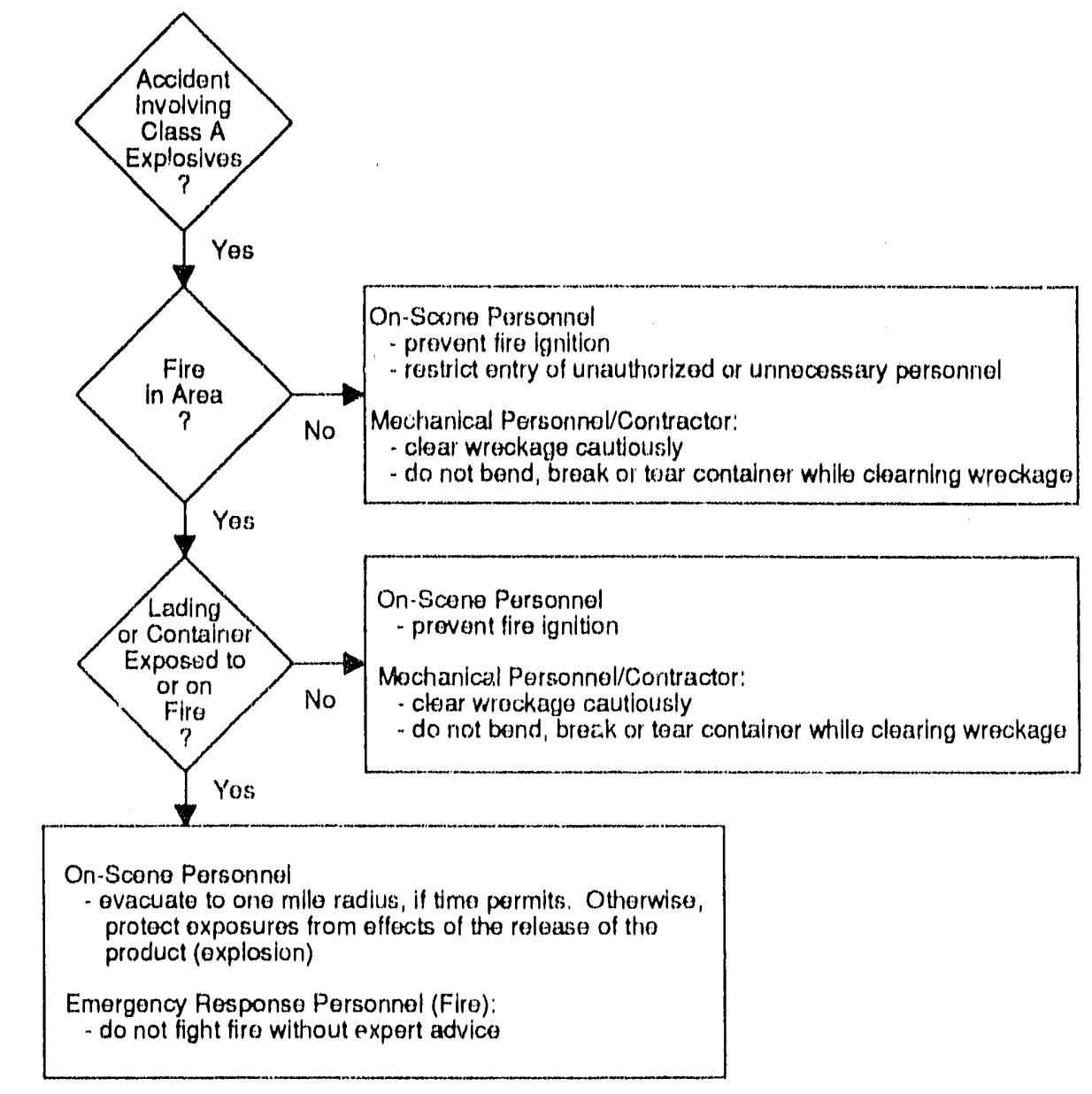

REMEMBER:

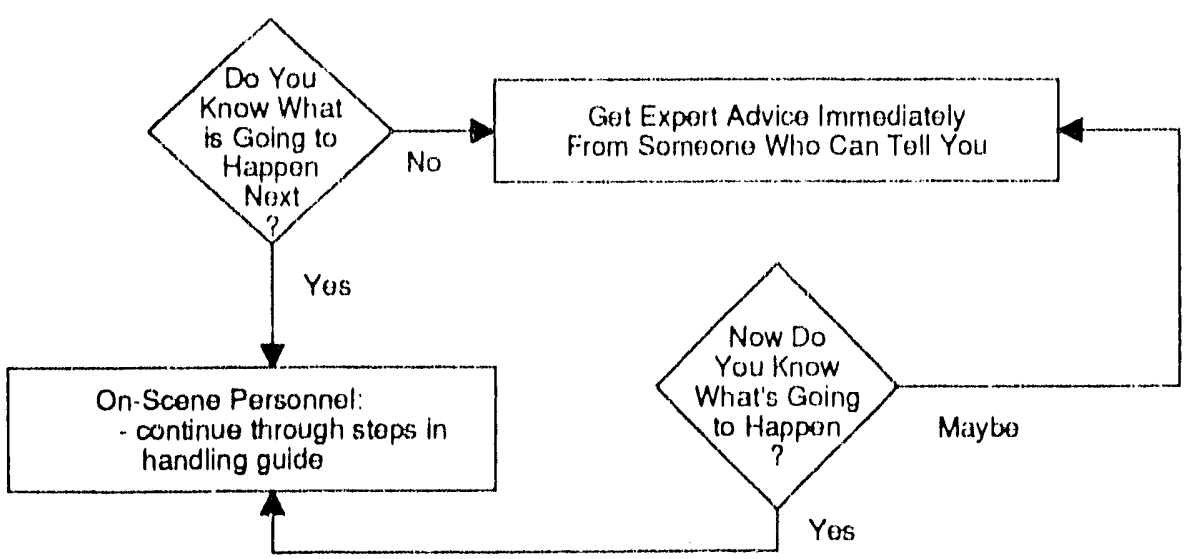

FIGURE 9 Decision Flowchart for Emergencies Involving Explosives "A" (Source: Chessie System Railroad, 1984) 
2. Ensure that civil responders are familiar with CHEMTREC and other information and assistance resources used by railroads. List these resources in emergency plans and procedures, and provide instructions for accessing them.

3. Carefully review waybills and shipping papers for all emergencles involving hazardous materials. This is particularly critical when placards are destroyed or otherwise unreadable, or when containers, trailers, or boxcars carry small shipments in multiple packages," (Under DO'T regulations placards are not required for some classes of hazardous materials if the individual shipment weighs less than 1000 pounds. For example, shipments of butane-filled, disposable cigarette lighters are often under this weight limit and can be deadly to emergency response personnel.)

4. Contact manufacturers and shippers for emergency response information and advice and to verify railcar contents. Waybills and shipping papers also contain the 24-hour telephone numbers at which manufacturers and shippers can be reached. Responders should telephone for more detailed assistance.

5. Develop the ability to obtain hard copies of CHEMTREC hazard information from mobile units. Advances in mobile communications and personal computers are making it increasingly cost effective for communities to join the Hazard Information Transmission program. Members can then access the CHEMTREC data base and obtain hard copies of hazard information. $\because$ modem. The hazardous matcrials response teams of large communities commonly use such mobile units, as do the state and county emergency services agencies that assist small communities with their response activities.

6. Obtain accurate meteorological data. Metcorological data used to estimate toxic cloud (plume) movements for airborne releases are generally obtained from central weather stations. However, when railyards are localed adjacent to rivers or other major natural features, wind velocity and direction at the emergency scene may differ from official readings for the metropolitan area. Railyard readings are the most useful.

7. Develop or use existing plume dispersion models for airborne releases. Some communities are experimenting with commercially available plume dispersion models (sec Secs. C.1 and E) that can be installed on personal computers. Outputs include overlays of the plume footprint on area, including railyard, maps. For small communities access to such models may be possible through state, county, or mulual-aid response organizations.

\footnotetext{
* Placards may also be incorrect. Il is not uncommon for shipping papers to be the sole source of information on ear contents. However, because shipping papers may also be incorrect (von lbsch, 1989), responders should excreise due caution and defer to higher authority if there is any question abotit car contents.
} 
8. Train emergency response personnel in the use of decision flowcharts. Flowcharts like the one in Fig. 9 can be very useful for identifying and verifying hazards and laying out effective courses of action.

\title{
G.2 Impact Assessment and Mitigation
}

Inspectors of other members of the yard crew gensally discover hazardous situations and perform the first assessment. At major railroads, these personnel are trained in basic techniques for identifying and assessing hazards, either as part of their regular safely training (sec Sec. F) or in addition to that training. Training should include a working knowledge of Emergency Action Guides and Emergency Handling of Hazardous Materials' in Surface Transportation (AAR). Both guides contain valuable information for assisting first responders in making preliminary appraisals of tank car and container damage, even when a release does not occur.

Note that appraisals by yard personnel are preliminary and should be limited to initial response actions. Such appraisals must be confirmed by a qualified expert on container damage becaluse (AAR, 1984, p. IV):

"The full assessment of the accidental damage suffered by a container of hazardous materials .. cspecially bulk containers such as tank cars, tank trailers, intermodal portable lanks and large cylinders ("ton containers") -- is a matter for experts. If there is any question about the continuing integrity of a lank, experts should make an examination before decisions aboul moving the lank or transferring its contents are made. Expertise is avalable from contaner manufacturers, some transportation companies, the Bureau of Explosives Association of American Railroadsl, and some shippers of dangerous products."

Similarly (AAR, 1989), p. 6.A):

\begin{abstract}
"The most treacherous damage that can oceur to tanks and other containers is that caused by bending, denting, scoring, or gouging without resultant leaks (emphasis added). T'ime, pressure, and handling can result in a delayed rupture. If this happens, there will almost always be ellough heal calused by the metal tearing to ignite lhe lank contents and causc ... |al| fireball."
\end{abstract}

One of the most dangerous situations of all can oceur when a lank car has been creased, that is, "... when the motal of a lank fnot on firel is so damaged that it has folded back on itself" (AAR, 1984, p. IV). Observed damage should immediately be reported to the appropriale railyard official and civil responders should be promptly notified of haxards. Responders should be trained to exercise extreme caution in any situation where damage assessment is highly uncertain. Factors not immediatcly measured or identified can significantly affect the degree of hazard. Such factors include the actual extent of the (AAR, 1989b, P.7-A) ".. damage to the tank itself, outside air temperalure, matcrial in the lank, its vapor pressure and the internal 
pressure in the tank. In a questionable situation, the best course is to withdraw onehalf mile, send for expert help and keep the tank cool."

Cases are on record in which the danger from accidents involving damaged lank cars appeared to be under control. Unexpectedly, serious releases occurred because of actions taken by responders who did not have expert advice on the extent of damage and the appropriate response (N'TSB, 1984).

Some railroads have obtained outstanding assessment and mitigation support from chemical companies participating in mutual-ald compacts. For example, one railroad reports that within minutes of a hazardous materials discovery, local chemical manufacturers sent chemical enginecrs and technicians with expertise and montoring equipment specific for the substance released. The preliminary analytical work, using equipment dispatched from a nearby fixed-storage facility, was covered by the mutual-aid agreement.

Incident assessment and reassessment continues throughout the emergency and recovery phases of a hazardous material incident. Upon arriving at the scene, the Incident Commander assesses the situation and selects an appropriate strategy for stabilizing and containing the hazardous matcrial. Stemming the leak, overpacking, and diking are common examples. Railroad personnel are asked to provide information on the hazard, explain what precipitated the emergency and what might affect its consequences, and describe any countermeasures that they have taken. To cnsure maximum possible coordination, the Incident Commander remains in continuous contact with the senior on-site railroad official to coordinate all emergency response activities.

The Incident Commander classifies the emergency according to how much fire and rescue support is needed (that is, local units only or local units supported by units from additional jurisdictions or other agencies). In many cases, the Incident Commander musi notify city or state emergency services agencies, which further classify the emergency according to the amount and kind of environmental release. For a given emergency, primary responsibility for assessment depends on whether the released matcrial is airborne or waterborne. Assessment is undertaken by emergency services agencies, assisted by cily or county public health, environmental monitoring, or water and sewer departments. Under most existing arrangements, detailed analyses to assess potential contamination of water, food, or other media (for example, soils around evacuated homes) are conducted under the auspices of these agencies. The costs are usually paid later by the railroad.

Some large communities are able to monitor toxic releases, determining how much was released, the concentration of the material in the transporting medium, and the speed and direction of movement. They are able to conduct contamination surveys and biological moniloring. They can also assess the safety of local food and water supplics. Gencrally speaking, however, these assessment activities require specialized equipment not readily available at the local level, they usually require the joint efforts of state or regional agencies. Railroad contractors are generally not 
asked to perform these analyses; however, they are asked to stand by so they can begin disposal and cleanup activities as soon as laboratory results are avallable.

Assessment provides the Inilial lactual basis for making protectlve action recommendations. Subsequent monltoring and reassessment provide the basis for deciding when recntry is safe and when mitigation and recovery actions can be terminated.

\section{Guidance}

1. Know the designated rallyard responder (by title, if not by name) and what hazard identification capabilities are in place at the rallyard. This information should be avallable in emergency preparedness plans as well as from carlicr contacts with railroad personnel.

2. Conduct incident and preliminary vessel damage assessiment to identify the hazardous materials involved and obtain complete information on their characteristics as soon as possible. Never assume that the emergency is over because no release has occurred.

Even if a release has not occurred, assessing container damage is critical. The personnel involved may fiecl relieved and lucky that no release oceured and that the emergency is over. However, dents and gouges that appear minor can lead to catastrophic containcr failure. The danger can be particularly serious if the lank, eylinder, or railcar is pressurized.

3. Consult with the designated responder or other qualified railyard personnel. The designated responder at the railyard has specialized information and expertise that can supplement the training and experience of civil responders. The Incident Commander should have the benefit of that expertise. For example, the dedicaled responder may be able to supply additional resources, specialized advice on company and industry capabilitics and cochnical procedures, and manpower for mitigation and recovery activilics.

4. Provide civil responders with complete information on the emergency situation and a roster of railroad and other privatesector personnel available and qualified to assist in mitigation and recovery activities. Section 2.4 includes a list of the emergency information to be provided. The rersonnel rosier should include local personnel and the estimaled arrival limes of (a) personnel coming from outside the local area for example, members of the company's hazardous matcrials response team); (b) specialists. 
including damage assessment experts, from the Bureau of Explosives of the AAR; and, if applicable, (c) members of shipper response teams.

5. Provide civil responders with an up-to-date inventory of emergency equipment and supplies stored at the railyard or available via agreements between the railroad and outside contractors. The inventory should state the source and location of each itcm and how quickly it can be brought to the scene.

6. Recognize the dangers of railcars with "residue" placards. These railcars should be treated with great care, as the residual product (heel) can be as much as threc percent of the capacity of the tank car which represents several hundreds of gallons of product. 


\section{H EMERGENCY PREPAREDNESS AND RESPONSE TRAINING}

The following discussion focuses on training. It is intended to summarize the guidance recommendations for training in specific functional areas that are found throughout this document, as well as to provide additional guidance on the general content and process of training for hazardous materials emergencies in railyards. Readers are reminded that implementing this guidance will require training of managerial and supervisory personnel, followed by training of operations personnel. That training may be informal and limited or formal and extensive, depending on the nature of the individual guidance item.

Table 5 lists purposes or tasks by functional area and activity. As a summary of the training aspects of this document, Table 5 also provides the information needed to develop a comprehensive training course for railyard emergency preparedness improvement. Such a course could be developed by one or more of the following: the AAR, the CMA, FEMA, and the DOT. Alternatively, individual railroads can use the information in the table to develop training programs in support of the guidance items they decide to implement.

\section{H.1 Training Content}

Most railroads provide some form of hazardous materials preparedness training, much of it informal. Training materials include instructional booklets, emergency response guidebooks, videotapes, and slide shows. Although some of the materials are orienled more toward safety than emergency response, they do emphasize the close relationship between the two. Training programs are usually limited to railroad personnel; however, individual sessions dealing with emergency response are sometimes offered to civil responders. Refresher training is generally provided at least annually, often using the same instructional materials.

Most major railroads provide comprehensive, rigorous, and frequent training to their key emergency response personnel. Often, these individuals are sent to outside training courses offered by such organizations as Texas A\&M University (College Station, TX), Louisiana State University (Industrial Fillemen Training Program, Baton Rouge, LA), the AAR (Transportation Test Center, Pucblo, Colorado), FEMA (National Emergency Training Center, Emmitsburg, Maryland), EPA, and various state firc training programs.

Most major railroads also provide a wide range of training activitics to their mechanics, engincers, train crews, and yard employecs. Many railroads have developed excellent safety training courses using videotapes, slide shows with scripts and related workbooks, real lank cars, flowcharts of response measures, and instruction booklets. Some of the visuals have informative captions added; others use instant replays or written quizzes to reinforce major points. Although the emphasis is usually not on railyards, courses typically include railyard situations in conjunction with such topics as safe rerailing and minor repairs of tank cars. Subjects commonly covered include prevention, appropriate response (for example, kecping hazardous matcrials contained in tank cars), train consist rules, pulling and spotting rules for railcars containing hazardous materials, proper documentation of 
TABLE 5 Training Useful for Implementing this Guidance

\begin{tabular}{|c|c|c|c|}
\hline $\begin{array}{c}\text { Training Purpose } \\
\text { or Task }\end{array}$ & $\begin{array}{c}\text { Functional Area } \\
\text { Activity }\end{array}$ & $\begin{array}{l}\text { Section } \\
\text { of } \\
\text { Guidance }\end{array}$ & $\begin{array}{l}\text { Guidance } \\
\text { Item } \\
\text { (Page) }\end{array}$ \\
\hline & $\begin{array}{l}\text { Roles and } \\
\text { Responsibilities }\end{array}$ & & \\
\hline $\begin{array}{l}\text { Performing effectively as railyard- } \\
\text { community planning liaisons }\end{array}$ & -Planning & A. 2 & (p. 21$)$ \\
\hline $\begin{array}{l}\text { Performing effectively as railyard- } \\
\text { community response liaisons }\end{array}$ & $\begin{array}{l}- \text {-Response Coordination } \\
\text { and Direction }\end{array}$ & A. 3 & (p. 23 ) \\
\hline \multirow[t]{2}{*}{$\begin{array}{l}\text { Performing assigned preparedness } \\
\text { roles effectively }\end{array}$} & $\begin{array}{l}- \text { Response Coordination and } \\
\quad \text { Direction }\end{array}$ & A. 3 & (p. 23 ) \\
\hline & Planning Analyses & & \\
\hline $\begin{array}{l}\text { Using lists of railyard hazardous } \\
\text { materials }\end{array}$ & --Hazard Analysis & B.1 & (p. 28$)$ \\
\hline $\begin{array}{l}\text { Using automated hazard information } \\
\text { systems }\end{array}$ & --Hazard Analysis & B.1 & $($ p. 28$)$ \\
\hline $\begin{array}{l}\text { Promptly identifying and } \\
\text { implementing classification levels } \\
\text { and action guidelines }\end{array}$ & --Emergency Classification & B. 2 & (p. 31$)$ \\
\hline \multirow[t]{2}{*}{$\begin{array}{l}\text { Using response decision making } \\
\text { charts }\end{array}$} & --Emergency Classification & B.2 & (p. 31$)$ \\
\hline & $\begin{array}{l}\text { Resource Acquisition } \\
\text { and Deployment }\end{array}$ & & \\
\hline $\begin{array}{l}\text { Developing specialized hazardous } \\
\text { material response leam }\end{array}$ & & $\mathrm{C}$ & $2^{2^{a}}$ \\
\hline $\begin{array}{l}\text { Using computerized information } \\
\text { systems (e.g., CAMEO and ICARIS) }\end{array}$ & $\begin{array}{l}\text {--Hazard Information } \\
\text { Systems }\end{array}$ & C. 1 & $\left(2^{b}\right.$ \\
\hline $\begin{array}{l}\text { Activating and using on-scene } \\
\text { command post and off-site } \\
\text { emergency operations center }\end{array}$ & $\begin{array}{l}\text {--Emergency Operations } \\
\text { Facilities }\end{array}$ & C. 2 & $\begin{array}{l}1,2,3 \\
(\text { p. } 4())\end{array}$ \\
\hline
\end{tabular}


TABLE 5 (Cont'd)

\begin{tabular}{|c|c|c|c|}
\hline $\begin{array}{c}\text { Training Purpose } \\
\text { or Task }\end{array}$ & $\begin{array}{c}\text { Functional Area } \\
\text { Activity }\end{array}$ & $\begin{array}{l}\text { Section } \\
\text { of } \\
\text { Guidance }\end{array}$ & $\begin{array}{l}\text { Guidance } \\
\text { Item } \\
\text { (Page) }\end{array}$ \\
\hline & $\begin{array}{l}\text { Resource Acquisition } \\
\text { and Deployment }\end{array}$ & & \\
\hline $\begin{array}{l}\text { Using a radio band dedicated to } \\
\text { emergency communications }\end{array}$ & $\begin{array}{l}\text {-Emergency } \\
\text { Communications }\end{array}$ & C. 3 & $\begin{array}{c}3,4 \\
(\text { p. } 42)\end{array}$ \\
\hline $\begin{array}{l}\text { Classifying personal protective } \\
\text { equipment by EPA categories A-C }\end{array}$ & $\begin{array}{l}\text {-Equipment Inventories } \\
\text { and Classification }\end{array}$ & C. 4 & $\begin{array}{c}1 \\
\text { (p. } 43)\end{array}$ \\
\hline $\begin{array}{l}\text { Ensuring readiness of facilities and } \\
\text { equipment }\end{array}$ & $\begin{array}{l}\text {--Inspection and } \\
\text { Maintenance }\end{array}$ & C.5 & $\begin{array}{l}1,2,3 \\
(\text { p. } 44)\end{array}$ \\
\hline \multirow[t]{2}{*}{$\begin{array}{l}\text { Ensuring sufficient railyard water } \\
\text { supplies for firc-fighting }\end{array}$} & --Water Supplies & C. 6 & $\begin{array}{c}1,2 \\
\text { (p. } 45)\end{array}$ \\
\hline & Alertand Notification & & \\
\hline $\begin{array}{l}\text { Promptly and effectively alerting } \\
\text { the public }\end{array}$ & - Alert & D. 1 & (p. 46) \\
\hline \multirow[t]{2}{*}{$\begin{array}{l}\text { Promptly and effectively notifying } \\
\text { response organizations }\end{array}$} & --Notification & D. 2 & $\begin{array}{c}2-8 \\
(p p .51-52)\end{array}$ \\
\hline & Protective Actions & & \\
\hline $\begin{array}{l}\text { Using CAMEO, ICARIS, and CERIS } \\
\text { computer systemIs }\end{array}$ & --Decision Making & E.1 & $\left(\begin{array}{l}1 \\
(\text { p. } 59)\end{array}\right.$ \\
\hline $\begin{array}{l}\text { Selecting and implementing } \\
\text { evacuation or sheltering }\end{array}$ & $\begin{array}{l}\text {--Decision Making } \\
\text {--Evacuation and Protecting- } \\
\text { in-Place }\end{array}$ & $\begin{array}{l}\text { E.1 } \\
\text { E. } 2\end{array}$ & $\begin{array}{c}4,5^{b} \\
(p .60) \\
1,2^{b} \\
(p p .61-62)\end{array}$ \\
\hline Effectively implementing recntry & - Recntry & E.3 & $\begin{array}{c}2 \\
(\text { p. } 63)\end{array}$ \\
\hline
\end{tabular}


TABLE 5 (Cont'd)

\begin{tabular}{|c|c|c|c|}
\hline $\begin{array}{c}\text { Training Purpose } \\
\text { or Task }\end{array}$ & $\begin{array}{c}\text { Functional Area } \\
\text { Activity }\end{array}$ & $\begin{array}{c}\text { Section } \\
\text { of } \\
\text { Guidance }\end{array}$ & $\begin{array}{c}\text { Guidance } \\
\text { Item } \\
\text { (Page) }\end{array}$ \\
\hline & Responder Safety & & \\
\hline $\begin{array}{l}\text { Effectively using responder safety } \\
\text { resources }\end{array}$ & --Resources & F.1 & $\begin{array}{c}3-7 \\
(\text { pp. } 71-72)\end{array}$ \\
\hline $\begin{array}{l}\text { Effectively using responder safety } \\
\text { procedures }\end{array}$ & $\begin{array}{l}\text {--Standard Operating } \\
\text { Procedures }\end{array}$ & F.2 & $\begin{array}{c}2-11 \\
(p p .75-76)\end{array}$ \\
\hline $\begin{array}{l}\text { Effectively using responder safety } \\
\text { procedures }\end{array}$ & $\begin{array}{l}\text {-Operating Procedures } \\
\quad \text { for Rail Yards }\end{array}$ & F.3 & $\begin{array}{c}1-4 \\
\text { (p. } 84)\end{array}$ \\
\hline & Incident Assessment & & \\
\hline Using basic references & --Information and Resources & G.1 & (p. 186$)$ \\
\hline $\begin{array}{l}\text { Carefully reviewing waybills and } \\
\text { shipping papers }\end{array}$ & --Information and Resources & G.1 & (p. 88$)$ \\
\hline Using response action flowcharts & --Information and Resources & G.1 & (p. 89 ) \\
\hline $\begin{array}{l}\text { Conducting preliminary incident } \\
\text { and vessel damage assessment }\end{array}$ & $\begin{array}{l}\text {-Impact Assessment and } \\
\text { Mitigation }\end{array}$ & G.2 & (p. 91$)$ \\
\hline $\begin{array}{l}\text { Recognizing the danger of "empty" } \\
\text { tankcars }\end{array}$ & $\begin{array}{l}\text {--Impact Assessment and } \\
\text { Mitigation }\end{array}$ & G.2 & (p. 92$)$ \\
\hline $\begin{array}{l}\text { Developing an objective-based } \\
\text { exercise evaluation system }\end{array}$ & Preparedness & I & $\begin{array}{c}4,6 \\
\text { (p. } 106)\end{array}$ \\
\hline & $\begin{array}{l}\text { Public Education and } \\
\text { Risk Communication }\end{array}$ & & \\
\hline Providing effective public speakers & -Public Education & J. 1 & (p. 108$)$ \\
\hline $\begin{array}{l}\text { Providing an effective official } \\
\text { spokesperson }\end{array}$ & --Emergency Communications & J. 2 & $\begin{array}{l}7 \\
\text { (p. } 111)\end{array}$ \\
\hline
\end{tabular}


TABLE 5 (Cont'd)

\begin{tabular}{|c|c|c|c|}
\hline $\begin{array}{l}\text { Training Purpose } \\
\text { or Task }\end{array}$ & $\begin{array}{c}\text { Functional Area } \\
\text { Activity }\end{array}$ & $\begin{array}{l}\text { Section } \\
\text { of } \\
\text { Guidance }\end{array}$ & $\begin{array}{c}\text { Guidance } \\
\text { Item } \\
\text { (Page) }\end{array}$ \\
\hline & $\begin{array}{l}\text { Public Education and } \\
\text { RiskCommunication }\end{array}$ & & \multirow{4}{*}{$\begin{array}{l}1 \\
\left.\text { (p. }{ }^{110}\right) \\
5 \\
\left.\text { (p. }{ }^{111}\right) \\
6 \\
\text { (p. } 111)\end{array}$} \\
\hline Using pre-scripted messages & --Emergency Communications & $\mathrm{J} .2$ & \\
\hline Developing a rumor-control system & --Emergency Communications & $\mathrm{J} .2$ & \\
\hline $\begin{array}{l}\text { Conducting door-to-door emergency } \\
\text { notification }\end{array}$ & --Emergency Communications & $\mathrm{J} .2$ & \\
\hline $\begin{array}{l}\text { Conducting post-incident } \\
\text { documentation and followup }\end{array}$ & $\begin{array}{l}\text { Post-Incident } \\
\text { Documentation }\end{array}$ & $\mathrm{K}$ & (p. $\stackrel{1}{112)}$ \\
\hline
\end{tabular}

a Item 5 in list of typical resources in overview discussion.

b Also preceding overview discussion. 
hazardous materials, and emergency response procedures. Instructional materials come from a varicty of sources. Some are produced in-house; others are obtained from other railroads; still others are obtained from commercial sources (for example, videotapes dealing with specific chemical groups, as discussed in Sec. F.1). Instructional matcrials are often made available to other railroads and could be distributed through the AAR or the American Short Line Railroad Association. Videotapes are also available through lending libraries or information services affiliated with the CMA, the AAR, the American Short Line Railroad Association, and FEMA. * Wider use of these matcrials, particularly by small railroads that do not have emergency plans, could greatly improve the safety of railyard employecs and adjacent communities.

Relatively few training materials focus specifically on emergency response in yard situations. The Operation EYE program discussed in Sec. F.3 is unique in this regard. In addition to the videotape Employees in Yard Emergencies, this program includes written excreises that reinforce the main points of the video, as well as provide additional information. For example, one excrcisc (Atchison, Topeka, and Santa Fe Railway Company, undated) lists a number of events as signaling that an emergency is taking place or is probable during the switching of a long string of railcars containing hazardous materials. The instructor then explains why such events are problems.

AAR's two guidcbooks, Emergency Action Guides and Emergency Handling of Hazardous Materials in Surface Transportation, are another important source of training materials. As discussed in detail in Sec. F.1, both contain important safety, first aid, and cmergency response information. In training programs for railyard employees, the emphasis should be on how to use the guidebooks to identify the type of initial response required for each chemical group. Specific responses can then be related to the types and degrecs of tank damage, both of which are discussed extensively in the guidebooks.

Some major railroads have devised new safety measures and expanded their training program, in response to recurring, dangerous situations. For cxample, following a number of emergencies involving intermodal shipments which were improperly blocked and braced by shippers, one railroad began inspecting ai! placarded containers. After a near-injury caused by cargo falling out as containers were opened for inspection, the railroad joined with an equipment supplier to design a container safety belt clip that protects personnel during the opening of such containers. Personnel were quickly and easily trained to install and use the new equipment.

Innovative solutions to dangerous problems descrve to be shared with other railroads; so should lessons learned and associated information about preparedness training, planning, and cquipment. To do so, an information exchange system should be established, either by the hazardous materials control officers of major railroads or in conjunction with existing nationwide systems. Onc such system, HMIX, is operated by FEMA and DOT. Frec to anyone with a personal computer, HMIX now has more than 11,000 users and could be expanded to include a filc on mainline and

\footnotetext{
*HMIX, which may be accessed via modem from a personal computer, contains a comprehensive listing of videotapes and other training materials. To join the exchange, call 1-800)-PLAN FOR.
} 
railyard emergencies. Note, however, that HMIX is not intended to be a response tool. HMIX also contains information about current training events and federal agency training courses relevant to hazardous materials emergencies. Some of these courses are offered free of charge or at nominal cost.

Almost without exception, training of emergency responders in large communities is continuous. Firc runs occur daily, with the specific circumstances of each case being slightly different. Communications exercises and actual 911 calls regularly test the ability to quickly dispatch appropriate assistance to geographically distant locations. Nevertheless, existing guidance and local officials strongly favor supplemental training for responding to emergencies involving hazardous materials. Supplemental training ranges from informal instruction to rigorous certification courses. In general, the larger the community, the more emphatic is the support for intense training.

Most communitics are in the process of upgrading local awareness and the skills and capabilities of designated responders. Local response officials widely acknowledge the usefulness of videotapes and other instructional materials developed by the CMA, the AAR, and communities with experience in responding to hazardous materials emergencies. Alexandria, Virginia, and Houston, Texas, for example, have produced outstanding training materials. In many communitics, firefighters regularly attend awareness and training sessions on hazardous materials offered by chemical manufacturers and railroads with nearby railyards. Some of these sessions use mobile consists of tank cars that vary in design and problem condition to teach trainees how to close leaking valves and patch small holes quickly and effectively, while paying strict attention to the dangers posed by the substances involved.

Similarly, the fire department in Alexandria, Virginia, has developed a training program specifically for dealing with hazardous materials emergencies at its Potomac railyard. It is an inexpensive program geared to conditions and operations at particular locations within that railyard, although the approaches could be adapted to other yards. Training sessions are conducted for fire department battalion commanders and communications personnel, primarily dispatchers. Overhead projector transparencies are used to show a varicty of damage profiles superimposed over images of the sides of tank cars. Simple coloring and shading patterns using ordinary sand produce realistic pictures of hazardous situations (for example, fires and releases of toxic liquids or gascous clouds). Following the visual displays, trainecs are presented with a series of simulated situations using maps of the railyard and nearby strects and required to deploy communications and other equipment, supplies, and response personnel.

Such simulated emergencies are often characterized as fast-breaking to stress the importance of rapid but thoughtful decision making and action. The training is designed to enhance these skills. Integrating railroad and community training exercises that are both innovative and well rehearsed into joint exercises emphasizing coordination and cooperation among the various responders is likcly to be extremely valuable.

The safe handling of damaged railcars is an important component of virtually all training programs. However, not all programs emphasize that railcars identified 
on waybills and in consist descriptions as "residue" should also be treated with great care. For example, in 1985 at the Conrail railyard in Elkhart, Indiana, a tank car labeled "empty" in accordance with DOT regulations at that time leaked much of its residual lading of 800 gallons of hydrogen fluoride. This toxic and corrosive material formed a cloud of vapor that traveled 2.5 miles. One thousand five hundred people were evacuated, and 75 people were hospitalized for minor skin and eye irritations. Following this incident, DOT issued a new rule requiring that a "residue" placard be used on tank cars with quantities up to three percent of volumetric capacity (NTSB, 1985b).

\section{Guidance}

1. Familiarize fire and rescue personnel with railyard layout, access points, and possible points of entry, the railroad's SOPs for handling involved railcars, and railroad information and response resources and capabilities.

2. Take advartage of available courses and other training resources. Assemble a library of videotapes on hazardous materials emergency response for training both railyard and community emergency response personnel. Many available videotapes are relevant to or deal specifically with railyard emergencies. Most can be borrowed at no cost, or leased or purchased at very low cost. Such tapes should serve as the cornerstone of training throughout the local emergency response network.

3. Instruct personnel in the proper use of basic references (for example, waybills, shipping papers, the Emergency Action Guides, and Emergency Handling of Hazardous Materials in Surface Transportation). Emphasize the importance of efficiently locating information on specific chemicals and assessing damage to containers as an indication of current or future hazard.

4. Conduct incident and preliminary vessel damage assessment training that stresses the importance of identifying the hazardous materials involved and obtaining complete information on their characteristics as soon as possible. Such training should also stress that, if a tank car or other container has been damaged, it can be dangerous for responders to assume that the emergency is over because no release has occurred. (Sec Sec. G.2)

5. Educate railyard personnel, train crews and civil responders about the dangers of railcars with "residue" placards. These railcars should be treated with great care, as the residual product (heel) can be as much as three percent of volumetric capacity of the tank car which represents several hundreds of gallons of product.

6. Use the Emergency Action Guides and Emergency Handling of Hazardous Materials in Surface Transportation to supplement training materials. The introductory sections of both guidebooks 
contain practical information about responding to hazards in railyards.

7. Railroads and communities should take advantage of courses offered by nearby firefighter training academies, universities, colleges, and similar institutions. Send at least one senior fire official or training officer to a railroad based training course. These individuals should then use the knowledge gained to prepare training sessions for other responders. The courses should be based on FEMA, CMA, DOT, and AAR training curriculums.

8. Obtain training materials from railroads and communities with superior emergency training programs, for example, Alexandria, Virginia, and Houston, Texas. Investigate the possibility of enrolling personnel in courses offered by these cities.

9. As part of training sessions, conduct initial tabletop drills to verify workers' understanding of their roles and responsibilities, and to test their ability to perform assigned tasks. Stress tcamworkcriented periodic drills to practice emergency response skills and procedures.

\section{H.2 Training Process}

For most railroads and communitics, emergency worker training is ongoing and continuous. Particularly in larger communities, some responders may be attending classes, vicwing vidcotapes, or undergoing other types of training virtuaily all the time. Training programs tend to be more formalized in larger railroads and communitics.

Training sessions are sometimes conducted jointly for railroad and local civil responders. In joint sessions, each organization has the opportunity to learn about the responsibilities, skills, and limitations of the other. Because of resource limitations, employecs of small railroads are particularly likely to sit in on training sessions for local civil responders.

As with all types of training, responders should be periodically retrained to refresh their memories and update their skills. The instruction received by each responder should also be recorded by topic and type (for example, videotape, videotape followed by oral questions, or classroom instruction followed by written examination). An individual should be assigned responsibility for ensuring that training sessions are available and for monitoring the progress of participants, especially if certification is an objective.

For all training activities, railroads and communities should use trainers and materials that are as dynamic as possible. 
Dynamic trainers and materials are essential because the safety of railroad employees, civil responders, and the public depends on effective training. Community responders observe that, except for the sensational parts of videotapes, trainecs casily become bored. Thus, shorter, more dramatic videotapes may be advisable.

Other means can be used to dramatize the importance of safety and proper response to emergencies. To remind his yard employecs to use safe practices, the hazardous materials control officer of one small railroad has two pictures of tank cars exploding into fireballs prominently displayed in his command center in the railyard tower.

Training can also be improved through planning for and participating in carefully designed emergency preparedness excreises highlighting real problems that can be solved using available skills and resources. Although all railroads recognize the need for hands-on training in occupational skills (for example, the repair of tank cars), some remain unconvinced that comparable training -- via fullscale railyard excreises -- is needed to demonstrate emergency response skills (see Sec. 2.9). For maximum effectiveness, excrcises used to practice skills and teamwork should be conducted regularly.

Joint exercises are extremely valuable for practicing teamwork, both internally among railroad or community cmployecs and extcrnally with other response participants. In an emergency, railyard and train crew members, as well as communicators, supervisors, enginecrs, mechanics, and hazardous matcrials specialists, can become involved almost instantly. They are responsible for a wide range of activities, including identifying and assessing the situation, notifying railroad and community officials, administcring first-aid, initiating mitigation measures, and recommending and implementing actions to protect the public.

\section{Guidance}

1. Evaluate existing training programs. Where gaps exist, develop programs and materials to supplement and enhance available resources. Emphasize the importance of efficicntly locating information on involved chemicals, assessing container damage, and minimizing worker and responder exposure to these hazards.

2. Designate (by title) the individual responsible for emergency worker training. In addition to developing appropriate training materials, his/her responsibilities should include recordkecping and monitoring the progress of trainecs, especially if certification is an objective. 
3. Create opportunities for railyard personnel to train with firefighters and other civil responders, and encourage railroad participation. Involve local railyard personnel in training sessions, and invite railyard officials and staff to participate in joint training. Note that training schedules should be flexible and sessions should explicitly address railyard conditions (for example, by using railroad-produced training programs) if railroad personnel are to actively participate.

4. If possible, have railroad officials conduct training sessions on railroad and railyard safety. Rail operations have their own unique set of hazards and the railroads spend a lot of time training their own employees in how to work safely around those hazards. During an emergency or inspection, such training helps ensure the safely of both railroad and non-railroad personnel.

5. Conduct critiques following all actual or simulated emergencies (exercises). These critiques should be an integral part of the overall response to actual emergencics. The lessons learned should be identificd as soon as possible, as should new ideas about planning, training and equipment.

6. Establish an information exchange mechanism to share lessons learned from actual and simulated emergencies. Information could be entered into an casily accessible computer file, such as HMIX, along with recommendations on planning, training, and equipment.

7. Acquire dynamic trainers and use dramatic materials for emergency preparedness training. Lively instructors and dramatic materials maximize traince interest, provide memorable learning cxperiences that increasc the amount of information retained, and minimize boredom. The library of training videotapes recommended above can provide some of these visually dramatic materials. 


\section{EMERGENCY PREPAREDNESS EXERCISES}

Although training courses are valuable, the best training activities combine course work with drills and exercises. Drills and exercises provide the opportunity to practice specific skills and procedures learned in training, as well as a means of testing emergency preparedness plans. When conducted jointly by a railyard and its adjacent community, drills and excrcises provide valuable opportunities to practice teamwork, both internally among railroad or community personncl and externally with other response organizations.

Railroads and communities should conduct more internal, teamworkoriented exercises. The focus should be on improving emergency response skills and coordination. Joint exercises with other response organizations should follow.

Most railroads that transport hazardous matcrials and most community response agencies favor testing emergency preparedness plans (sec also Sec. H). However, hazardous materials excrcises are far more likely to be conducted by communities than by railroads, and by larger railroads rather than smaller ones. Jarger railroads are also far more likely to have developed guidelines for the safe conduct of hazardous materials exercises. Generally speaking, periodic drills and tests of components of a hazardous materials emergency response (that is, functional exercises) are far more common ihan full-scale exercises.

Although relatively few joint exercises have been conducted, their number has been increasing since the fall of 1987. Railroads have had mixed reactions to them. A common complaint among railroad participants is that joint cxercises have often tested plans that do not fully incorporate railroad needs and expertise. Some railroads go further, describing the plans as more appropriate for manufacturers of hazardous materials or as generally unrealistic and poorly conceived or developed.

Community response agencies, on the other hand, appear relatively pleased with their exercise experiences. Many communities have held hazardous materials exercises, both internally and in conjunction with outside organizations. Exercises have ranged $f r=m$ partial tabletop efforts to full-scale tests of joint iailroad and community capabilities or area mutual-aid systems. Communitics expect more tabletop, partial, and full-scalc exercises to be undertaken because of SARA, Title III, and other state and federal requirements. The quality and usefulness of those exercises should be greatly enhanced by the recently relcased guidance Developing $a$ Hazardous Materials Exercise Program: A Handbook for State and Local Officials, (National Responsc Team, Scpt. 1990).

At present, however, railyard exercises do not appear to have high priority, possibly because of the cost and difficulty of justifying them in the absence of formal commitments to conduct them regularly. Clearly, there is a need for more widespread commitment to regular exercises. The best place for making such commitments is in an integrated emergency planning document. The most successful plans authorize a 
specific official or full-time response group to oversee exercise development and execution and to ensure that all affected parties are committed to regularly scheduled exercises.

Alternatively, commitments to regular exercises could be made a condition of participation in regional mutual-aid compacts. In other words, those who agree to provide and accept equipment, materials, and expertise in emergencies also agree to help develop and participate in regular exercises. For example, the 84 member organizations of the Houston Channel Industries Mutual-Aid Organization must participate in all practice drills of the organization, as a condition of membership (FEMA and DOT, 1986).

There is also a need for careful planning. During the planning stage, participants should establish rigorous objectives for the exercise. This step makes the exercise experience more rewarding and effective. In recent years, FEMA has planned and conducted hundreds of exercises to test the off-site radiological emergency preparedness plans and capabilities of state and local response agencies for individual commercial nuclear power plants. Each of those exercises was designed around specific objectives. Responding to radiological emergencies is similar in many respects to responding to other emergencies involving technological hazards; therefore, establishing clear objectives for emergency preparedness excrcises applies equally well to railyard emergencies involving hazardous materials.

During the planning stage, participants should also establish criteria for evaluating the exercise. An cvaluation system should be developed, evaluators should be field trained, and evaluation checklists should be prepared well in advance of the exercise. FEMA has developed objective-based criteria for evaluating hazardous materials preparedness exercises which could provide valuable assistance to cxercise participants (FEMA, 1989).

\section{Guidance}

1. Conduct an initial tabletop exercise to determine whether those responsible for responding to emergencies involving hazardous materials fully understand their roles las described in the emergency preparedness plan) and can ierform them adequately. Participants should also be questioned to further explore how well they understand what the plan requires of them or their operation. Large railroads with widespread operations may need to decide at which particular railyards and local communities the exercises should take place and in what order.

2. Designate (by title) a specific official or group responsible for developing a program of regularly scheduled exercises. That individual or group should also be responsible for setting exercise objectives and establishing an exercise evaluation system. 
3. Establish guidelines for participating in safe joint exercises. Railroads should establish guidelines for participating in joint exercises and then share them with adjacent communities.

4. Use exercise results to help determine whether emergency preparedness plans or training programs and materials need revision. Periodic updating may also be needed in response to changes in emergency capabilities and responsibilities, or changes in plant and railyard operations and infrastructures.

5. Include all major public- and private-sector participants in exercise planning. Exercise results may be misleading if any of the important participants were excluded from formulating the exercise scenario. The NRT's exercise handbook, Developing a Hazardous Materials Exercise Program: A Handbook for State and Local Officials, provides extensive guidance for planning, conducting and evaluating exercises.

6. Develop an exercise evaluation system that establishes objectives and determines whether they are met. The objectives should test the workability of the plan and the overall performance of participants, and should reflect local and site-specific needs. Evaluation systems are most effective when evaluation forms, designed in advance for each location tested, are used during the exercise. The forms help evaluators identify problem areas at the same time as they are determining which objectives are met.

7. Conduct a postexercise meeting to tell exercise participants which functions were performed well and what problems (if any) were found. The evaluation system should designate responsibility for follow-up to be sure that problems are indeed corrected. 


\section{J PUBLIC EDUCATION AND EMERGENCY INFORMATION}

Public education and the communication of emergency public information are key elements in the emergency preparedness plans of most large communities. These functions include (1) informing and instructing citizens in advance about what to do in cmergencies, (2) develcping and implementing methods and procedures for alerting the public, (3) notifying affected persons of necessary protective actions, and (4) briefing the media on the status of the emergency and ongoing response activities.

\section{J.1 Public Education}

Most large and many small railroads have effective community relations programs. Some provide speakers for schools, civic groups, and other organizations. The topics discussed include safety at crossings and other good-neighbor activities, as well as carcer opportunitics in railroading. Railroads handling large quantities of hazardous materials have recently begun to discuss issues associated with hayardous matcrials, often in conjunction with CAER and TRANSCAER outrach activities. Thesc programs inform the public about placards, their meaning and use, and how individuals can safely help identify leaks or other potentially hazardous situations.

Railroads do not generally prepare public information brochures relating 10 their railyards. Under SARA, Tille III, communities will be preparing emergency guidance for a wide varicty of hazardous matcrials risks, including those al railyards. Although communitics are responsible for disscminating this information, railroads can help in preparing it.

The risk information needed for the community brochures should be provided by railyards and other sources of risk. The brochures should explain notification procedures, provide instructions for each action level or emergency class, and discuss the basis for protective action decisions, such as sheltering and evacuation. Especially important are instructions for sheltering and cvacuation, and maps of alternative cvacuation routes. Finally, the publ:: information network, which might involve the railroad, should be described. Providing information of this type in advance increases public understanding of hazards and preparedness measures and thereby increases the ability of communities to protect the public by conserving time and effort.

Many small railroads have a long and proud tradition of good community relations. Because much of their business has come from shippers in small- 10 medium-sized towns, their sense of civic responsibility is correspondingly high. Providing advance information to the public about emergency response may significantly increase the emergency preparedness of small railroads and communities without extensive resources. They would otherwise lose valuable time and have to rely heavily, if not exclusively, on outside expertise and resources.

Most communitics recognize the importance of advance information and intend to identify community forums, provide speakers, and develop and distribute educational materials. However, only a few communities have made much progress in distributing advance information. Limited resources and the magnitude of the 
task are the major constraints. Communities having several railyards may also have hundreds of fixed facilities where hazardous substances are produced, processed, or stored. Any of these could be the site of a hazardous materials emergency that could threaten different neighborhoods. Each neighborhood may have unique information requirements and need different channcls of communication. Effective public information therefore requires comprehensive planning.

Some communities usc local telephone directories to (1) show designated evacuation routes (with the qualifier that the actual route selected must be based on metcorological and other conditions), (2) discuss possible emergency response actions like sheltering in place and evacuation, and (3) show the locations of shelters serving each geographic area. This approach has been most effective when backed up by prescripted messages requiring insertion of event-specific data.

\section{Guidance}

1. Provide public speakers. Public speakers should emphasize how important chemicals and other potentially dangerous substances are to maintaining our high standard of living. They should also stress that these matcrials are almost always transported safely. However, when such materials are cscaping from their containers (tank cars, cylinders, or drums) during transport, individuals can help by first recognizing the nature of the hazard and then promptly contacting railroad personnel or the fire department. Individuals should not take any personal risks.

2. Enhance public information efforts. In view of the far-reaching ramifications of SARA, Title III, railroads should cooperatc even more with the civil authorities in the communities adjacent their railyards. One way 10 do that is 10 participate in preparing public information brochures about the management of emergencies involving hazaidous matcrials. When just a few hazardous malcrials are regularly transported, the amount of information that must be communicated to and understood by the public is much reduced.

3. Inform persons likely to be affected by railyard emergencies involving hazardous materials well in advance about potential hazards and possible responses. Information malcrials should be prepared and distributed in advance, as part of the community's public information program. Local media representatives should also be told in advance what to expect, how $10 \mathrm{get}$ additional information, and what locations are off-limits during actual cmergencics.

\section{J.2 Communication of Emergency Information}

During railyard emergencics, the public information function is almost always conducted jointly. The railroad and the community usually coordinale their 
efforts at a media center established in an emergency operations center or at a separate location selected by the community responders.

Small railroads tend to have fewer prohibitions against railroad personnel other than the public information officer responding 10 media representatives. Clearer instructions for these personficl may be warranted.

Some communities have identified cerlain groups that must be informed and warned in an emergency, and have developed public notification procedures 10 meet their special needs. In some communities, warning messages are broadeast in English and Spanish. Local Spanish-language radio stations are used. In other communities, listeners are asked to inform hearing-impaired persons of the emergency message. Similarly, vicwers of televised emergency messages are asked to inform visually impaired persons.

To implement sheltering-in-place or evacuation beyond a specified distance from an emergency scenc, communities typically rely on sirens and public-address systems mounted on law enforecment vehicles that cruise the affected neighborhoods. For mobile notification activilies, few communities make special provisions for forcign-language notification or special methods for warning hearing-impaired persons. Also common is door-lo-door notification by local law enforcement officers. Voluntecrs, including railroad personnel, may be called upon to assist with door-10-door notification.

With the cooperation of local radio stations, some communities regularly test their emergency broadcast procedures. Such testing is provided for in emergency broadcast agrements between the communitics and the stations. However, most local radio stations are not covered by such formal agreements and are therefore not required to broadcast essential emergency information. Also, small communities generally do not have EBS agrecments in place. Some communities rely on community-access cable television channels. The problem here is that some community residents may not have acess to cable television and that others may seldom vicw it.

Essential emergency information needing 10 be broadcast includes (1) the area covered by the sheltering or cvacuation order, expressed in $10 \mathrm{rms}$ of neighborhood names or well-known landmarks; (2) instructions for safe sheltering in place; (3) instructions for properly sccuring a dwclling beforc cvacuation; (4) lists of clothing and supplics that cvacuecs should take along; (5) cvacuation routes to follow and routes or areas to avoid; and (6) designated reception and care shelters, including those with facilities for handicapped persons, non-Englishspeaking persons, and other special-needs populations.

Timely generation of the information to be contained in emergency broadeast messages requires advance planning, especially if the information is going 10 be easily understood. Unfortunately, however, few communitics have developed prescripted cmergency broadcast messages or standardized instructions for sheltering or evacuation for broadcast over mobile public-address systems. Typically, messages and instructions are written as needed. 
The chicf executive of the community is ultimately responsible for public information activitics. During major hazardous matcrials emergencies, however, the public information function is usually coordinated by the chicf executive's press officer or city clerk. For less serious emergencies, the public information officer of the fire and rescuc service may coordinatc public information activitics. Such coordination involves working with city departments and agencies, railroad employees, and other outside personnel. This individual also decides whether to establish a joint public information center (for example, with the railroad or regional, state, or federal authorities). Press bricfings are usually conducted and news releases distributed from a media center located close to the community's emergency operations center or, if established, from the joint public information center.

Some large communitics also provide for rumor-control programs in their plans. Gencrally speaking, rumor control programs develop and train rumor-control teams consisting of public information officers from cach of the involved community agencics and departments. Such leams are activated by a crisis management team composed of the heads of these same agencies and departments. The rumor-control teams forward all major rumors 10 the crisis management team.

Railroads do not establish independent public inquiry or rumor-control operations during an emergency. However, staff members often work with community public information officers to provide necded information, respond to questions about facts and rumors associated with the emergency, and reassure citizens.

If media representatives question railroad personnel working at the seene of an emergency, SOPs state that those representatives should always be referred to the railroad spokesperson at the media contact point. Only the public information officer will have a good grasp of the overall situation. His or her statements are much less likely to be misunderstood, and misunderstandings can hinder the response effort.

\section{Guidance}

1. Develop prescripted messages for various types of hazardous materials emergencies. Such messages save time and help cnsure that messages are clear, concise, and frec of unnecessarily alarming language.

2. Ask viewers and listeners to inform handicapped persons (especially those who are vision- or hearing-impaired) of the emergency and to pass along any needed information. Such assistance is especially necded in large communities because police or fire and rescuc personnel are less likely to know handicapped individuals personally. Some small communities also have large transient populations. In some others, persons from outside the local community are responsible for notification. 
3. If appropriate, broadcast warning messages in several languages. Local radio and telcvision stations, including those that broadcast in forcign languages, should be contacted and necessary arrangements made in advance. Procedures and scripts should be tested regularly to ensure that they will serve the intended purpose in an actual emergency.

4. Enter into formal EBS agreements with one or more local or regional radio and television stations, and ensure regular broadcast of test emergency messages. Such agrements ensurc timcly broadcast of accurate and complete emergency information. Regular broadcast of test messages helps cnsure that EBSs will function properly when needed.

5. Develop a rumor-control program and train participating personnel. An cffective rumor-control program greatly enhances overall response. The program should have a public information component because most people know little about the hazards of specific chemicals. Rightly or wrongly, they may equate a local accident with the severe accidents that $100 \mathrm{k}$ place at Bhopal and Chernobyl.

6. Develop plans and procedures for door-to-door notification of handicapped and foreign-language-speaking individuals during mobile public alerting activities. Who and where these individuals are should be known beforehand, preferably by means of written lists. Such plans and procedures help establish the special methods needed for notifying vision- and hearing-impaired individuals.

7. Provide for an official spokesperson. If a railyard is far from railroad headquarters, someone should be designated as the interim railyard spokesperson until the corporate public information officer arrives. The interim spokesperson should be authorized to act, if necessary, until the emergency is over, or at least beyond the point at which protective action recommendations are asked for by the Incident Commander. The designated spokesperson should be the only person at the scenc of the emergency authorized to respond 10 questions from media representatives. 


\section{K POST-INCIDENT DOCUMENTATION}

Railyard emergencies involving hazardous materials need to be documented, preferably by means of detailed chronological logs of activities and communications. Maintained by all response organizations until the recovery phase is complete, the logs constitute the paper trail that is essential when hazardous materials emergencies lead to legal proceedings. In addition, in the event of a very serious railyard emergency, the NTSB will probably investigate, taking depositions or testimony from all involved parties. Complete logs of all activitics will help participating organizations answer questions accurately and effectively.

The logs also serve as a valuable source of information for internal follow-up investigations. They provide information for post-response critiques and evaluations, and assessments of the overall effectiveness of the response. They also help to identify needs for additional planning or training to better protect responding personnel and the public. Railroads sometimes use self-criticism after emergencies to improve training and modify safety equipment (sec Sec. $H$ ). Even when they do not result in new equipment, training changes, or revised emergency preparedness measures, the lessons learned from previous emergencies increase local awareness and emergency preparedness.

Although large railroads and communities are more likely to have the resources to document emergencies, all railroads and communities document them to various degrees. In larger organizations, responsibility for cstablishing and maintaining these logs is often assigned to specific personnel, by position title.

\section{Guidance}

1. Keep chronological logs of conversations held and activities undertaken during emergency and recovery phases. Both railroads and communities should keep logs of communications and activities to assist subsequent investigations and legal proceedings. Large railroads and communitics should assign responsibility, by position title, for kecping chronological logs that are as specific and detailed as possible. The logs should detail actions taken and agreements and commitments made during conversations with other partics, including outside contractors, emergency responders, and officials of other organizations (see Sec. H).

2. Establish procedures and assign responsibilities for post-incident documentation and investigative follow-up. Communitics adjacent to railyards should make such activities part of their SOPs. 


\section{REFERENCES}

Alexandria, Virginia, Fire Department. S.O.P. [Standard Operating Procedure] 18 -Potomac Yards, Alexandria, Virginia, revised July 1, 1984.

Association of American Railroads. Emergency Action Guides, P.C. Conlon and A.M. Mason, eds., Washington, D.C., periodically revised, 1984.

Association of American Railroads. Hazardous Materials Emergency Response Plan Guidance Document for Railroads, prepared for the Federal Railroad Administration, Contract No. DTFR53-81-C-00238, Washington, D.C., March 1989a.

Association of American Railroads. Emergency Handling of Hazardous Materials in Surface Transportation, Washington, D.C., Fcb. $1989 \mathrm{~b}$.

Atchison, Topcka, and Santa Fe Railway Company. Operation EYE -- Employees in Yard Emergencies, videotapc, Chicago, undated.

Atchison, Topeka, and Santa Fe Railway Company. Training quiz, Chicago, undated.

Brooks, A. Federal Railroad Administration, Office of Safety, material presented at Regional Directors Mecting, Washington, D.C., Oct. 1986.

California Public Utilities Commission. Motion of the Safety Division to Adopt General Order 161, OIR 88-07-039, May 1991.

Chemical Manufacturers Association. Community Awareness and Emergency Response Program Handbook, Washington, D.C., April 1985.

Chemical Manufacturers Association. Conference Reinforces Need to Integrate CAER, Title III, CAER, Community Awareness and Emergency Response and Tille III Activities, newsletter, Washington, D.C., May 1989.

Chemical Manufacturers Association. LEPCs and Sites Find Drills Do More Than Test Plans, CAER, Community Awareness and Emergency Response and Title III Activities, newsletter, Dec. 1990 - Jan. 1991.

Chemical Manufacturers Association and Association of American Railroads. Recommended Terms for Personal Protective Equipment, Hazardous Matcrials Technical Bulletin, Washington, D.C., Oct. 1985.

Chessie System Railroad. Yard Hazardous Materials Incident Response Manual, Baltimore, Md., Junc 1984.

Conrail Corporation. Operation E (Employees in) Y (Yard) E (Emergencies), foldout card, Philadelphia, undated.

*Federal Emergency Management Agency. CPG 1-8, Guide for Development of State and Local Emergency Operations Plans, Oct. 1985a.

*Federal Emergency Management Agency, CPG 1-8A, Guide for the Review of State and Local Emergency Operations Plans, Interim Guidance, Oct. 1985b. 
*Federal Emergency Management Agency. FEMA 89, New Mexico Hazardous Materials Emergency Response Program: A Prototype. Dec. $1985 \mathrm{c}$.

Federal Emergency Management Agency. Hazardous Materials Exercise Evaluation Methodology (HM-EEM) and Manual, Interim Use, 1989.

Federal Emergency Management Agency, U.S. Department of Transportation, and U.S. Environmental Protection Agency. Handbook of Chemical Hazard Analysis Procedures, 1989.

Federal Emergency Management Agency and U.S. Department of Transportation. Report to the Congress on Hazardous Materials Training, Planning, and Preparedness, July 1986.

Federal Railroad Administration. Accident/lncident Reports Master File, computer tape compilation of reports for calendar years 1984-1988 submitted by U.S. railroads under regulation 49 CFR 225, Office of Safety, RRS-22, 1986-1989.

Houston Fire Department. Training Program for Hazardous Materials Incidents: Training Module, Dec. 1987.

McRae, M.H., District Chief, Houston Fire Department. Letter to S, Perez, Federal Emergency Management Agency, Washington, D.C., Feb. 13, 1989.

National Fire Protection Association. Standards for Professional Competence of Responders to Hazardous Materials Incidents, NFPA 472, 1989.

National Response Tcam. NRT-1, Hazardous Materials Emergency Planning Guide, March 1987.

National Response Tcam. NRT-1a, Criteria for Review of Hazardous Materials Plans, May 1988.

National Response Tcam. NRT-2, Developing a Hazardous Materials Exercise Program: A Handbook for State and Local Officials, Sept. 1990.

National Transportation Safety Board. Hazardous Materials Special Investigation Report: Release of Oleum during Wreckage-Clearing Following Derailment of Seaboard System Railroad Train Extra 8294, North Clay, Kentucky, NTSB/SIR.85/091, Feb. 1984.

* National Transportation Safcty Board. Hazardous Materials Accident Report: Anhydrous Hydrogen Fluoride Release from NATX 9408, Train No. BNEL3Y at Conrail's Receiving Yard, Elkhart, Indiana, NTSB/HZM-85/03, Feb. $1985 \mathrm{a}$.

National Transportation Safety Board. Special Investigation Report: Railroad Yard Safety -. Hazardous Materials and Emergency Preparedness, NTSB/SIR-85/02, April 1985 b.

*Nulty, P. Crash Course for Rail Disasters, Fortune Magazine, pp, 100-105, March 28, 1988. 
Occupational Safety and Hcalth Administration. Hazardous Waste Operations and Emergency Response: Final Rule, 29 CFR Part 1910, Part III, Fed. Reg., 54(42):92949336, March 6, 1989.

Southern Pacific Transportation Company and St. Louis Southwestern Railway. Pocket Guide to Tank Cars, San Francisco, undated.

* Southern Pacific Transportation Company. How to Obtain Emergency Response Information on the Southern Pacific Rallroad: A Guide for Firemen, San Francisco, undated.

Ujihara, A.M. Responding to Chemical Accidents by Sheltering in Place, Resources, Winter(94):11-13, 1989.

U.S. Department of Transportation, Office of Hazardous Materials Incidents, 1990 Emergency Response Guidebook, Report DOT P 5800.5, 1990.

U.S. Environmental Protection Agency, Levels of Protection, Fact Sheet, April 1982.

*U.S. Environmental Protection Agency. Chemical Emergency Preparedness Program, Interim Guidance: Chemical Profiles, Dec. 1985.

U.S. Environmental Protection Agency, Federal Emergency Management Agency, and U.S. Department of Transportation. Technical Guidance for Hazards Analysis: Emergency Planning for Extremely Hazardous Substances, Dec. 1987.

von Ibsch, E.A., Statc of California, Public Utilitics Commission, Rail/Transit Planning and Policy Branch, San Francisco. Personal communication, March 27, 1989.

Woodhouse, L.R. How City of Miamisburg Averted Disaster: Five-Day Tanker-Car Fire Spotlights Hazardous Materials lssues, Nation's Cities Weckly, pp. 1-6, July 21, 1986.

* Reference not separately cited in the text, but used as a general resource. 

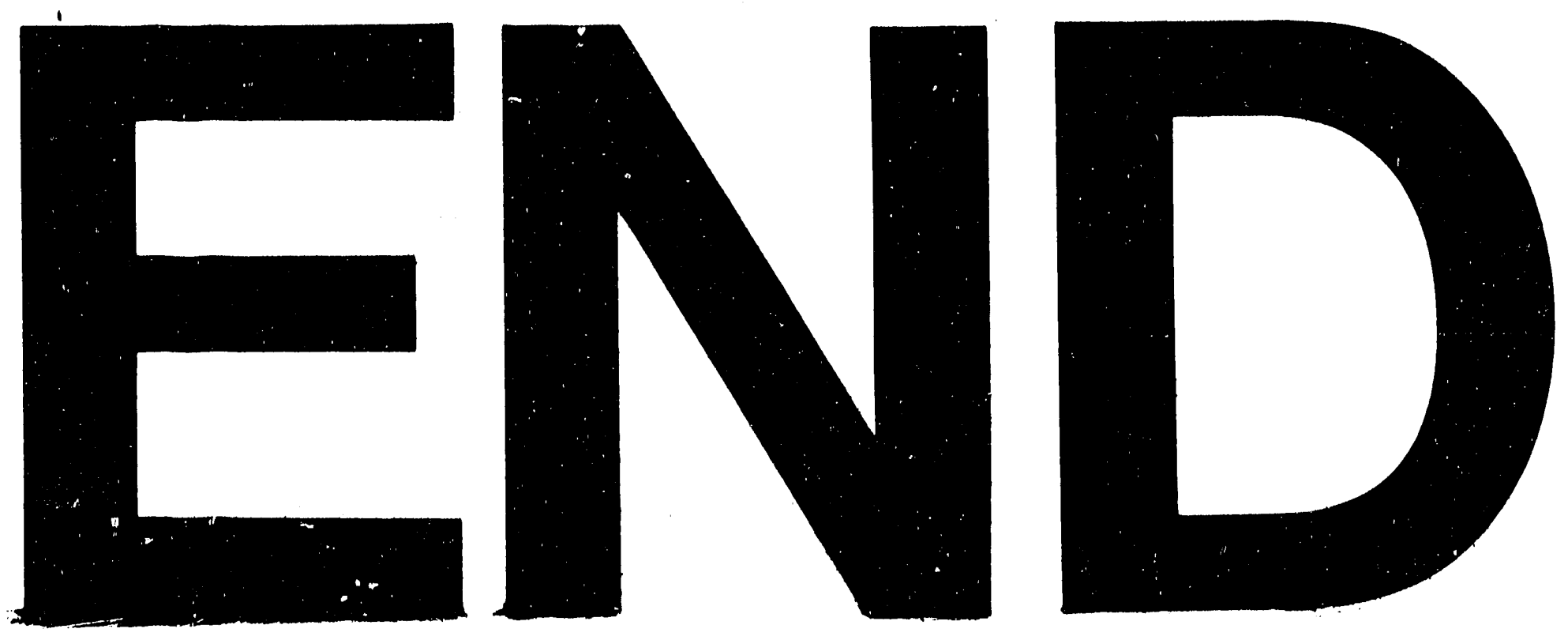

\section{5}


